\title{
Ueber die Haltung des Kopfes beim Schreiben.
}

Von

Dr. Paul Schubert in Nürnberg.

Die Messungen, über welche berichtet werden soll, wurden unternommen, um die Beziehungen kennen zu lernen, welche beim schreibenden Kinde zwischen Heftlage and Kopfhaltung stattfinden, und um daraus Anhaltspunkte zur Beantwortung der Frage zu gewinnen, welche Heftlage für den Schreibunterricht die bygienisch beste sei.

Wenn Aenderungen der Kopfhaltung gemessen werden sollen, muss man von einer primären Kopfhaltung ausgehen. Die physiologische Optik versteht darunter jene Lage des Kopfes, in welcher die Augen in Primärstellung stehen und die Blickebene horizontal gerichtet ist.*) Da aber die Ermittelung der Primärstellung der Augen, selbst wenn man von deren bei demselben Individuum und zuweilen während desselben Versuches eintretenden Schwankungen **) absehen wollte, bei Schulkinderuntersuchungen nicht ausführbar ist, so musste für vorliegenden Zweck der Begriff

*) Hering, Hermann's Handbuch d. Physiolog. III, 1. 476.

**) Aubert, Gräfe-Sämisch's Handbuch II. 654,

Graefe's Archiv fiar Ophthalmologie XXXII. 1. 
der Primärstellung des Kopfes so festgestellt werden, dass diese im einzelnen Falle schnell und sicher anfgefunden werden kounte. Dazu sind zwei Ekenen exforderlich, welche durch anatomisch genau localisirte Kopfpunkte bestimmt werden können. Fine solche Ebene ist die Sagittal- oder Medianebene, welche durch die Mitte der Augengrundinie senkrecht $z$ dieser $z u$ denken ist. Als zweite Ebene kơnnte man die Frontalebene wählen, welche bei Primärstellung des Kopfes senkrecht stehen soll. Angesichts der grossen individueilen Versehiedenheiten der Stirn-, Nasen und Kieferbildung ist aber gerade diese Ebene schwer zu anatomischen Punkten von anähernd constanter Lage in Beziehung zu setzen. Besser eignet aich jene Ebene, welche man durch die Nasenwurzel und die oberen Ohrmuschelansätze legen kann, und welche Grund - oder Basal-Ebene des Kopfes genannt werden soll. Zwar ist auch sie nicht bei Allen gleich gelagert, denn nicht immer stehen beide Ohren unter sich und mit der Nasenwurzel in gleicher Höhe, doch sind diese Unterschiede gering und können hier deshalb bis zu einem gewissen Grade vernachlässigt werden, weil es dabei nicht sowohl auf das Studium der Primärlage an sich ankommt, als auf Grad und Richtung der Abrreichung ron dieser wenn auch einigermassen willkürlich gewählten Primärlage.

Es warde daher jeno Kopfhaltung als die primäre festgesetzt, bei welcher die Medianebene des Kopfes mit der des übrigen Körpers zusammenfallt, wnd die Basalebene horizontal verlüuft.

Um die Lage der Basalebene fur Messungen bequem zugängig zu machen, wurde ein brillenartiges Gestell construirt, dessen $22 \mathrm{Cm}$. lange Stangen am hinteren Ende durch ein grades $18 \mathrm{~cm}$. langes Metallstäbchen verbunden sind (Fig. 1). Dieses Gestell findet beim Aufsetzen seine Stützpunkte auf der Nasentrurzel und beiden Obrmuschelansătzen; es kann durch Bänder am Hinterkopf 
befestigt werden. Die Stangen (ac und bd) nebst dem Verbindungsstäbchen (ab) liegen alsdann in der Basalebene.

Fig. 1.

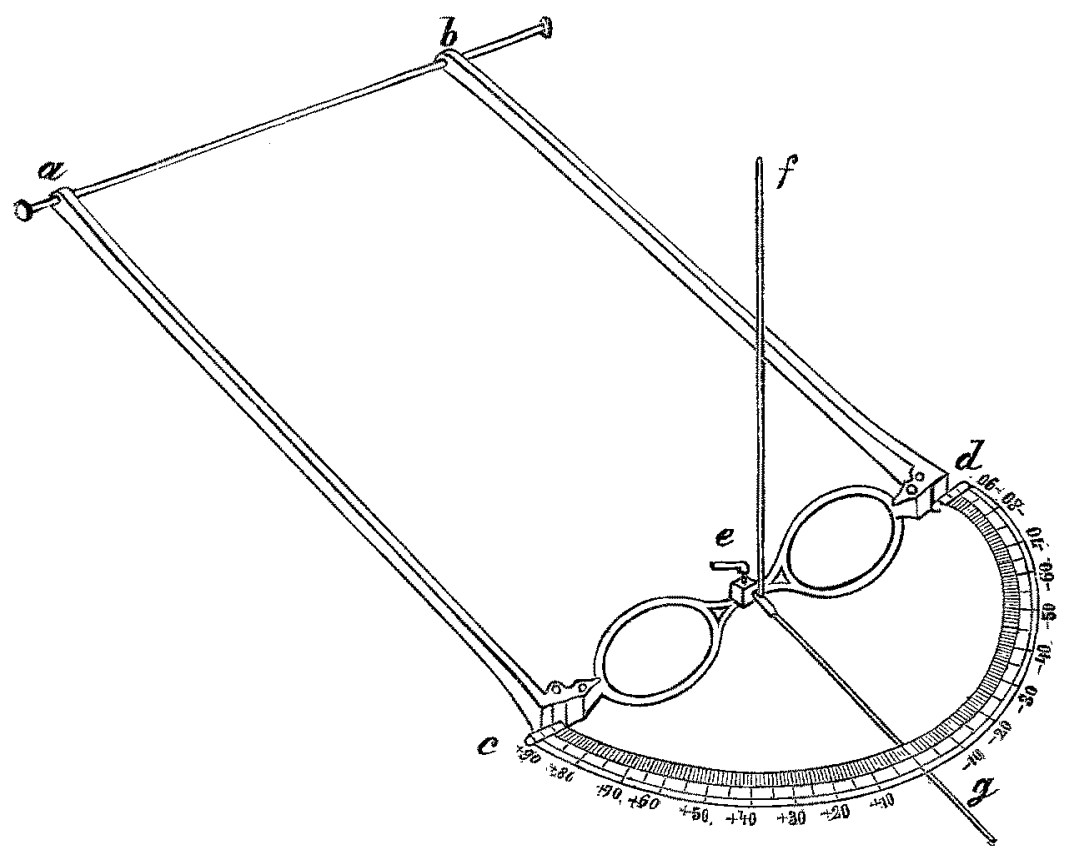

Falls beide Ohrmuschelansätze in gleicher Höhe liegen, so ist das Verbindungsstäbehen parallel zur Augengrundlinie gelagert, und alle Messungen der Richtung dieses Stäbchens gelten ohne weiteres auch für die Grundlinie; es möge daher als Grundlinienstäbchen bezeichnet werden. Bei jedem Individuum aber muss vorerst geprüft werden, ob Stäbchen und Basallinie bei richtig sitzendem Gestell wirklich zu einander parallel stehen, um jede Abweichung bei der Messung in Anschlag bringen zu können.

Nach Voraussetzung steht das Grundlinienstäbchen bei Primärstellang des Kopfes horizontal und in gleicher 
Höhe mit der Nasenwurzel; auch ist es, wenn die Versuchsperson symmetrisch vor dem Schreibpult sitzt, parallel zum oberen und unteren Pultrand. Hier sei zugleich bemerkt, dass bei der Pult- oder Schreibflache, anch wenn sie horizontal gelagert ist, der Ausdruck "oben" gleichbedentend mit "rorn" sein soll, und "unten" gleichbedeutend mit "hinten".

Abweichungen des Kopfes ron dieser Primärstellung sind dann unzweideutig bestimmt, wenn erstens die Lageveränderung des Grundlinienstäbchens und zweitens die Drehung des Kopfes am dasselbe oder um eine ihm parallele Achse (die quere Schädel-Atlas-Gelenk-Achse) bekannt sind.

Um nun die Lage des Grundlinienstabchens im Raume zu bestimmen, ist die Kenntniss zweier Winkel erforderlich, welche dasselbe entweder mit zwei ihrer Lage nach bekannten, unter sich nicht parallelen Ebenen, oder mit zwei eben solchen geraden Linien, oder endlich mit einer Ebene und einer Linie bilden; doch darf im letzteren Fall als solche Linie nicht die senkrechte Projection des Grundlinienstäbchens auf die Ebene gewählt werden, weil sonst. beide Winkel identisch wären.

Für die vorliegenden Messungen werden zur Bestimmung der Lage des Grundlinienstäbchens bei irgend welcher secundären Kopthaltung folgende zwei Winkel gewählt:

1) Der Winkel, welchen dasselbe mit der in allen nachfolgenden Versuchen horizontal verlaufenden Schreibebene bildet.

2) Der Winkel, welchen die senkrechte Projection des Grundlinienstäbchens auf die Schreibebene mit dem unteren Pultrand bildet.

Zur Messung dieser Winkel diente ein vierkantiges mit einer kleinen Wasserwage versebenes Lineal, welches an beiden Enden mit je einem graduirten Kreisbogen ausgerustet war, dessen Centrum im Lineal lag und eine Marke trug (Fig. 2; Centrum bei 0 und $0_{1}$ ). Der 
Winkel zwischen Grundlinienstäbchen und Horizontalebene wird gemessen, indem man dem Lineal eine horizontale Lage und zugleich eine solche Orientirung giebt, dass es parallel steht mit der senkrechten Projection des Grundlinienstäbchens auf die Horizontalebene. Um letztere Einstellung recht genau zu bewirken, kann man an beiden Enden des Grundlinienstäbehens ein kleines Senkblei anbringen, doch genügt, da es hier nicht auf Bruchtheile von Winkelgraden ankommt, das Augenmaass.

Fig. 2.

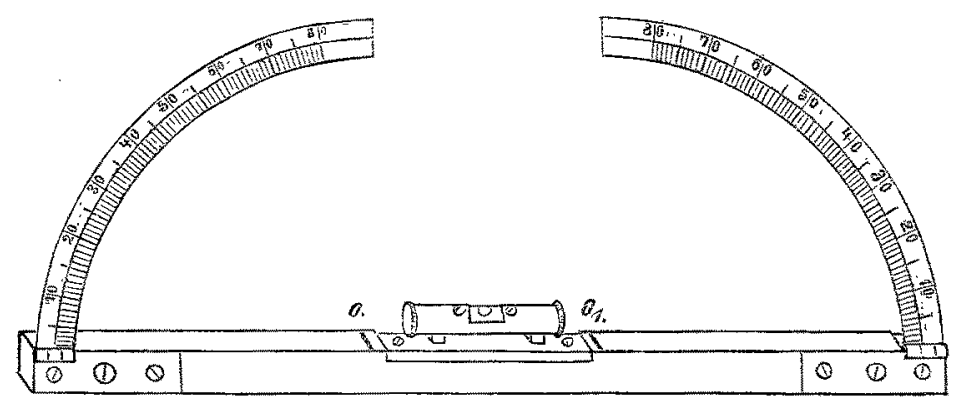

Lässt man das Stäbchen durch das Centrum des Kreisbogens gehen, dann ist an letzterem der Grad der Ablenkung ablesbar. Da dieser Winkel in der Verticalebene liegt, so wurde er als Verticalablenkung der Grundlinie, oder kurz als Winkel $v$ bezeichnet. Er bekam ein positives Vorzeichen wenn das rechte Ende, ein negatives, wenn das linke Ende der Grundlinie höher stand.

Der Winkel, zwischen dem Pultrand und der Projection der Grundlinie auf die horizontale Schreibebene wird derart gemessen, dass der Untersuchende, indem er von oben herab visirt, das Lineal bei horizontaler Lage des Gradbogens dem Tischrand parallel stellt und das Grundlinienstäbehen durch das Centrum des Kreisbogens 
streichen lässt. Dieser Winkel stellt die Horizontalablenkung der Basallinie vom Pultrand dar, weshalb er als Winkel $h$ bezeichnet wurde nnd zwar als positiv, wenn das rechte, als negativ wenn das linke Ende der Grundlinie nach vorn abweicht.

Um zu messen, welche Drehung der Kopf um eine dem Grundlinienstabchen parallele Achse vollzogen hat, mit anderen Worten, welchen Grad von Bengung oder Streckung der Kopf vollzogen hat, bringt der Untersuchende sein eigenes visirendes Auge in diese Ebene, sodass die Theile des Gestells einander decken, und nach. dem das Lineal in horizontaler Lage derart adaptirt ist, dass das zu einem der Kreisbogen gehorige Centrum in gleicher Höhe mit dem visirenden Auge auf den Punkt eingestellt ist, in welchem die Visirlinie die Basalebene trifft, liest man am Gradbogen den Winkel ab, welchen die langs der Stangen (ac und bd) des Gestells zu diesem Zwecke gravirte gerade Linie mit dem Lineal bildet. Is ist dies der Neigungswinkel der Basalebene gegen die Horizontale; denn fur das visirende Ange, dessen Sehachse nach der Voraussetzung sowohl in der einen, als in der anderen Ebene, mithin in der Schnittinie beider liegt, decken sich alle in jeder der beiden Ebenen ziehbaren Linien, also auch jene beiden anf der Schnittlinie senkrecht stehenden Linien, wellehe den Neigungswinkel der Ebenen eínsohliessen. Auf solehe Weise Kann man die Veränderungen dex Kopfhaltung nach jeder Richtung hin, insbesondere die Beugung, Drehung und Seitwärtsneigung messen*).

*) Die ron Herrn Prof. Pflüger auf der Heidelberger Ophth. Versammlung 1885 demonstriten sinnreichen Instrumente dienen aux Messung ganz derselben Winkel. Das Somatothetoskop erlaubt sowohl $<v$ als $<h$, als auch die Kopfoengung zu messen, das Kephalothetosirop eignet sich besonders zu schneller und bequemer Ablesung des $<v$ und des Kopfbeugungswinkels. Meine Messungen waren hei Publication der Pflizger'schen Instrumente schon vollendet. 
Die Messungen wurden an 316 Kindern, sämmtlich Schüler der III., IV. oder V. Elementarklasse (65 Mädchen und 251 Knaben) rorgenommen. Die Schreibtischfläche war in allen Fällen horizontal, das Heft liniirt, die Schriftgattung deutsch.

Alle Messungen beziehen sich auf einen Schreibact von wenigen Zeilen, stellen also die Haltung beim Beginn des Schreibens dar. Es wäre sehr wichtig, zu wissen, wie sich dieselben Messungen bei halb ermüdeten Kindern, nach etwa einhalbstündigem Schreiben gestalten würden, doch war es vorerst nicht ausführbar, auch diese Maasse zu gewinnen. Die Messungen sind ohnedies sehr zeitraubend. In einer Sitzung von 1-1/4 Stunden konnten nur 6 bis 8 Kinder untersucht werden, obgleich alle Maasse, bei denen dies ausführbar war, z. B. die Neigung der Buchstaben und Zeilen, erst nachträglich vorgenommen wurden.

Die Winkel $v$ und $h$ wurden bei gerader Medianlage des Heftes und Steilschrift; ferner bei schiefer Medianlage mit $30^{\circ}$ betragender Heftdrehung und willkürlicher Schriftrichtung, endlich bei willkürlicher Heftlage und Schriftrichtung gemessen, im Ganzen jeder Winkel $1201 \mathrm{Mal}$. Es wurde sorgfältig darauf geachtet, dass zwischen den Messungen beider Winkel keine Aenderung der Kopfhaltung eintrat; beide Messungen erfolgten daher moglichst schnell nacheinander und wurden nur dann in die Liste eingetragen, wenn inzwischen eine Aenderung der Kopfhaltung nicht bemerkt worden war.

In der ersten Untersuchungsreihe stehen sich je 185 Messungen bei gerader und bei schiefer Medianlage gegenüber, ausgeführt an 113 Kindern. Während des ganzen Schreibactes mussten Becken und Schultern dem Tischrand parallel gerichtet bleiben und es durfte weder das Heft gerückt, noch der Oberkörper nach links gebeugt werden; die Kopfhaltung blieb sowohl bei dieser als bei allen übrigen Messungen durchaus unbeeinflusst. Der 
Ausdruck mediane Heftlage bedarf noch einer Erläuterung. Streng genommen solite bei derselben die zu beschreibende Fläche des Heftes von der Medianebene des Körpers halbirt werden. Das stösst aber bei jenen Kindern, welche für solche Heftlage nicht geswhult sind, häufig auf Hindernisse. Der Federhalter wird von ihnen meist dicht an der Feder gefasst; wenn nun der Anfang der Zeile mehrere Centimeter nach links von der Medianebene liegt und die reclute Hand beim Beginnen einer neuen Zeile nach links hinüberm gefuhrt werden muss, so ist dies nicht nur unbequem, sondern es verdeckt auch die schreibende Hand nicht selten die Stelle des Heftes, auf welche gerade gesehrieben wird und stets jene Stelle, auf welche die nächsten Buchstaben zu stehen kommen. Aehnlich wirkt die beliebte rechtw winklige Beugnng des Zeigefingers im ersten, verbunden mit Dorsalfexion im letzten Phalangealgelenk, wodurch die Entfernung zwischen Federspitze and Metacarpo Phalangealgelenk erheblich verkürzt wird. Auch die nicht seltene abertriebene Pronation der schreibenden Hand führt leicht zum Verdeoken der Federspitze. Es ist aber ein unabweisbares Bedürfniss jedes Sohreibenden, die Federspitze zu sehen und sogar derselben mit dem Blicke anf dem Papier vorauszueilen. In vielen Fillen musste es daher den Kindern, wenn sie mit lang gefasstem Federhalter nicht schreiben lernten, gestattet werden, die mediane Heftlage derart umzuändern, dass die Medianebene durch den Anfang der Zeile ging. Um diesen Fehler möglichst gering zu machen, wurden kurze Zeilen von nur $10 \mathrm{Cm}$. geschrieben. - Viel Mühe kosteti es bei den meisten Kindern, ihnen bei gerader Medianlage das Schreiben ron senkrecht zur Zeile gestellten Buchstaben beiznbringen. Damit ist nicht die Schwierigkeit gemeint, welche manche Beobachter in der Vollendung einer ganzen Zeile bei gerader Medianlage finden. Auch nur einen senkrechten Buchstaben vermochten die meisten Kinder erst nach 
längerer Uebung auszuführen. Die Kleinen können sich schon nach 2jährigem Unterricht nicht mehr vorstellen, dass ein Buchstabe ausnahmsweise auch einmal senkrecht stehen könnte. Schon der Haarstrick wird so stark rechts geneigt hinauf geführt, dass ein senkrechter Grundstrieh mit ihm einen ungebührlich grossen Winkel bilden and der ganze Buchstabe ein Zerribild darstellen würde, welches dem Kinde nicht aus der Feder will. Daher mühen sich die Kleinen mit Hilfe einer gewaltsamen Handstellung, die aus Dorsalfexion und Abduction zusammengesetzt ist, trotz der geraden Medianlage rechtsschiefe Grundstriche herzustellen und verschmähen es, senkrechte Grundstriche $\mathrm{zu}$ machen, obgleich dieselben bei ungezwungener Handhaltung in solcher Heftlage ganz mühelos fliessen. Bei manchen Kindern genügte es nach einer Vorübung im Ziehen einfacher senkrechter Striche sie zu steil hinaufgeführten Haarstrichen zu veranlassen; es schloss sich dann der geforderte senkrechte Grundstrich ron selbst an. Oft aber wollte das nicht fruchten, weil die Kinder hartnäckig an Abduction und Dorsalfiexion des Handgelenkes festhielten. Man kam in solchen Fällen nur zum Ziel, wenn man die schreibende Hand fast gewaltsam in normale Lage zurückdrückte; dann kamen die Buchstaben alle schön senkrecht, oft auch ein wenig links schief zum Vorschein. Die Messungen am Kopfe wurden aber erst dann vorgenommen, wenn die Kinder gelernt hatten, ohne Nachhilfe streng senkrecht zu schreiben. Sowohl $v$ als $h$ wurden beim Beginn der Untersuchung bei jedem Kinde und in jeder Heftlage nur einmal gemessen, später 2-3 mal und zwar anfangs derart, dass nach jeder Messung die Heftlage wechselte, während später die zu derselben Heftlage gehörigen 2-3 Messungen in kurzen Pausen auf einander folgten und dann erst die Heftlage gewechselt wurde. Stets abor wurden boi einem und demselben Kinde beide Heftlagen, hinsichtlich der Zahl 
sowohl, als der Reihenfolge der Messungen streng gleichmässig behandelt. Das Resultat war in Bezug auf $v$, dass bei gerader Mediankage die Durchschnittsgrösse dieses Winkels $+2,8^{0}$, bei schiefér Medianlage $+5,0^{\circ}$ betrug. Dieser Unterschied wäre gering, wenn es sich um eine einzelne Méssung handelte, als arithmetisches Mittel ist ex umso beachtenswerther, je kleiner die zu vergleichenden Winkelgrossen an sich sind. Gruppirt man die Messungen in Rubriken, deren jede 50 umfasst, so zeigt es sich (Tab. I. 1a und 2a), dass bei gerader Medianlage auf die 3 Gruppen - 50 bis Null, ferner Null, tendlieh. Null bis $\div 50$, zusammen 57,3 pot. aller Messungen entfallen; bei schiefer Medianlage kommen auf dieselben 3 Gruppen nur 45,5 pCt. Die höheren, +200 überschreitenden Winkelgrade kommen bei gerader Medianlage nur 2 moal, bei schiefer $11 \mathrm{mal}$ vor.

Der Durchschnittswerth von Winkel $h$ beträgt bei gerader Medianlage $-1,80$, bei schiefer $+1,2^{0}$. Von der Bedeutung dieses Winkels wixd später mehr zu sagen sein.

Eine zweite Reihe von Untersuchungen wurde etwas abweichend vorgenommen; es hatte sich nämlich im Laufe der vorhergebenden Versuche beransgestellt, dass bei schiefer Medianlage die Kinder gern das Heft nach rechts zu rücken suchten, and da dies verhindert wurde, den eigenen Körper nach links schoben. Häufiges Zurechtschieben der Schultern war erforderlich, um wenigstens wieder das Heft die Medianlinie berahhren zu lassen. Die Ursache war unschwer zu erkennen, da namlich, wie weiterhin noch ausfuhrlicher berichtet werden soll, bei dieser Heftlage die Grundstriche keineswegs streng senkrecht auf den Tischrand gerichtet, sondern ein wenig rechts geneigt waren (weil nämlich die in der Schule geforderte und den Kindern schon zum Gesetze gewordene Rechtsneigung des Grundstriches gegen die Zeile grösser ist, als die bei schiefer Medianlage in meinen Versuchen 
stets 300 betragende Linksdrehung des Heftes), so schrieben die Kinder, um diese Grundstrichneigung herzustellen, immer noch mit einem ubermässig dorsal flectirten und abducirten Handgelenke und suchten bei fühlbarer Unbequemlichkeit die normale Stellung des Handgelenkes dadurch zu erzielen, dass sie zwar die Hand nnverrückt liegen liessen, weil dies für Herstellung schräger Schrift nöthig war, den Ellenbogen aber gegen den Körper drängten um so Dorsalfection und Abduetion des Handgelenkes zu vermindern. Der. Ellenbogen näherte sich der Brust, der Körper selbst wich nach links aus. Wenn das Pult die richtige Höhe hat, $d$. h. im Niveau des zum Zweeke des Schreibens nach rechts vorn gehobenen Ellenbogens liegt, dann stellt die Lage des Oberarmes die Hypothenuse jenes rechtwinkligen Dreiecks dar, welches dieser mit dem Pultrand und der vom Schultergelenk gefällten Senkrechten bildet; jedes Heranrücken des Armes an den Thorax verkürzt die Pultrandkathete und müsste demnach auch die Hypothenuse verkleinern. Da dies nicht möglich ist, so muss entweder die ursprüngliche Grösse der Pultrandkathete durch Seitwärtsschieben des Körpers wiederhergestellt werden, oder es yerlängert sich die andere Kathete, d. h. es hebt sich das Schultergelenk. Wie dem auch sei, sicher ist die Beobachtung, dass die Kinder die schiefe Medianlage in eine schiefe Rechtslage umzuwandeln strebten. Aehnliches konnte bei der geraden Medianlinie nieht beobachtet werden. Die senkrechten Grundstriche fordern eine Handstellung, bei welcher der Handrücken mit der Aussenfläche des Unterarms und die Phalanx des Daumens mit der Achse des Radius einen sehr stumpfen Winkel bilden. Dies ist eine "schwache Dorsalfexion und noch schwächere Abduction der Hand. Rückt die Hand im Verlauf der Zeile weiter nach rechts, so folgt der Unterarm, da er zur Hand in derselben Weise orientirt bleiben muss, in einer zur ursprünglichen an- 
whahernd parallelen Stellung; er zieht somit Schulter und Oberkörper weit eher nach rechts, als dass er sie, wie bei schiefer Medianlage, nach links drangte.

Bei der zweiten Versuchsreihe wurde nun von der Erwägung ausgegangen, dass diese Verhältnisse nicht vernachlussigt werden durfen. Zweck der Messungen war ja nicht, zu erfahren, welche Haltung ein Find einnimmt, das während des Schreibens weniger Zeilen wiederholt zurecht gerukekt wird, sondern wie sich die Sache gestaltet, wenn man das Kind, nachdem es in richtige Lage gebracht wurde, selbstständig schreiben lässt. Denn nur in letzterem Sinne kann in der Schule verfahren werden, wenn ein Lehres: 50-60 Schüler schreiben lässt.

Es wurden daher die Kinder der zweiten Unterm suchungsreihe fur die gerade Medianlage mit senkrechter Schrift ebensowohl, wie fur die schiefe Medianlage mit beliebiger Schriftrichtung nach obiger Norm einmal vorschriftsmässig zurechtgeruckt und dann in jeder Heftlage je 2 mal das Winkelpaar $h$ und $v$ gemessen, obne eine inzwischen vorgenommene leichte Seitwärtsschiebung des Korpers zu hintertreiben; Heftverschiebung wurde nicht geduldet. Auch durfte die Linksschiebung des Eörpers bei schiefer Medianlage nio derartig sein, dass letztere Bezeichnung in etwas erweitertem Wortsimne nieht mehr anwendbar gewesen wäre. Um auch äber die Art, wie die Kinder für gewöhnlich schreiben, ein Drtheil zu gewinnen, wurde jedes Kind vor Untersuchung der schiefen und geraden Medianlage aufgefordert, bei willkurlich gewählter Heftlage in gewohnter Weise einige Zeilen zu schreiben. Es wurde dabei neben einigen anderen Messungen, auch je einmal das Winkelpaar $h$ und $v$ gemessen. Bei allen $h$ und $v$ Messungen der zweiten Versuchsreibe machte ein Gehilfe mit dem Blaustifte ein Zeichen an derjenigen Stelle der Zeile, welche während der Messung gerade geschrieben worden war, um später die Richtung der 
bei einer bestimmten Kopfhaltung gefertigten Grundstriche messen zu können.

Diese zweite Versuchsreihe umfasste 107 Kinder. An ihnen wurde das Winkelpaar $v$ und $h 107 \mathrm{mal}$ bei willkürlicher, $215 \mathrm{mal}$ bei schiefer und eben so oft bei gerader Medianlage gemessen.

Für $v$ ergaben sich dabei als Durehschnittswerthe für willkürliche Heftlage $+8,4^{0}$; für schiefe Medianlage $+9,4^{\circ}$, für gerade Medianlage $+2,70$. Auch hier zeigt sich also, dass die Basallinie bei gerader Medianlage nur sehr wenig nach links geneigt ist. Wemn nicht der Durchschnittswinkel in Betracht gezogen wird, sondern die einzelnen Messungen wie bei der ersten Versuchsreihe in Gruppen vereinigt werden, welche je $5^{0}$ umfassen (Tab. I. 1. $b, 2$. b, und 3. a), so ergiebt sich, dass jene Fälle, in welchen $v$ zwischen -5 und $+5^{0}$ schwankte, also nicht allzuweit von der Horizontalen abwich, bei willkürlicher Heftlage 43 pCt., bei schiefer Medianlage 32,1 pCt., bei gerader Medianlage 57,2 pCt. betrug.

Die Zahl der $+20^{\circ}$ übersteigenden Winkel war bei willkürlicher Heftlage 9, bei schiefer Medianlage 20, bei gerader Medianlage 4.

Auch aus diesen Zahlen geht hervor, dass bei gerader Medianlage die Abweichung der Basallinie von der Horizontalen geringer ist, als bei den anderen Heftlagen.

Die Durchschnittsgrösse des Winkels $h$ war bei allen 3 Gruppen von Heftlagen negativ; bei der willkürlichen - 15,8 , bei der schiefen medianen $-1,0$, bei der geraden medianen - 6,0. Es zeigen diese Winkel bezüglich der letztgenannten Heftlagen gleichfalls eine gewisse Uebereinstimmung mit jenen der ersten Untersuchungsreihe, in sofern als bei gerader Medianlage die senkrechte Projection der Besallinie vom Pultrand im Sinne nicht unerheblicher Rechtsdrehung abweicht, bei sehiefer Medianlage um die Parallellage sehwankt, in der ersten 
Reihe ein wenig nach links, in der zweiten ebenso unbefeutend nach rechts gedreht ist. Darauf soll zurückgegriffen werden, wenn die Messungen gewisser Augenbewegungen bekannt gegeben sind.

Nach Abschluss der ersten und zweiten Untersuchungs" reihe lagen zum Behufe der Vergleichung der geraden and schiefen Medianlage je 400 Messungen der Winkelpaare wor mit dem Durchschnittswerthe von $v+2.8, h-4,0$ für gerade Medianlage and ron $v+7.4, h=0$ für schiefe Medianlage.

Bei ersterer gehörten $57,25 \mathrm{pCt}$ aller $v$-Messungen den Winkeln $-5 \mathrm{bis}+5$ an, welche man noch als annahernd horizontal bezeichnen kann. Bei der schiefen Medianlage fallen nur 38,25 pct. unter diese Rubrik, die Winkelgrösse $(+$ und -) 200 wurde bei gerader Medianlage 10 mal, bei schiefer Medianlage 31 mal übersehritten. Daraus geht hervor, dass bei gerader Medianlage und senkrechter Schrift mit einer von der Horizontalstellung seltener und in geringerem Grade abweichenden Basallinie geschrieben wird, als dies bei schiefer Medianlage mit $30^{\circ}$ Heftdrehung der Fall ist.

In einex dritten Versuchsreihe sollte grösseres Material für Vergleichung der willkurlichen mit der schiefen medianen Heftlage gewonnen werden, Es wurden zu diesem Zweeke an 68 Kinderi je zwei Messungen des Wintelpaares $v$ und $h$ gemaeht, in jeder Lage also 136 Messungen. Als Durchschnitt ergab sich für erstere $v+9.5, h-12.8$ und für Letztere $v+9,4, h-1,9$.

Berechnet man noch aus einer zu anderem $Z_{w e c k}$ angestellten vierten Versuchsreihe 15 Messungen bei willkurlicher Heftlage an 15 Kindern and 7 Messungen bei schiefer Medianlage an sieben anderen Kindern hinzu, dann stehen sich behufs Vergleichung beider Heftlagen im Ganzen für die schiefe Medianlage 543 Messungen an 289 Kindesn und für die willkürliche Lage 258 Messungen 
an 190 Kindern gegenüber; allerdings beziehen sich diese Maasse, wie aus obigem hervorgeht, nur zum Theil in beiden Heftlagen auf dieselben Individuen.

Die durchschnittliche Grösse der Winkel beträgt alsdann bei schiefer Medianlage $v+7,9, h-0,7$, bei willkürlicher Heftlage $v+9,0, \mathrm{~h}-13,9$.

Es entsteht die Frage, von welchen Umständen Richtung und Grōsse des Winkels $v$ abhängen. Weitaus am häufigsten ist derselbe positiv, d. h. die Basallinie ist nach links geneigt. Die entgegengesetzte Neigung kam bei gerader Medianlage $88 \mathrm{mal}$, bei schiefer Medianlage $60 \mathrm{mal}$ und bei willkürlicher Heftlage $16 \mathrm{mal}$ vor; im Ganzen also 164 mal, d. h. in 13,6 pCt. der Falle. Dabei ist zu berücksichtigen, dass sich diese negativen Werthe in 64 Fällen zwischen 0 und $5^{\circ}$ bewegten, eine Abweichung von der Horizontalen, die als geringfügig bezeichnet werden muss. Die Durchschnittsgrösse von $v$ war in allen 3 Heftlagen positiv, und zwar sehr gering bei gerader Medianlage $\left(+2,8^{\circ}\right)$; erheblich grösser und nicht weit von einander abstehend bei schiefer Medianlage $(+7,90)$ und bei willkürlicher Heftlage $(+9,00)$.

Das, was die Gruppe der geraden Medianlage einerseits und jene der schiefen Medianlagen und der willkürlichen Heftlagen andererseits unterscheidet, ist die Drehung des Heftes, resp. das schräge Aufsteigen der Zeilen, welche bei schiefer Medianlage mit dem Pultrande stets einen nach rechts offenen Winkel von $30^{\circ}$ bildeten, bei willkürlicher Heftlage, wie an Tabelle III. 4. ersichtlich ist, zwischen -50 (leichte Linksdrehung des Heftes) und $+50^{\circ}$ schwankte, aber nur 2 mal negativ und 3 mal Null war und im Durchschnit +180 betrug.

Deutlicher noch erkennt man das Gemeinsame der beiden mit stärkerer Linksneigung der Basallinie verknüpten Heftlagen, und das, was beide von der geraden Medianlage mit mehr horizontalem Grundlinienverlauf 
unterscheidet, wenn man die Zeile nicht zum Pultrand in Beziehung setzt, sondern zur rechtwinkeligen Projection der Basallinie auf die Schreibfläche.

1) Bei gerader Medianlage ist der Durchschnittswerth von $h=-4^{0}$, d. $h$. die senkrechte Basallinienprojection schneidet den Pultrand, mithin anoh die bei lieser Heftlage zu ihm parallelen Zeilen, von links oben nach rechts unten unter dem sehr spitzen Winkel von 40 . Der Winkel $v$ beträgt hierbei im Mittel $+2,80$.

2) Bei schiefer Medianlage ist im Durchschnitt $h=-0,7$, die Grundlinienprojection also fast parallel dem Pultrand. Da nun bei dieser Lage die Zeilen mit letaterem einen nach rechts oben offenen Winkel von 300 bilden, so schneidet die Grundlinienprojection die Zeilo gleichfalls von links oben nach rechts unten, unter einem. Winkel von circa $30^{\circ}$. Winkel $v$ hat dabei den Mittelwerth $+7,90$.

3. Bei willkürlicher Heftlage, in welcher Rubrik die mehr oder minder geneigte Rechtslage vorherrscht, beträgt $h$ durchsehnittlich $-13,90$; dazu kommt ein Zeilenpultrandwinkel ron der Durchschnitisgrösse $+17,70$ (Tabelle III. 4), so dass dio Basallinienprojection die Zeile unter $31,6^{\circ}$ schneidet, und zwar gleichfalls von links oben nach rechts unten. Der Winkel wurde hierbei im Mittel $+9,00$ gefunden.

Scheidet man ans der Gruppe der willkürlichen Heftlagen alle Nedianlagen ans und betrachtet allein die Rechtslagen, dann gestalten sich die Verbältnisse so, wie es Tabelle I, 4., a) b) e) und d) zeigt.

a) Im Durehschnitt aus 98 Schreibacten bei Rechtslage des Heftes war $<y=+9,9^{\circ}$.

b) Wurden nur die stärker ausgeprägten Rechtslagen gereehnet, deren Richtungslinienwinkel (Definition desselben siehe im letzten Theil der Arbeit) grösser war als $10 \mathrm{Grad}$, so finden sich 84 Schreibacte mit einem Durchschnittswerthe von $v=\div 10,0^{\circ}$. 
c) Bei allen Rechtslagen, welche mit einem Heftdrehungswinkel von mehr als 20 Grad combinirt waren, und deren Zahl 41 betrug, war $v$ im Durchschnitt $=+12,7^{\circ}$.

d) Stärkere Grade von Rechtslage waren selten mit grösseren Heftdrehungswinkeln combinirt; je weiter rechts vom Körper das Heft lag, desto mehr pfiegte sich der untere Heftrand der Parallelsteilung mit dem Pultrand zu nähern. Nur 6 mal war bei stärker ausgeprägter Rechtslage der Rechtsdrehungswinkel grösser als $20 \mathrm{Grad}$; in diesen Fallen aber war $v$ im Mittel $+16,6^{\circ}$ !

Es zeigt sich also, dass die Basallinie am wenigsten von der horizontalen Richtung abweicht, wenn ihre senkrechte Projection zur Zeile annähernd parallel steht; dass sie aber eine nm so stärkere Linksneigung erfährt, je grösser der Winkel zwischen Grandlinien-Projection und Zeile ist.

Das kann kein Zufall sein und findet seine Erklärung in dem Streben des Schreibenden, die Zeile in die Visirebene zu bringen, oder wenigstens den Winkel zwischen beiden möglichst zu verkleinern.

Wir wissen, dass die innerhalb der primären Blickebene und die innerhalb der Medianebene liegenden Blickbahnen vom Ange bevorzugt werden gegenüber den transversalen Richtungen. Je kleiner ferner der Winkel ist, welchen die Blickbahn mit einer der genannten Ebenen bildet, desto schneller, und wie wir hieraus wohl schliessen dürfen, desto bequemer erfolgen die Blickwendungen in ihr, verglichen mit den rein transversalen, welche za jenen Fbenen unter 45 Grad geneigt sind. Nun wird aber beim Schreiben die entstehende Zeile mit dem Blick verfolgt, wie ich dies weiter unten durch directe Messungen nachweisen werde; folglich muss der Schreibende ein Interesse daran haben, dass die Zeile mit der Visirebene einen möglichst v. Grafe 
kleinen Winkel bildet. Dass dieses Ziel unter den bei schiefer Medianlage und bei Rechtslage gegebenen Verhältnissen durch einen gewissen Grad von Linksneigung der Grund. linie erreicht werden kann, ist unschwer zu beweisen. Die Schnittlinie zwischen Visirebene und horizontaler Schreibebene muss unter allen Umständen dureh die Zeile gehen, weil in dieser der Fixationspunkt liegt (der zuletzt geschriebene Buchstabe). Sie muss ferner, solange die Grundlinie horizontal bleibt, parallel verlaufen zu dieser and zu deren senkrechter Projection auf die horizontale Schreibebene, muss mithin mit der Zeile denselben Winkel bilden, wie die Projection. Da nun genannte Projection in jenen beiden Heftlagen die Zeile von links oben nach rechts unten sehneidet, so that dies auch die Visirebenenschnittlinie. Bei jeder Neigung der Grundlinie nach links verlässt die Visirebenenschnittlinie ihre zur Grundlinienprojection parallele Lage; denn da sie sowohl durch den in der Zeile liegenden Fixirpunkt, als auch durch jenen Punkt gehen muss, in welchem die Verlängerung der nach links geneigten Grundlinie deren senkrechte Projection in einem gleichfalls links gelegenen Punkte trifft, schneidet sie diese Projection in demselben Sinne, wie dies die Zeile thut, nämlich von links unten nach rechts oben. Es muss also einen Grad der Grundlinienneigung geben, bei welehem Visirebenenschnittlinie und Zeile zusammenfallen.

Die Berechnung des hierzu erforderlichen Grundlinienneigungswinkels kann nur mit Hilfe des Visirebenenneigungswinkels erfolgen, weshalb die Messung des letzteren hier eingeschaltet werden soll.

Die Messungsmethode des Neigungswinkels der Basalebene (= des Kopfbeugungswinkels) wurde bereits angegeben. In ähnlicher Weise konnte der Winkel zwischen Visirebene und Basalebene bestimmt werden. Die Summe beider Winkel giebt die absolu te Visirebenenneigung; der Winkel 
zwischen Visirebene und Basalebene soll relativer Visirebenenneigungswinkel heissen.

Die Messung der relativen Visirebenenneigung geschah in der Art, dass ein Stäbchen von dem zuletzt geschriebenen Buchstaben bis zu jener Stelle der Gestellstange, welche in der Richtung der Augengrundlinie der Versuchsperson liegt, gehalten wurde. Der Visirstandpunkt des Untersuchenden wurde so gewählt, dass seine Visirlinie mit der Augengrundlinie der Versuchsperson zusammenfiel, mithin, da dies die Schnittlinie der Gestellebene und der Visirebene ist, zugleich in beiden Ebenen lag. Da nun das vom Buchstaben zum Gestell führende Stäbchen in der Visirebene liegt, so kann der Winkel, welchen es von diesem Visirpunkte aus mit der Stange des Gestelles bildet, direct als Neigungswinkel beider Ebenen angesehen und gemessen werden, da alle Linien je einer der beiden Ebenen sich bei dieser Projection decken, mithin auch jene auf der Schnittlinie senkrecht stehenden Linien, welche den Neigungswinkel einschliessen.

Diese Winkelmessung ist nicht ganz einwandfrei, denn jener Punkt der Gestellstange, an welchen das Stäbchen angelegt wurde, konnte nur mit dem Augenmasse bestimmt werden, und zudem müsste es für jeden einzelnen Fall erst bewiesen werden, dass die Augengrundlinie der Versuchsperson wirklich durch die Gestellstange geht; aber für rorliegenden Zweck konnte diese Fehlerquelle vernachlässigt werden. Diese Winkel wurden je einmal bei jedem Kinde der II., III. und IV. Versuchsreihe gemessen, resp. berechnet, im Ganzen jeder Winkel $197 \mathrm{mal}$ und zwar $161 \mathrm{mal}$ bei willkürlicher Heftlage und $36 \mathrm{mal}$ bei schiefer Medianlage. Ein nennenswerther Einfluss der Heftlage war dabei nicht ersichtlich. Die Durchschnittswerthe aller Messungen betrugen:

1) für die Kopfbeugung $42,3^{\circ}$; als kleinster Werth fand sich $12^{\circ}$, als grösster $75^{\circ}$. 
2) für die relative Visirebenenneigung 18,40 ; als kieinster Werth fand sich -120 , als grosster $+50^{\circ}$.

3) für die absolute Visirebenenneigung 60,70 ; als kleinster Werth fand sich $30^{\circ}$, als grösster $85^{\circ}$.

Das negative Vorzeichen bei der relativen. Visirebenenneigung bedentet oin Erheben der Visirebene über die Basalebene des Kopfes. Dieser Fall wurde 9 mal beobachtet und $18 \mathrm{mal}$ war der Winkel $=0$.

Sicherlich bat der Umstand, dass auf horizontalem Pult geschrieben warde, vergrössernd auf den absoluten Visirebenenneigungswinkel gewirkt und es gilt obiger Durchsehnittswerth nicht ohne Weiteres von dem in der Schule üblichen Schreibact auf schrägem Pult.

Aus diesen Messungen lasst sich nun, wenn $v, h$ und der Zeilenpultrandwinkel bekannt sind, der Winkel berechnen, welchen die Zeile mit der Visirebene bildet.

Es soll zunächst der Verlauf der Schnittlinie zwischen Visirebene und horizontaler Pultfläche ermittelt werden. Wenn die Basallinie wagerecht steht $(v=0)$, dann ist sie parallel zu ihrer senkrechten Projection auf die Horizontalebene und zugleich parallel zu obengenannter Schnittlinie. Mithin sind auch Schnittlinie and Projection unter sich parallel and erstere schneidet den Pultrand unter demselben Winkel, wie letatere $(=<h)$. Iierbei lrommt der Visirebenenneigungswinkel nicht in Betracht. Wenn die Basallinie aber geneigt ist, mithin gehörig verlängert, die Pultflache in irgend einem Punkte $(O$ in Fig. 3) trifft, dann muss die durch sie und den Fixirpunkt gelegte Ebene (Visirebene) die horizontale Pultfläche in einer Linie schneiden, welche den Pankt $O$ mit dem in der Pultfläche gelegenen Fixirpunkt verbindet. In Fig. 3 sei $O A$ die Basallinie, $O$ der Punkt, in welchem sie die horizontale Pultfläche trifft; $B O C$ liege in der horizontalen Pultebene, $B$ sei Fixirpunkt, $A B O$ Visirebene $O C$ die senkrechte Projection der Grundlinie auf die Pult- 
ebene, $<v$ mithin der Neigungswinkel der Grundlinie. $A B C$ sei das za genannten sich schneidenden Flachen gehörige sphärische Dreieck, mithin $\varepsilon$ der Visirebenenneigungswinkel. Der rechte Winkel liegt bei $C$. Wenn daher der Winkel zwischen Schnittlinie und Projection $(=<B O C=<\alpha)$ gesucht werden soll, so ergiebt sich für ihn die Formel sin. $\alpha=\frac{\text { tang. } v}{\text { tang. } \varepsilon}$.

Aus dieser Formel geht hervor, dass der Werth für $\alpha$ im geraden Verhältnisse mit tang. $v$ und in umgekehrtem mit tang. $\varepsilon$ wächst. -

Wenn $v=0$, dann ist auch $\alpha=0$; Winkel $v$ kann

Fig. 3.

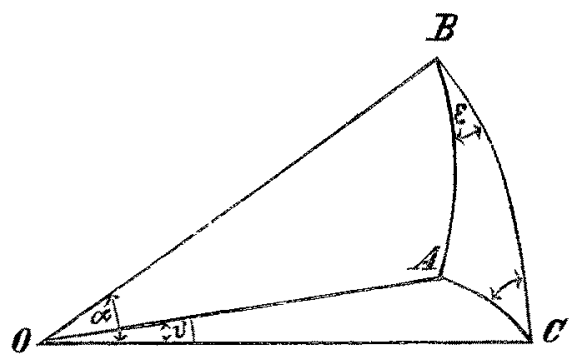

nie grösser werden, als Winkel $\varepsilon$, sonst würde der Werth für sin. $\alpha$ grösser als 1 , was keinen Sinn hat.

Wenn $\varepsilon=90^{\circ}$, dann wird $\alpha=0$ unabhängig ron der Grösse des Winkels $v, \alpha$ ist gleich $90^{\circ}$, wenn $v$ und $\varepsilon$ gleich sind; es sind also für $\alpha$ alle Werthe von 0 bis $90^{\circ}$ möglich.

Zugleich ist ersichtlich, dass $\alpha$ nach rechts oben sich offnet, wenn $v$ positiv ist, und dass $\alpha$ nach links oben sich offnet, wenn $v$ negativ ist. Mithin dreht ein positiver Winkel $v$ das obere Ende der Schnittlinie nach links, ein negativer nach rechts. Da mit verschwindend seltenen Ausnahmen bei schiefer Heftlage die Zeilen mit dem 
Pultrand einen nach rechts offenen Winkel bilden, so wird in diesen Fällen wenn der Winkel $v$ positiv ist der Winkel zwischen Zeile und Visirebenensehnittinie um den Winkel $a$ verkleinert und wenn $v$ negativ ist, vergrössert.

Die Messungen des Visirebenenneigungswinkels $(\varepsilon)$ wurden beim Beginn des Sehreibactes vorgenommen, jene des Winkelpaares $v$ und $h$ etwas später. Es bezieht sich daher zwar je ein Winkelpaar $v$ und $h$ auf dieselbe Kopehaltung, soweit dies bei zwei sebnell nach einander vorzunehmenden Messungen überhaupt möglich ist; wenn man aber die mebrere Minuten vorher vorgenommene Messung von $\varepsilon$ auf dieselbe Kopfhaltung beziehen will, so liegt darin eine gewisse Willkür und Ungenauigkeit, gemildert allerdings durch den Umstand, dass zwischen beiden Messungen das Heft nicht verschoben wurde; es mag vielleicht der Antheil, welchen Kopfbeugung und relative Visirebenenneigung an der Bildung von $s$ nahmen, sich inzwischen geändert haben, der Werth für $\varepsilon$ selbst aber kaum oder nur unerheblich. Bei der II. und III. Versuchsreihe wurden nur aus jenen Messungen von $v$ und $h$, welche zu der Heftlage gehören, für welche Winkel $\varepsilon$ gemessen worden war, der Werth furr $\alpha$ berechnet und zwar beziehen sich diese Berechnungen $185 \mathrm{mal}$ (bei 146 Kindern) auf willkürliche und $58 \mathrm{mal}$ (bei 29 Kindern) auf schiefe Medianlage, in Summa auf 243 Schreibacte bei 175 Kindern. Die gefundenen Werthe sind aus Tab. III 1. ersichtlich. Bei der Berechnung wurden hier sowohl, wie bei den spater zu erwähnenden Winkeln die Logarithmen nur fünfstellig genommen und die gefundenen. Winkelwerthe zu ganzen Graden abgerundet. $16 \mathrm{mal}$ war $\alpha$ negativ, (weil $v$ negativ war), $48 \mathrm{mal}=0$ (weil $v=0$ ), in den übrigen 179 Fällen war $\alpha$ positiv und zwar bis zu $60^{\circ}$; doch kommen die Werthe über $20^{\circ}$ nur vereinzelt vor. Der Durchschnittswerth für $\alpha$ beträgt $+5,8^{\circ}$. Bei schrägliegender Pultfläche und dadurch 
verkleinertem Visirebenenneigungswinkel würde der Werth für $\alpha$ nicht unerheblich wachsen.

Kennt man nun $\alpha$, den Zeilenpultrandwinkel und $h$, so wird die Berechnung des Winkels zwischen Visirebenenschnittlinie und Zeile $(=\beta)$ zur einfachen Additions- und Subtractionsaufgabe.

Fig. 4.

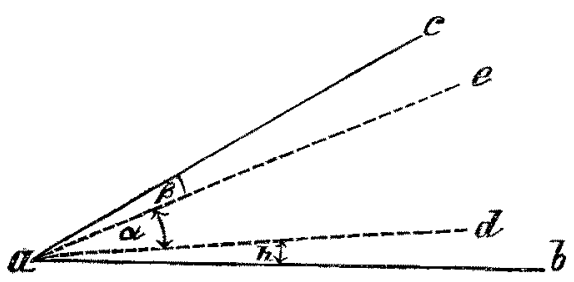

Es sei $a b$ der Pultrand, $a c$ die Zeile, $a d$ die senkrechte Projection der Basallinie, und ae die Visirebenenschnittlinie, mithin $c a b=$ Zeilenpultrandwinkel, $e a d=\alpha$ (hier positiv); $d a b=h$ (hier positiv) nnd $c a e$ der gesuchte Winkel $\beta$.

$$
\beta=c a b-\alpha-h \text {. }
$$

Fig. 5.

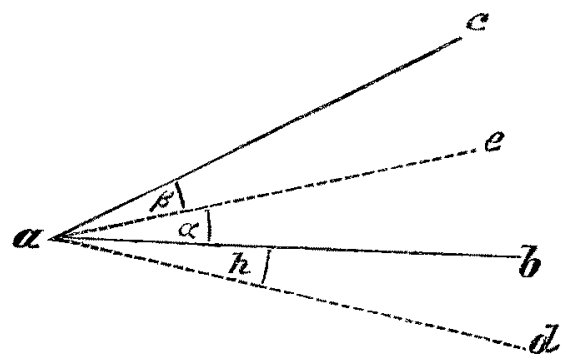

Wenn $h$ als negativ in die Rechnung tritt, so wird hieraus natürlich $\beta=c a b-\alpha+h$, was sich planimetriseh aus Fig. 5 ergiebt, für welche die Buchstaben dieselbe Bedeutung haben, wie für Fig. 4. 
Wenn $\alpha$ negativ ist, so ist $\beta=c a b+a-h$.

Demgemäss fanden sich für $\beta$ die in Tab. UI 2 verzeichneten Werthe, zwischen -31 und +60 schwankend, im Durehsehnitt $+26,5$ betragend.

Im Grunde interessirt aber nicht sowohl der Winkel zwisohen Visirebenenschnittlinie und Zeile, als vielmehr jener zwischen Visirebene und Zeile, dessen Werth aus Fig. 6 ersichtlich ist. Es sei $A O C$ die horizontale Pultfäche, $A O B$ die Visirebene, $A O$ die Schnittlinie beider, $C O$ die Zeile, $B O$ die rechtwinklige Projection derselben auf die

Fig. 6.

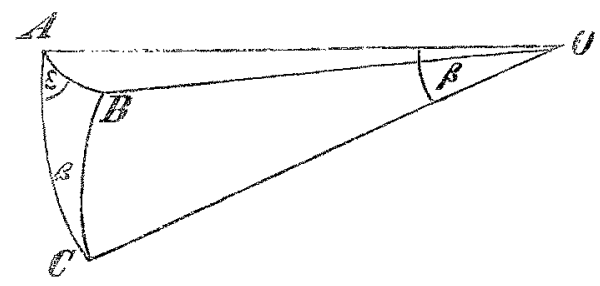

Visirebene, mithin in dem sphärischen Dreiecke $A B C$ bei $B$ der rechte Winkel, die Seite $A C=$ Winkel $\beta$ in obigem Sinne (Zeilen-Sehnittlinienwinkel), und $\varepsilon$ wieder, wie oben, der Visirebenenneigungswinkel. Gesucht wird Winkel $B O O$, der Zeilen-Visirebenenwinkel.

sin. $\varepsilon=\frac{\sin . B O C}{\sin . \beta} ; \sin . B O C=\sin . \varepsilon . \sin . \beta$.

Wird diese Berechnung ausgeführt, so ergeben sich für die mehrerwähnten 243 Schreibacte die in Tab. III. 3 eingetragenen Werthe für den Winkel zwischen Zeile und Visirebene. Der Winkel schwankt zwischen - 26 (Leile erhebt sich in ihrer linken Hälfte über die Visirebene) and +49 ; im Durchschnitt beträgt er $+21,9^{\circ}$.

Aus der Formel sin. $B O C=\sin , \varepsilon$, sin. $\beta$ geht zugleich hervor: 
Der Winkel $B O C$ wird umso kleiner, je kleiner $\varepsilon$ und $\beta$ sind; nun steht aber $\beta$ in Bezug auf sein Wachsthum annahernd in umgekehrtem Verhältnisse zu $\alpha$; man kann also auch sagen: $B O C$ wird umso kleiner, je kleiner $\varepsilon$ und je grösser $\alpha$ sind; von $\alpha$ wurde gezeigt, dass es im geraden Verhältnisse mit $v$ und im umgekehrten mit $\varepsilon$ wächst; mithin wirkt das Kleinerwerden von $\varepsilon$ in doppeltem Sinne verkleinernd auf $B O C$, weil sein Einfluss, in sofern er sich auf $\beta$ erstreckt, auch in der Formel sin $B O C=$ $\sin \varepsilon \sin \beta$ enthalten ist und in demselben Sinne wirkt. Dieselbe Wirkung, wie das Kleinerwerden von $\varepsilon$, hat in Bezug auf $B O C$ das Grösserwerden von $v$, weil es dadurch $\alpha$ vergrössert, mithin $\beta$ verkleinert.

Es fragt sich: warum hat es sich in den beobachteten Fällen so selten ereignet, dass der Winkel $v$ solange in positivem Sinne wuchs, bis $B O C=$ Null wurde, mit anderen Worten, warum neigten die schreibenden Kinder ihre Basallinie nicht solange nach links, bis die Visirebene mit der Zeile zusammenfiel?

Gesetzt, es sei mit einer Basallinienhaltung geschrieben worden, deren Winkel $h$ gleich Null war, d. h. deren senkrechte Projection dem Tischrande parallel stand. Alsdann müsste $\beta$ und in Folge dessen nach obiger Formel auch Winkel $B O C$ in dem Falle gleich Null werden, dass $\alpha$ die Grösse des Zeilenpultrandwinkels erreicht. Nimmt man den Fall, es betrage letzterer $18^{\circ}$, wie dies die Durchschnittsgrösse des genannten Winkels bei den willkürlich gewählten Heftlagen war und giebt man ferner dem Winkel $\varepsilon$ den gefundenen Durchschnittswerth $60^{\circ}$, so ergiebt sich aus der Formel sin. $\alpha=\frac{\text { tang. } v}{\text { tang. } \varepsilon}$ für $v$ der Werth tang. $v=\sin .18$ tang. $60 ; v=28,10^{\circ}$. Thatsächlich ist aber die Annahme, dass mit einer Basallinie geschrieben wurde, deren senlrechte Projection dem Pultrande parallel stand, für die willkürliche Heftlage nicht 
zutreffend; der Werth fur $h$ war vielmeht unter 208 Messungen $233 \mathrm{mal}$ negativ und sein Durchschnittswerth betrug $-13,9^{\circ}$.

Wenn aber unter diesen Verhaltnissen $\beta=$ Null werden soll, dann muss gemäss der Formel

$$
\beta=c a b-\alpha-h=c a b-(\alpha+h),
$$

in welcher cab den Zeilenneigungswinkel bedeutet, dieser letztere gleich sein $\alpha+h$, und im Falle $h$ als negativ in die Rechnung tritt $=\alpha-h, \mathrm{~d}$. $\mathrm{b}$. es muss für $\alpha$ eine Grösse erreicht werden, welche nach Abzug von $h$ noch immer dem Zeilenpultrandwinkel gleich ist. Um daher obige Berechnung den Thatsachen anzupassen, ist eine Vergrösserung des Winkels $\alpha$ um rund $14^{\circ}$ erforderiich. Es ergiebt sich dann: tang. $v=\sin .(18+14)$. tang. 60 ; $v=42^{\circ} 33^{\prime}$,

Dieser Werth von $v$ wäre schon als Einzelleistung sehr gross; denn unter 1200 Messungen überschritt $v$ die Höhe von $30^{\circ}$ nur 7 mal und jene von 35 niemals. Als Durchschnittswerth ist diese Grösse geradezu physiologisch unmöglich, da sehr oft $\varepsilon$ grösser ist, als $60^{\circ}$, oder der negative Werth ron $h$ grösser als 14, oder der Zeilenpultrandwinkel grösser als 18, sodass, um die Zeile in die Visirebene zu bringen, unmögliche Kopfdrehungen erforderlich wären.

Alles was für gewöhnlich erreicht werden kann, ist eine Annäherung der Visirebene an die Zeile. Dass diese Tendenz vorhanden ist, beweist die mit grosser Regelmässigkeit gefundene Linksneigung der Basallinie; dass sie keine zwingende ist, sondern im Conflict mit entgegenstehenden Interessen zuweilen unterliegt, beweist die in 13,6 pCt. der Falle beobachtete Rechtsneigung der Basallinie. Mithin waren wir Alle, die wir sagten, dass der Sohreibende die Basallinie so zu drehen sucht, dass seine Visirebene die zu schreibende Zeile in sich aufnehme, in sofern im Recht, als sich dieses Bestreben 
wirklich nachweisen lässt, im Unrecht aber, in sofern wir annahmen, diese Stellung werde für gewöhnlich wirklich erreicht.

Die allerdings nicht correcte, aber allgemein richtig gedachte und richtig verstandene Ausdrucksweise lautete: dass der Schreibende die Basallinie der Zeile parallel zu stellen sucht; gemeint war natürlich die Projection der Basallinie innerhalb der Visirebene auf die Schreibfläche, oder deutlicher, die Schnittfläche der Visir- und Schreibebene.

Wolchen Sinn hat nun der Winkel $h$ d. h. die Drehung des Kopfes in der Art, dass die rechtwinklige Projection der Basallinie auf die Schreibebene ihre in der Primärstellung zum Pultrande parallele Lage aufgiebt und mit letzterer einen positiven oder negativen Winkel bildet?

Es wäre mit Zuhilfenahme entsprechender Grösse und Orientirung des Winkels $h$ ein leichtes, das verstehend erörterte Problem zu lösen, nämlich die Basallinie mit der schräg aufsteigenden Zeile in eine Ebene zu bringen. Gleichwohl nimmt, wie soeben gezeigt wurde, der Winkel $h$ eine Lage ein, welche dieser Tendenz in vielen Fällen, und bei Rechtslage des Heftes sogar fast immer geradezu entgegen steht. Fs muss also dieser Winkel von anderen Umständen abhängig sein. Ein Vergleich der Durchschnittswerthe für $h$ in den verschiedenen Heftlagen lehrt, dass dieser Winkel seiner Lage nach stets und seiner Grösse nach gleichfalls, allerdings mit einer noch zu erorternden Einschränkung, von der Lage des Fixationspunktes abhängt.

Liegt dieser nach links von der Medianebene, dann wird $h$ positiv, liegt er nach rechts, dann wird $h$ negativ und zwar ist er in beiden Fällen um so grösser, je weiter seitwärts der Fixationspunkt liegt.

Bei schiefer Medianlage, zu welcher ein im Allgemeinen geradeaus liegender Fixationspunkt gehört, ist $h$ im Durchschnitt $-0,7^{\circ}$, also fast Null. Bei der Gruppe 
der willkurlichen Heftlage, welche neben einer Reihe schiefer Medianlagen viele mehr oder minder schiefe Rechtslagen in sich fasst, findet sich als Durchschnittswerth für $h-13,9^{\circ}$. Auch innerhalb letzterer Gruppe lässt sich diese Bedentung des Winkels $h$ erkennen, wenn man die stark ausgeprägten Rechtslagen von jenen sondert, welche sich mit geringerer Abweichung um die Medianlage grupiren. Um die willkürlich gewählten Heftlagen auch später noch in Bezug auf Drehung und Seitenlage des Heftes unterscheiden und messen zn können, wurden nãmlich bei jedem Kinde, sobald es sich das Heft zurechtgerïckt und $\mathrm{zu}$ schreiben angefangen hatte, auf letzterem zwei Linien gezogen, beide rom Anfangspunkte der ersten Zeile ausgehend, die eine senkredit auf den Pultrand, die andere gegen die Mitte der Brust des Schreibenden. Die erste zur Unterscheidung aus Punkten bestehende dient zur Bestimmung des Heftdrehungswinkels, die zweite, roll ausgezogene, welche Richtungslinie des Heftes genannt werden soll, lässt aus ibrer relativen Lage zur ersteren und aus dem Winkel, welehen sie mit ihr bildet, erkennen, ob das Heft nach rechts oder nach links verschoben war und in welchem Grade dies der Fall war. Als Maass für den Grad des Seitwärtslage wurde eben jener Winkel zwisehen der Richtungslinie und Pultrandperpendikel gewählt, weil dieser Winkel zwar nicht gleich, aber doch direkt proportional ist jenem Winkel, auf den es hier hauptsächlich ankommt, nämlich dem Drehungswinkel des Kopfes aus der Primärstellung nach jenem Zeilenanfang hin. Letzterer Winkel ist in Wirklichkeit nicht unerheblich grösser als ersterer, weil stets mit vorgebeugtem Kopfe geschrieben wird, die Richtungslinie des Heftes aber streng genommen nicht gegen die Mitte der Brust des Schreibenden hätte geführt werden sollen, sondern gegen den Fusspunkt eines vom Atlas auf die Schreibebene gefällten Perpendikels. 
In Tabelle III. 4. und 5. sind die Werthe der gefundenen Heftdrehungs- und Richtungslinienwinkel eingetragen. Letztere waren häufig negativ, $d$. h. es lag der Zeilenanfang links von der Medianebene. Wie schon erwähnt wurde, muss dies ja bis zu einem gewissen Grade bei Medianlage der Fall sein, und berechtigt noch nicht zur Bezeichnung Linkslage. Wäre es darauf angekommen, streng zwischen Median-Links- und -Rechtslage zu unterscheiden, so bätte die Richtungslinie von der Mitte anstatt vom Anfang der Zeile ausgehen müssen.

Um nun den Einfluss der Rechtslage auf den Winkel $h$ zu erkennen, wurden die Schreibacte auf stark nach rechts verschobene Hefte von den übrigen abgeschieden, welche bei einer der medianen sich nähernden Heftlage stattfanden.

Es zeigte sich, dass bei allen Heftlagen, deren Winkel zwischen Richtungslinie und Pultrandperpendikel kleiner als $+10^{0}$ oder negativ war, der Winkel $h$ im Durchschnitt aus 159 Messungen an 114 Kindern - 10,90 betrug, bei jenen Heftlagen aber, deren Richtungswinkel die Grösse $+10^{\circ}$ überschritt, im Durchschnitt aus 84 Messungen an 61 Kindern $-20,7_{0}$.

Jene 15 Messuugen des Winkels $h$ bei willkürlicher: Heftlage, welche der IV. Untersuchungsreihe angehören, konnten hier nicht verwerthet werden, weil bei ihnen die Richtungslinien und der Pultrandperpendikel nicht verzeichnet worden waren.

Allerdings schwankte der Werth für $h$ bei der ersten Gruppe von - 35 bis zu +15 und bei der zweiten von -40 bis zu 0 , doch darf nicht vergessen werden, dass die $h$-Messung sich nie auf den ersten Buchstaben der Zeile bezog, für welchen der Richtungswinkel gilt, sondern stets auf den Schreibact eines mehr gegen Mitte oder Ende der Zeile gelegenen Buchstabens.

Es kann also die Regel aufgestellt werden, dass der Winkel $h$ negativ ist bei Fixation von rechts seitwärts 
gelegenen Punkten und dass die Grösse desselben abhängig ist von dem Grade der Rechtslage.

Bevor auf diese Verhältnisse des Winkels $h$ näher eingegangen wird, ist es unerlässlich, die Beziehungen zu erörtern, welche bei gewissen Kopfdrehungen zwischen der Drehungsachse einerseits und den Lageveränderungen der Sagittalebene und Grundlinie andererseits bestehen. Anders als auf Grundlage solcher rein stereometrischer Vorbetrachtung kann meines Erachtens ein Verständniss der Anatomie und Physiologie der Kopfbewegungen nicht gewonnen werden. Es sollen nur jene Achsen in Betracht kommen, welche in der Sagittalebene des Kopfes liegen. Sie müssen alle durch den Indifferenzpunkt der combinirten Halswirbelgelenke gehen. Auch vereinfacht es die Anschauung, wenn man durch eben diesen Indifferenzpunkt eine Parallele zur Basallinie denkt und alle an der Basallinie gemessenen Lagenveränderungen $(\mathrm{d}$. h. die Winkel $v$ und $h$ ) auf diese Parallele bezieht.

Die Kopfbewegungen, welche bei beabsichtigter Fixation eines seitwärts gelegenen Punktes gemacht werden, geschehen zu dem Zweck, diesen Punkt in die Sagittalebene zu bringen. Denn die binoculare Fixation eines weit von der Sagittalebene gelegenen Punktes hat das Unerwünschte, dass der Abstand beider Augen vom Fixationspunkt verschieden gross ist. Das Einstellen der Sagittalebene auf den Fixationspunkt kann nun durch Drehung um eine jede der in dieser Ebene gelegenen Achsen geschehen. Die Primärstellung der Sagittalebene, von welcher die Drehungen ausgehen sollen, sei senkrecht im Raume und senkrecht auf den Pultrand.

Steht die Achse vertical, dann bleibt bei jeder Drehung um dieselbe die Basallinie horizontal $(v=0)$. Die Projectionen der Basallinie auf die Horizontalebene vor und nach der Drehung bilden dann unter sich einen Winkel, welcher dem Drehungswinkel gleich ist; es ist 
dies der Winkel $h$, und zwar mit negativem Vorzeichen, wenn die Drehung nach rechts hin erfolgte.

Die Schnittlinie zwischen Visirebene und horizontaler Schreibfläche wird in jedem Stadium der Drehung zur Basallinie sowohl, als zu deren senkrechter Projection parallel bleiben, mithin wird der Winkel, den sie mit dem Pultrand bildet, dieselbe Grösse und dasselbe Vorzeichen haben, wie $h$, unabhängig vom Visirebenenneigungswinkel.

Die Sagittalebene bleibt bei dieser Drehung lothrecht, die Schnittlinie der Sagittalebene mit der Horizontalebene bildet mit dem Pultrand einen Winkel, welcher gleich ist dem Drehungswinkel.

Wenn die Sagittalebene aus derselben Primärstellung um eine horizontale Achse gedreht wird, dann verlassen Sagittalebene und Basallinie, erstere ihre verticale, letztere ihre horizontale Lage; alsdann ist der Neigungswinkel beider gleich dem Drehungswinkel der Sagittalebene um diese Achse ( $v=$ Drehungswinkel), und zwar mit positivem Vorzeichen, wenn die Drehung nach rechts erfolgte; der Winkel $h$ bleibt Null.

Die Lage der Schnittlinie zwischen Visirebene und horizontaler Schreibebene ist dabei nicht, wie bei Drehung um die verticale Achse, einzig und allein von dem Grade dieser Drehung abhängig, sondern anch vom Visirebenenneigungswinkel. Der Sinus des Winkels, den sie mit der senkrechten Projection der Basallinie auf die Horizontalebene bildet, ist gleich dem Quotienten aus der Tangente des Drehungswinkels (hier $=v$ ) und der Tangente des Visirebenenneigungswinkels. Die Formel geht aus Fig. 3 hervor. Der Winkel hat dasselbe Vorzeichen, wie $v$ (= Drehungswinkel) d. h. wenn $v$ nach rechts oben offen ist, wird er nach rechts vorn offen sein.

Die Schnittlinie zwischen Sagittalebene und Horizontalebene bleibt in jedem Stadium dieser Drehung ihrer ur- 
sprünglichen Lage parallel, d. h. unter der gegebenen Voraussetzung senkrecht zom Pultrand.

Ausser der senkrechten und horizontalen Lage der Drehungsachse sind unzăhlig andere Lagen möglich.

Liegen dieselben so, dass ihr oberes Ende nach vorn geneigt ist, dann wird bei Drehung der Sagittalebene im Sinne der Rechtswendung des Blickpunktes stets im ersten Quadranten der Drehung die Sagittalebene, mithin auch die Basallinie sich nach links und vorn neigen, Winkel $v$ wird positiv werden, Winkel $h$ negativ.

Ist die Drehungsachse mit dem oberen Ende nach hinten gerichtet, dann werden bei Rechtsdrehung im ersten Quadranten derselben sowohl Sagittalebene wie Basallinie eine Neigung nach rechts und hinten erfahren; Winkel $v$ wird negativ, Winkel $h$ gleichfalls.

Bei. der vorliegenden Schulkindermessung lässt sich also aus dem Vorzeichen des Winkels $h$ erkennen, nach welcher Seite die Drehnng des Kopfes erfolgt und ferner, wenn letzteres bekannt ist, aus dem Vorzeichen des Winkels $v$, ob die Achse nach vorn oder nach hinten geneigt war.

Da $h$ hei den Schulmessungen meist negativ, $v$ meist positiv war, so ist auf Rechtsdrehung um eine im oberen Ende nach vorn geneigte Achse zu schliessen. Unter allen diesen nach vorn geneigten Achsen zeichnet sich jene, welche auf der nach vorn geneigten Visirebene senkrecht steht, insofern aus, als bei der Drehung um dieselbe die Lage der Visirebene sich nicht ändert und nur der Wixationspunkt innerhalb derselben fortrückt. Ls ist dies jener Fall, welcher in der Berliner klin. Wochenschrift No. 44 und 45 des Jahrganges 1884 and No. 26 des Jahrganges 1885 besprochen ist; leider bedarf der im letzteren Aufsatz die Figur begleitende Text einer Berichtigung, welche ich auch in einer der nächsten Nummern folgen liess. Obgleich es nämlich zwei Zeilen vor der Figur 
ganz richtig heisst, dass im sphärischen Dreiecke $G H F$ der rechte Winkel bei $H$ liegt, begegnete mir doch das Versehen, denselben für die Formelbildung als bei $G$ liegend anzunehmen; es muss daher überall statt tang. $x$ und tang. $\varphi$ heissen, $\sin$. $x$ und sin. $\varphi$; auch muss der nachfolgende Text dementsprechend geändert werden. Im Jebrigen kann in Bezug auf diese Achsenlage auf die genannten beiden Aufsătze verwiesen und hier nur kurz erwähnt werden, dass im gedachten Fall, wenn nämlich die Kopfdrehung um eine auf der Visirebene senkrecht stehende Achse erfolgt, nicht nur die Visirebene, sondern selbstverständlich auch die Schnittlinie derselben mit der horizontalen Schreibebene dieselbe Lage beibehalten, d. h. dem Pultrand parallel bleiben muss. Da nun, wie man sich leicht dureh Versuche überzengen kann, welche loco citato genauer beschrieben sind, diese Schnittlinie bei Fixation seitwärts gelegener Punkte nie zum Pultrande parallel bleibt, denselben vielmehr von links vorn nach rechts hinten schneidet, so muss daraus auf eine andere Lage der Drehungsachse geschlossen werden.

In jenen Aufsätzen wurde die Secundärstellung aus zwei aufeinander folgenden Drehungen um zwei verschiedene Achsen entstanden gedacht, weshalb dort gesagt ist, es sei zur Rotation eine Seitwärtsneigung gekommen, welche das linke Ende der Basallinie über die primäre Visirebene erhebt. In der vorliegenden Arbeit wurde die Bewegung auf eine einzige, entsprechend geneigte Achse bezogen, was natürlich ebenso berechtigt ist.

Ferner muss aus dem thatsächlichen Verlauf der Visirebenenschnittlinie beim Rechtsblick geschlossen werden, dass die Achse der ausgefuhrten Kopfwendung sich der senkrechten im Raume nähert. Da nämlich die Messungen eine durehschnittliche Neigung der Visirebene von $60^{\circ}$ ergaben, so müsste die Drehungsachse der Sagittalebene um $60^{\circ}$ von der Senkrechten nach vorn abweichen, wenn die 
Visirebene bei der Drehung nicht verändert werden sollte, ihre Sehnittlinie mithin wie bei einfacher Kopfbeugung dem Pultrand parallel bliebe. Letzteres ist aber, wie die Messungen zeigen, thatsächlich nicht der Fall; rielmebr ist der Winkel zwischen Visirebenenschnittlinie und senkrechter Projeotion der Basallinie (Winkel $\alpha$ ) bei 185 Messungen willkürlicher Heftlagen durchschnittlieh $+5,6$ und der Winkel $h$ bei 258 willkurlichen Heftlagen durchsehnittlich $-13,9$, mithin die durchschnittliche Kreuzung zwischen Visirebenenschnittlinio und Pultrand $=-8,8$. Hierbei ist noch der Umstand nicht in Anschlag gebracht, dass der Winkel $\alpha$ aus Winkel $v$ resultirt, Winkel $v$ aber bei willkürlicher" Heftlage nur wenig grösser ist, als bei sehiefer Medianlage, mithin nicht eigentlich zur Rechtswendung des Blickpunktes gehört, sondern wie oben gezeigt wurde, rom Zeilenverlauf abhängt.

Daraus folgt, dass die Drehungsachse allerdings eine Neigung nach vorn hat, aber eine solche, die von der Senkreehten im Raume weniger abweicht, als jene Achse, die anf der nach rom geneigten Visirebene senkrecht steht.

Hier ist nun der Ort zu untersuchen, ob die der Senkrechten sich nähernde Lage der Kopfdrehungsachse eines ron der Primårstellung zum Schreiben auf rechts seitwärts liegendem Heft übergehenden Kindes mit dem Schreibact als solchem zusammenhängt, oder bei jeder Fixation eines seitwärts gelegenen Punktes zu beobachten ist, gleichgiltig, ob dabei geschrieben wird oder nicht.

In dem genannten Aufsatz vom Jahre 1884 zeigte ich, dass die Kopfdrehung anch bei einfacher Fixation in ganz analoger Weise stattfindet.

Um dies noch näher zu prüfen, wurden die mit dem Messapparat bewaffneten Versuchspersonen (meist Kinder, doch anch einige Erwachsene) vor die Mitte eines kleinen Tisches gesetzt, auf dessen Platte 9 Ziffern in folgender Anordnung geschrieben worden waren: 
Fig. 7.

\begin{tabular}{|lll|}
\hline 1. & 2. & 3. \\
4. & 5. & 6. \\
7. & 8. & 9. \\
\hline
\end{tabular}

Die Zahlen 2. 5. 8 entsprechen der Mittellinie des Tisches. Während nun auf meine Aufforderung der Reihe nach die Zahlen 1. 2. 3. scharf betrachtet wurden, musste der Kopf nacheinander jene Stellungen einnehmen, welche zur Fixation eines links und unten, eines geradeaus und unten, endlich eines rechts und unten gelegenen Punktes gehören.

Wurden darauf nacheinander die Zahlen 4. 5. 6. angesehen, dann wiederholte sich dieselbe Kopfbewegung, nur dass hierbei die Visirebene stärker geneigt und gewobnlich auch der Kopf stäker gebeugt war. Aehnlich bei der Reihe 7. 8. 9.

Es zeigte sich nun, dass bei allen hierbei gemachten Kopfdrehungen die Augengrundlinie horizontal blieb. Dasselbe Verhalten wies die Grundlinie auf, wenn die Zahlen in anderer Reihenfolge fixirt wurden, z. B. 1. 4. 7.; 2. 5. 8.; 3. 6. 9. Auch änderte sich nichts, wenn statt der Zahlen an den entsprechenden Stellen einfache Punkte als Fixationsmarken angebracht wurden. In allen diesen Fällen blieb der Winkel $v$ entweder Null oder höchstens + oder $-5^{0}$ bis $7^{\circ}$; keineswegs aber waren die beobachteten kleinen Werthe von $v$ derart vertheilt, dass die positiven den Blick nach der einen, die negativen den nach der anderen Seite begleitet hätten. Mit anderen Worten: Zur Fixation eines rechts seitwärts gelegenen Punktes 
gebort nicht eine mit dem linken Ende nach unten ge neigte Grundlinie; dieselbe bleibt vielmehr entweder streng horizontal oder neigt sich in sehr geringem Grade und regellos bald nach rechts, bald nach links; die Drehungsachse des Kopfes bei wechselnder Fixation mehrerer in gleicher Höhe theils links, theils rechts gelegener Punkte ist daher fast genau senkrecht gestellt.

Wenn nun beim Schreiben auf rechts gelegenem Heft die Neigung der Basallinie nach links (= positiver Werth des < v) fast ausnahmslose Regel ist, so muss dies im Sehreibact selbst seinen Grund haben.

Nachdem so die Drehungs-Achsen in stereometrischer Hinsicht besprochen worden sind, muss anch ihre anatomische Lage aufgesucht werden.

In der Physiologie der Kopfbewegung hat bisher die Seitwärtsneigung des vorher gebengten Kopfes nur geringe Beachtung gefunden. Es muss hier auf die Darstellung Henke's*) von der Rechtsdrehung des aufrecht gehaltenen Kopfes näher eingegangen werden.

Das Schraubengelenk $z$ wischen Epistropheus und Atlas hat nur eine Achse; diese steht genau senkrecht und geht durch den Zahnfortsatz des Epistropheus. Das complicirtere Gelenk zwischen Schädel und Atlas hat deren zwei; die eine verläuft quer horizontal und dient der Kopfbeugung; die andere Achse dient der Seitwärtsneigung, liegt in der Sagittalebene und weicht mit dem vorderen Ende von der Horizontalen nach oben ab. Dureh den Bandapparat der ligamenta alaria, welche rom hinteren Theile der Spitze des Zahnfortsatzes nach den beiden Gelenkiöpfen des Schädels gehen, werden aber die beiden in Betracht Kommenden Bewegungen, die Rotation des Kopfes rum die senkrechte Atlas-Epistrophensgelenk-Achse und die Seitwärtsneigung desselben um die stark vorwärts geneigte Schädel-Atlasgelenk-Achse, von einander derart abhängig,

*) Handbuoh dex Anatomie und Mechanik dex Gelenke 1863. 
dass eine bereits vollzogene, ausgiebige Bewegung um die eine Achse hemmend wirkt auf die Excursionsfähigkeit um die andere Achse.

„(1. c. pag. 100.) Die Anheftungen der Bänder am Zahnfortsatz liegen hinter der senkrechten Achse der Drehung in demselben und ihre ganze Ausspannung unter der annähernd sagittalen der Neigung (sc. Seitwärtsneigung des Kopfes). Das rechte beschränkt also durch seine Spannung die Drehung des Gesichts nach links, weil dabei die rechte Seitenmasse des Atlas mit dem in ihr ruhenden Gelenkkopf nach vorn geht, und die Neigung des Gesichtes nach links, weil dabei der rechte Gelenkkopt nach oben und zur Seite geht, sich vom Zahnfortsatz entfernt. Ist es durch die eine der beiden Drehungen bereits gespannt, so ist die andere nicht auch noch vollkommen ausführbar, weil das Band die doppelte Dehnung nicht verträgt. Also kann das Gesicht nicht zugleich durch Drehung des Atlas auf dem Epistropheus nach links gedreht and durch Drehung des Schädels in der Pfanne des Atlas nach links geneigt werden. Eines hindert das andere. Dieser beschränkende Einfluss kann ein entgegengesetzt direct bewegender werden. Wird das Gesicht nach links gedreht, und dadurch das rechte Ligamentum alare gespannt, so zieht es von selbst den Gelenkkopf, an dem es sitzt, in der Pfanne des Atlas berab gegen den Zahnfortsatz, bewirkt also eine Neigung des Gesichts nach rechts. .... Daher wird die Wendung des Gesichts zur Seite gewöhnlich nur mittels der Drehung auf dem Epistropheus zu Wege gebracht und es verbindet sich bei der ungezwungenen Ausführung dieser Bewegung ganz von selbst mit ihr die Neigung zur anderen Seite, die zwischen Schädel und Atlas geschieht."

(pag. 102.) "Die natürliche Combination der in den obersten Gelenken ausführbaren Drehung und Neigung des Gesichtes hat ihren Grund auch ebenso sehr und im 
Grunde wohl ursprïnglicher. .... darin, dass es nur ein grosser Muskel vor allen anderen ist, der beide zugleich bewirkt. Denn kein anderer wirkt günstiger und kräftiger auf eine von beiden, als der M. sternocleidomastoideus. Der rechte zieht den Kopf mit dem Atlas auf dem Epistropheus herum zur Drehung des Gesichts nach links und zugleich am Atlas herunter zur Neigung nach rechts. Der linke umgekehrt."

Hierbel spricht Henke aber nur von der Seitwärtsdrehung des aufrechten Kopfes. Wollte man nun, wozu B. keine Veranlassung giebt, annehmen, dass die Bervegungen im Schädel-Atlas-Epistrophens-Gelenk auch bei gebeugtem Kopfe in derselben Weise vor sich geht, dann würde bei Rechtswendung die schon ohnedies durch die Kopfbeugung nach vorn geneigte Basalebene des Kopfes noch eine zweite Neigung nach links erfahren, und ihre Schnittlinie mit der horizontalen. Schreibebene würde von links unten nach rechts oben verlaufen müssen, während sie in Wirklichkeit den Pultrand in entgegengesetzter Richtung kreuzt. Wie früher bewiesen wurde (Berliner Klin. W. 1885. Nr. 26), bewirkt eine Rechtswendung des gebeugten Kopfes um eine anf seiner Basallinie senkrechte Achse ( =-Zahnfortsatz des Epistropheus), dass die Basalebene des Kopfes dieselbe Neigung nach vorn beibehält und nur die Basallinie innerhalb derselben ihre Lage insofern ändert, als $v$ positiv und desto grösser wird, je mehr der Kopf nach rechts gedreht warde und je stärker er vorher gebeugt war. Es gilt die Frormel sin. $v=$ sin. des Drehungswinkels mal sin. des Kopfbeugungswinkels.

Würde nun die von Henke rom aufrechten Kopf nachgewiesene Gelenkbewegung, dass nämlich jede Rechtswendung mit Linksneigung verknüpft sei, auch für den gebeugten Kopf gelten, dann würde das linke Ende der Basallinie sich tiefer neigen, der Winkel $v$ mithin grösser 
werden, als obige Formel angiebt. Die Beobachtung lehrt im Gegentheil, dass der Winkel $v$ kleiner ist, als er nach dieser Formel sein müsste, mithin erheblich kleiner ist, als es zu erwarten wäre, wenn der ron Henke für den aufrechten Kopf ernittelte Bewegungstypus auch für den gebeugten Geltung haben würde.

Daraus folgt, dass im Gegentheil die Rechtswendung des gebeugten Kopfes mit einer leichten Rechtsneigung combinirt sein muss. Es ist vielleicht nicht überflüssig; hier nochmals hervorzuheben, dass diese Rechtsneigung des Kopfes nicht nothwendig sofort zu einem Tieferstehen des rechten Auges führt; denn es ist von dem erst gebeugten und sodann um die Zahnfortsatzachse nach rechts gedrehten Kopfe die Rede; diese Bewegung führt für sich allein zu einem Tieferstand des linken Auges; tritt nun eine Rechtsneigung des also gedrehten Kopfes hinzu, so wird dadurch zunächst nur bewirkt, dass die Basallinie sich wieder der Horizontallage nähert; erst bei fortgesetzter Rechtsneigung würde diese Horizontallage und späterhin auch ein Tieferstehen des rechten Auges bewirkt werden.

Wenn daher die oben erwähnten Versuche lehren, dass Rechts- und Linkswendungen des gebeugten Kopfes (bei blosser Fixation seitwärts und unten gelegener Punkte, ohne dass dabei geschrieben wird) mit horizontal verlaufender Basallinie ausgeführt werden, so folgt daraus, dass hierbei der gebeugte Kopf nicht nur einfach um die Zahnfortsatzachse nach rechts gedreht wird - denn alsdann müsste die Basallinie sich nach links neigen - sondern dass sich zu dieser Drehung auch eine Rechtsneigung gesellt haben muss, und zwar um einen Winkel, dessen Sinus gleich ist dem Product aus dem Sinus des Kopfbeugungswinkels und dem Sinus des Kopfdrehungswinkels.

Henke geht auf die Seitwärtsdrehung des gebeugten Kopfes nicht ausführlich ein, was er aber sagt, genúgt 
zam Verständniss. Es spannen sich nåmlich (1. c. pag. 97 und 99) bei Kopfbeugung beide Ligamenta alaria, und da jedes derselben als Hemmungsband furr die Drehungen um mediane Achsen auch dann wirkt, wenn es vorher nicht anderweitig gespannt war, so muss genannte Hemmung noch viel früher eintreten and sowohl die Rechts-, als Linksdrehung treffen, wenn beide Ligamente schon anderweitig gespannt sind.

Henke hebt herror, dass die Niekbewegung am vollkommensten ausfuhrbar ist, wenn das Gesicht gerade aufsteht und nach vorn sieht und dass sie gehemmt wird, wenn es nach der einen oder anderen Seite abweicht. Daraus dürfte zn schliessen sein, dass umgekehrt, je starker die Kopfbeugung ist, desto geringer die Excursionen um die sagittale Schädel-Atlasm-Gelenkachse und um die verticale Atlas-Epistropheus-Gelenkachse sein können. Nun zeigten aber directe Messungen, dass die Kinder durchschnittlich mit ciner Kopfbeugung von $42^{\circ}$ schreiben und dass dieselbe sogar bis zu 70 und 750 betragen kam. Es ist klar, dass hierbei die Beugung im Schädel-Atlasgelenk nicht unr sehr stark in Anspruch genommen wird, sondern in manchen Fällen gar nicht genügt, so dass es noch einer Beugung in den übrigen Halswirbelgelenken bedarf.

Jedenfalls werden aber die Ligamenta aloria stark gespannt und damit wabrscheinlioh die Excursionen um mediane Achsen im Schüdel-Atlas-Epistropheus-Gelenk sehr beschränkt. Es muss dann - Henke sagt es allerdings nicht ausdrucklich - ein ähnlicher Fall eintreten, wie bei extremer Wendung des nicht gebeugten Kopfes über eine Sohulter nach hinten, in welehem Falle das Ligamentum alare der entgegengesetzten Seite hemmend eingreift und die Bewegung in die Gelente der Halswirbel abwärts vom Epistrophens verlegt. Bei diesen Halswirbeln liegen aber die Gelenkachsen 
durchaus anders; Henke giebt an, dass unter den Bewegungen um median gelegene Achsen jene um horizontale sowohl als um senkrechte Achsen ,auf ein sehr geringes und nur mit Anstrengung ausführbares Wackeln beschränkt bleibe, während die Verbindung beider, wobei die Vorderfläche der Wirbelkörper sich nach derselben Seite dreht, nach welcher die Säule hingebogen wird, einen beträchtlichen Ausschlag gebe."

Die Achse dieser combinirten Bewegung erhebt sich, wenn eine, allerdings nur schematisch gehaltene Zeichnung Henke's wenigstens annähernd Geltung beanspruchen darf, mit ihrem hinteren Ende etwa $30^{\circ}$ über die Horizontale.

Erfolgt eine Rechtsdrehung des Kopfes sammt den oberen beiden Halswirbeln, die für den Angenblick als gegen einander unbeweglich angenommen werden sollen, um eine dieser medianen, nach hinten oben gerichteten, den unteren Halswirbeln zugehörigen Achsen, so wird die Basallinie nicht nur einen negativen Winkel $h$, sondern auch einen negativen Winkel $v$ bilden, $d$. h. ibr linkes Ende muss sich heben.

Werden nun Kopf und Hals nach vorn gebeugt, so müssen die genannten Achsen der unteren Halswirbel an dieser Bewegung theilnehmen, ihr hinteres Ende wird sich heben, ihre Lage der Senkrechte sich nähern. Je mehr dies geschieht, desto mehr wird bei Drehung des Kopfes um diese Achse der Winkel $h$ vorherrsehen, der Winkel $v$ zurückbleiben, bis bei Senkrechtstellung der Achse $v=$ Null und $h=$ Drehungswinkel werden würden. Doch dürfte diese Senkrechtstellung der Achse in Wirklichkeit kaum stattfinden, da bei den Schulkindermessungen eine Kopfbeugung von $60^{\circ}$ nur selten gefunden wurde.

Es ist zu bedauern, dass die Bewegungen des gebengten Kopfes noch wenig studirt worden sind. Vorderhand glaube ich nach meinen geschilderten ,Versuchen soviel als festgestellt bezeichnen zu dürfen, dass, 
rom Schreibact abgesehen, zum Zweck der Fixation seitwärts und unten liegender Punkte die Kopfdrehung mit horizontaler Basallinie erfolgt. $O b$ dabei der Antheil der oberen oder der unteren Halswirbelgelenke grösser ist, und wie die Achsen der einzelnen Gelenke stehen, muss einstweilen unentschieden gelassen werden. Sicher ist nur, dass die resultirende Achse der combinirten sämmtlichen betheiligten Gelenke senkrecht stehen muss, denn dies folgt aus dem Horizontalbleiben der Basallinie.

Anders aber als bei blosser Fixation verhalt sich die Basallinie beim Schreiben auf rechtsliegendem Heft. Der Winkel $v$ war unter 84 Fällen nur 5 mal negativ and 14 mal Null, im übrigen aber positiv and von einer Grösse bis zu $30^{\circ}$ (Tab. I. 4b). Darans folgt, dass die beim Schreiben auf rechts liegendem Heft so constante Linksneigung der Basallinie nicht zur Wesenheit der Rechtswendung des Kopfes gehört, sondern eine andere, im Schreibact selbst liegende Ursache haben muss. Wir haben als solche das Streben kennen gelernt, den Winkel zwischen Visirebene und Zeile zu verkleinern.

Aus dem bisher Gesagten folgt:

d) Winkel $h$ hängt ron dem Grade der Seitenlage des Heftes, resp. des zu sehreibenden Buchstabens ab.

2) Winkel $v$ steht in directem Verhältniss zur Grösse des Winkels, welchen die Zeile mit der senkrechten Projection der Grundlinie bildet; letzterer aber wäehst sowohl mit der Grösse des Heftdrehungswinkels als mit dem Grade der Rechtslage des Heftes.

Weiter muss untersucht werden, ob die Drehung des Kopfes beim Schreiben auf rechtsliegendem Heft für gewohnlich so ausgiebig ist, dass der Fixationspunkt, d. h. der zu schreibende Buchstabe anch wirklich in die Sagittal- 
ebene fallt, oder ob der Schreibende sich begnügt, die zur Fixation eines so gelegenen Punktes erforderliche Wendung nur zum Theil mit dem Kopfe, zum anderen Theil aber mit blosser Augenbewegung zu vollziehen.

Letzteres wurde von mir in früheren Aufsätzen behauptet. Berlin-Rembold*) bestritten es und sagten, dass beim Verschieben des Fixationspunktes während des Schreibens einer Zeile der Kopf allein die entsprechende Bèwegung mache, während eigentliche Augenbewegungen nur gewisse Strichelemente der einzelnen Buchstaben, nicht aber den Zeilenverlauf begleiten und dass beim Schreiben auf rechtsliegendem Heft mit seltenen Ausnahmen beide Augen gleich weit von der Federspitze entfernt seien. Zahlen werden über die in letzterer Richtung angestellten Messungen nicht gegeben, es heisst nur (pag. 30): „der Unterschied in den Ausnahmsfällen war so gering, dass er eine Berücksichtigung nicht erheischte."

Um dies nachzuprüfen, schien eine andere Untersuchungsmethode erforderlich; denn die Messung des Abstandes jeden Auges von der Federspitze, welcher sich Berlin-Rembold bedienten, schliesst Fehlerquellen in sich. Im Augenblick der Messung musste das Kind zu schreiben aufhören und den Kopf so lange unbewegt halten, bis beide Entfernungen gemessen waren. Auch konnte der Maassstab nicht gut an das Auge selbst angelegt werden, sondern an die Schläfe, so dass die Ablesung am Maassstab sich mit dem Visirstandpunkt ändert, und geringe parallactische Verschiebungen relativ grosse Irrthümer herbeiführen können, zumal bei der Kleinheit der Basis des Dreieckes, d. h. der Augengrundlinie.

Ich wählte daher eine kleine Vorrichtung, welche es ermöglicht, während des Schreibactes und ohne dass dieser

*) Untersuchungen über den Einfluss des Schreibens auf Auge- und Körperhaltung des Schulkindes, Stuttgart, W. Kohlhammer 1883 pag. 14, 27, 29, 30 etc. 
unterbrochen wird, in jedem Augenblicke direct am Instrument ablesen zu können, ob der Fixationspunkt resp. die schreibende Federspitze in der Sagittalebene des Kopfes liegt, oder um wie viel Grad sie nach rechts oder links von ihr abweicht. $\mathrm{Zu}$ diesem Zweck wurde dem mehrerwähnten kleinen Messapparat ein in Grade getheilter kleiner Halbkreis derartig beigefügt, dass der Diameter desselben dicht vor den Angen, und parallel zur Basallinie verläuft, das zugehorige Centrum auf dem Nasenrücken liegt und am Gestell markirt ist, der Kreisbogen selbst aber um seine Diagonale gedreht, d. h. nach oben oder unten geklappt werden kann. Die Gradeintheilung geht von einem in der Mitte des Kreisbogens gelegenen Nullpunkt aus, die nach rechts gelegenen 90 Grade haben ein positives, die nach links gelegenen ein negatives Vorzeichen (cf. Fig. 1). Kniet der Untersuchende vor dem mit solchem Gestelle versehenen und schreibenden Kinde nieder, und visirt er von unten herauf über die Federspitze hinweg nach dem am Nasenrücken markirten Kreiscentrum, während der Kreisbogen so weit nach abwärts geklappt ist, dass der Beobachter die Gradeintheilung übersehen kann, dann wird die Visirlinie den Kreisbogen an irgend einem Punkte schneiden müssen. Ist dies der Nullpunkt der Gradbogenseala, dann liegt die Federspitze in der Sagittalebene; trifft die Visirlinie des Untersuchers einen seitwärts gelegenen Punkt, dann kann man an der Skala den Winkel ablesen, welchen eine von der Federspitze nach der Mitte der Basallinie gezogene Linie mit der Sagittalebene bildet.

Freilich hat auch diese Messung ihre Schwierigkeit, welche hauptsächlich in dem Umstande liegt, dass der Untersucher durch den Pultrand am Visiren behindert wird. Irrthümer von $2-3$ Grad sind dabei nicht mit Sicherheit zu vermeiden, doch handelt es sich hier um weit grössere Winkel, denen gegenüber diese Fehlerquelle 
zurücktritt. Dieser Winkel sei der Augenwendungswinkel genannt, für welche Bezeichnung die Fiction zu Grande liegt, als besitze der Schreibende nur ein einziges in der Nasenwurzelgegend liegendes, also ein Cyklopenauge, dessen Wendungswinkel gemessen wird. Denn in Wahrheit passt der gemessene Winkel weder für das rechte, noch für das linke Auge, da beide, wie schon an anderer Stelle*) besprochen wurde, bei allen Blickwendungen verschieden grosse Excursionen machen, es sei denn, dass der secundäre Fixationspunkt in dem durch den primären Fixationspunkt and beide Augendrehpunkte gelegten Kreis zu liegen käme.

Diese Messung wurde an Kindern der ersten und zweiten Versuchsreihe vorgenommen, im Ganzen $574 \mathrm{mal}$ an 194 Individuen. Die Versuchsanordnung war eine zweifache; zunächst wurde an 93 Kindern der ersten Versuchsreihe die Forderung gestellt, bei gerader und bei schiefer Medianlage, bei gerader und bei schiefer Rechtslage je ein Wort in beliebiger Schriftrichtung zu schreiben. Es wurde dann bei jeder Heftlage eine Messung vorgenommen; das Ergebniss war folgendes:

Bei gerader Medianlage schwankte der Winkel zwischen - 10 (Fixationspunkt liegt links von der Sagittalebene des Kopfes), war in sehr vielen Fällen Null ( $45 \mathrm{mal}$ ), in manchen +10 , einmal sogar $\div 200$, im Durchschnittbetrug er $-0,5$.

Bei schiefer Medianlage war das Verhalten ganz ähnlich; der Winkel erreichte vereinzelt -15 und +200 , war 57 mal Null, im Durchschnitt $+1,90$. Anảers bei gerader Rechtslage. Hier war der Winkel nur einmal negativ, nur 6 mal Null, wuchs bis +35 und war im Durchschnitt +110 . Auch bei schiefer Rechtslage war er nur 3 mal negativ, und $9 \mathrm{mal} \mathrm{Null}$, erreichte $+30^{\circ}$ und war im Durchschnitt $+10,4$.

Tabelle III. 9. a.b. lehrt die nähere Vertheilung der

*) Aerztl. Intelligenzblatt 1881, No. 6. 
gefundenen Winkelgrade auf die einzelnen Rubriken, wobe: beide Medianlagen and beide Rechtslagen in je eine Zahlenreihe zusammengezogen wurden.

Bei der zweiten Versuchsanordnung, welche 101 Kinder der zweiten Versuchsreihe umfasst, sollte ermittelt werden, in welcher Weise sich dieser Winkel andert, wabrend eine ganze Zeile bei willkürlicher Heftlage gesehrieben wird. Es wurde daher der Winkel beim Beginn und beim Ende der $10 \mathrm{Cm}$. langen Zeile notirt.

Die Heftłage war meist eine der Medianlage sehr nahe Rechtslage, in etwa $1 / 3$ der Falle eine starker ausgeprägte Rechtslage. Der Anfang der Zeile wurde mit einem Augenwendangswinkel geschrieben, der sich von Null wenig entfernte, 49 mal Null war and im Durchschnitt $+1,20$ betrng. Das Ende der Zeile aber weist einen. Winkel ron durchschnittlich +140 auf, der vereinzelt bis $+35^{\circ}$ stieg, 1 mal negativ und 7 mal Noll war. (Tab. MI. 9.c. d.)

Es bleibt also beim Schreiben einer Zeile die Sagittalebene durchschnittich 130 hinter dem fortrückenden Fixationspunkt zurück, der Rest muss mit blosser Augenbewegung ausgefüllt werden; mithin folgt das Auge dem Verlaufe der Zeile nicht nur in verschwindenden Ausnahmefällen, sondern ganz regelmässig. Dass dabei auch Kopfbewegung stattfindet, ist sicher, doch darf dies nicht Veranlassung geben, die Augenbewegung zu vernachlässigen. Es steht zu vermuthen, dass bei sehr genaner Fixation, z. B. bei Beginn des Schreibunterrichtes im ersten Schuljahre die Sagittalebene genauer eingestellt wird. Da meine Untersuchungen sich nur auf Kinder der IIL, IV. und V. Klasse erstreckten, so kann über die Art, wie im ersten Schuljahre fixirt wird, nichts gesagt werden, doch scheint es, dass der gesehilderte Modus einer gewissermassen nachlässigen und ungenauen Fixation schon sehr 
früh sich einstellt, denn er war im dritten Schuljahre nicht nur vorhanden, sondern auch in demselben Grade vorhanden, wie im vierten und fünften. Fon den 101 Schülern, bei welchen das Verhalten des Augenwendungswinkels im Verlauf einer Zeile gemessen wurde, gehörten 31 der III. Klasse an und es betrug die Durchschnittsgrösse des Winkels bei ihnen $12,3^{\circ}$, der vierten Klasse gehörten 48 an mit dem Durchscīnittswinkel $13,5^{\circ}$ und der fünften Klasse 22 mit dem Durehschnittswinkel 13,50.

Doch trat es bei einer bestimmten Gelegenheit sehr dentlich hervor, dass bei sorgfältiger Fixation auch von diesen Schülern die Sagittalebene recht genau eingestellt wird. Wenn senkrechte Schrift bei gerader Medianlage geschrieben wurde, fiel es nämlich auf, dass der Winkel $h$ sofort negativ wurde, wenn beim Schreiben der Zeile die Buchstaben mehr nach rechts rückten. Es spricht sich dies auch sehr deutlich in dem Durchschnittswerth für $h$ aus, der wie oben erwähnt, bei gerader Medianlage - 4,0, bei schiefer Medianlage $-0,7$ gefunden wurde. Damals musste zur Erklärung auf eine spätere Stelle verwiesen werden, weil erst die vorstehende Besprechung des Augenwendungswinkels den Schlüssel zu diesem Verhalten giebt. Die Haufigkeit des negativen Werthes für $h$ bei senkrechter Schrift war während der Messungen, welche hinter dem Kinde stattfanden anfangs unverstandlich, bis eine Betrachtong dieses Schreibactes von vorn zeigte, dass der Augenwendungswinkel in allen diesen Fallen annähernd gleich Null war. Die Anfertigung senkrechter Buchstaben war den Kleinen so ungewohnt, dass sie sorgfältigste Fixation für diese neue Technik verwendeten. Sicher darf angenommen werden, dass nach längerer Uebung auch die steile Schrift derart geschrieben werden wäde, dass der Kopf der Zeile nur zum Theil folgt.

Eine weitere Erage ist, welche Orientirung die Sagittalebene zu gewissen Strichelementen, insbesondere zu den 
Grundstrichen annimmt, mit anderen Worten: ob die Sagittalebene selbst oder eine durch die schreibende Federspitze zur Sagittalebene gelegte Parallelebene den Grundstrich seiner Richtung nach in sich aufnimmt, oder von ihm gekreuzt wird. Bevor hierauf eingegangen werden kann, muss die Lage der Grundstriche beider verschiedenen Heftlagen besprochen werden, denn diese Grandstrichrichtung ist von vornherein durch die Physiologie der Arm-, Hand- and Fingergelenke gegeben, von der Kopfhaltung in keiner Weise abhängig, sie muss bekannt sein, bevor von Orientirung des Kopfes zu ihr gesprochen werden kann. Die Richtung dex Strichelemente aus den anatomischen Verhältnissen der beim Schreibact betheiligten Gelenke zu construiren, ist eine schwierige Aufgabe. Bekanntlich hat sich Wilb. Mayer*) derselben in dankenswerther Weise unterzogen.

Ein anderer Weg; diese Verhältnisse zu ermitteln, ist der empirische, den ich in dem mehr erwähnten Aufsatze vom Jahre 1881 betrat. Es wurde damals gesagt, dass die schreibfertig vor die Mitte des Körpers gelegte Hand mit der Federspitze einen Kreisbogenabschnitt zu schreiben vermag, dessen Centrum entweder im Stützpunkt des kleinen Fingers oder in anderen Fällen im Handgelenke gelegen ist; dass nur ein kleines, dem linken Quadranten angehörendes Stück dieses Kreisbogens bequem ausführbar ist und dass die zu diesem Stuek gehörige Sehne die naturgemässe Richtung der Grundstriche für die betreffende Handlage darstellt. Auf solche Weise wurde damals die inzwischen von allen Autoren einwandlos acceptirte These motiviert, dass bei Medianlage des Heftes und der Hand nur annähernd senkrechte Grundstriche naturgemäss sind.

Man kann hinzufügen, dass kurze Strichelemente auch in der Richtung des zu dem Kreisbogen gehörigen Radius

*) Bayr. Aerztl. Intelligenzbl, 1882, pag. 315 . 
bequem ausführbar wird; in der That finden sich in alten Handschriften auch überaus hänfig die Grundstriche der kleinen Buchstaben sehr stark nach links geneigt.

In dem Aufsatz rom Jahre 1884 wurde dieser Satz dahin erweitert, dass auch bei Rechtslage der sehreibenden Hand die Grundstriche auf den Schreibenden hin gerichtet sind.

Allerdings kommen hierbei nicht unerhebliche Schwankungen vor, welche davon abhängen, ob bei Rechtslage der Oberarm dem Körper genähert ist; denn die Richtung des Unterarmes ist das Massgebende.

Wenn an der Voraussetzung festgehalten wird, dass die Hand eine bequeme Mittellage zwischen Abduction und mässiger Dorsalflexion innehält, so liegt der bequem zu schreibende grösste Kreisbogen derart, dass seine Sehne mit der Richtung des Unterarms einen nach unten offenen Winkel von $40^{\circ}$ bildet.*) In Bezug anf die Stellung der Hand zum Arm scheint mir als Norm festgehalten werden zu müssen, dass jene Stelle, wo die drei griffelführenden Finger den Federhalter berühren, in der Verlängerung des Unterarmes liegt.

Hierbei befindet sich die Hand in mässiger Dorsalflexion. Man kann sich aber leicht davon überzeugen, dass eine nur wenig stärkere, oder schwächere Abduction und Dorsalflexion die Lage des leicht herstellbaren Kreisbogens nicht nur wesentlich zu ändern vermag, sodass bei einer stärkeren aber immer noch keineswegs unbequemen Abduction und Dorsalflexion der Kreisbogen sich dem oberen Quadranten nähert, die hierzu gehörige Sehne also eine leichte Rechtsneigung erhält. Es geht daraus hervor, dass in geringem Grade rechts geneigte Schrift

*) Zu ganz entsprechenden Resultaten gelangt Hllinger in der Berl.-Klin. Wochenschrift vom 14. September 1885; beim Erscheinen dieser Arbeit wax die meinige schon im Manuscript vollendet. 
bei gerader Medianlage ohne besondere Mühe herstellbar ist.

Bei den vorliegenden Untersuchungen wurde die Richtung der Grundstriche in einer Reihe von Fallen gemessen und zwar in doppelter Hinsicht.

Erstens worde der Winkel, welchen die Grundstriche mit dem innerhalb der Schreibebene auf dem Pultrand errichteten Perpendilel bilden, gemessen; dieser Winkel soll $\gamma$ heissen und positiv sein, wenn das obere Ende des Grundstriches nach rechts vom Perpendikel abweicht, im entgegengesetzten Falle negativ.

Zweitens fand der Winkel Berücksichtigung, welchen der Grundstrich mit der Richtangslinie des Buchstaben bildet, das heisst mit jener Linie, welehe rom Buchstaben gegen die Mitte der Brust des Schreibenden gezogen wird.

Ueber den Winkel $\gamma$ ergab sich folgendes:

Bei 309 auf schiefe Medianlage bezüglichen Messungen wurden die Grundstriche jener langen Buchstaben berücksichtigt, welche während der Messung des Winkelpaares $v$ and $h$ geschrieben and als solche markirt worden waren.

Der zu schreibende Text war mit Rüeksicht hierauf so gewählt, dass der Buchstabe „s" recht oft darin rorkam. Die Sohwankungen sind nicht unerheblich und liegen zwischen -20 and +25 ; wie Tab. III. 6 . zeigt, waren die extremen Winkelgrössen selten; der Durchsehnitt betrug $+8,20$; es fand also im Allgemeinen eine leichte Rechtsneigung statt. Die Zabl der links geneigten Grundstriche verhielt sich zur Zahl der rechts geneigten wie $1: 10$.

Ferner wurden von denselben Handschriften, auf welche sich die genannten 309 Messungen beziehen, 275 Zeilen herausgegriffen, bei welchen der Winkel $\gamma$ jener Grundstriche gemessen wurde, welche dem ersten nnd letzten langen Buchstaben der Zeile angehören. Unter den 275 Winkeln des Zeilenanfangs kamen negative Werthe relativ oft vor (Tab. III. 6. f. g. und h.), der Durch- 
schnittswerth war $+3,5$. Die entsprechenden Winkel am Ende der Zeile hatten selten negativen Werth, ihr Durchschnitt war $+9,8$. Diese Differenz zwischen erstem und letztem Grundstrich der Zeile ist von hohem Interesse; sie lehrt, dass die Grundstrichrichtung von der Hand abhängt und dass sie auch von den mehr seitwärts gelegenen Punkten immer nach dem Körper des Schreibenden hinzielt.

Bei diesen Messungen darf aber nicht vergessen werden, dass zwar das Heft im Allgemeinen median, der Zeilenanfang aber oft etwas links, das Ende der Zeile stets entsprechend rechts von der Mitte des Körpers gelegen war.

Auch die im Moment der Messung von $h$ und $v$ geschriebenen Buchstaben gehören meist der zweiten Hälfte der Zeile, mithin einer leichten Rechtslage an.

Um eine grössere Genauigkeit zu erzielen, wurde die Richtung der Grundstriche aus jener Versuchsreihe gemessen, bei welcher zur Ermittelung des Augenwendungswinkels von 93 Kindern je ein Wort in strenger Medianlage geschrieben worden war. Der Heftdrehungswinkel betrug hier, wie bei allen anderen schiefen Medianlagen der vorliegenden Untersuchung $30^{\circ}$, überdies wurde der Pultrandperpendikel noch bei jedem Wort auf dem Heft mit Lineal und Bleistift eingezeichnet, bevor das Heft gerückt worden war.

Es ergab sich ein Durchschnittswerth von $+2,6$, also minimale Rechtsneigung.

Im ganzen liegen also 952 auf schiefe Medianlage sich beziehende Messungen des Winkel $\gamma$ vor; der Durchschnittswerth berechnet sich für dieselben auf $+6,8$.

Bei gerader Medianlage müsste die Grundstrichriehtung genau dieselbe sein, denn sie wird ja nicht mit Rücksicht auf das Heft, sondern mit Rukoksicht auf den Pultrand gemessen. Gleichwohl ergaben jene 93 in gerader Medianlage geschriebenen Worte, bei denen die Grundstrichrichtung 
den Kindern überlassen worden war, eine durchschnittliche Rechtsneigung von $21,7^{\circ}$; ein Beweis, wie ubermächtig die Vorstellung von der nothwendigen Schiefheit der Buchstaben wirkt. Die Handgelenke wurden gewaltsam abducirt und dorsalflectirt, um nur eine gewisse Rechtsneigung zu arzielen. Die Schriftproben der geraden Medianlagen, bei welcher $v$ und $h$ gemessen wurden, sind naturlich hier nicht verwerthbar, weil dort alle Sorgfalt auf strengste Senkrechtstellung der Grundstriche geriehtet war. Die aus Tab. III. 6. ersichtlichen Werthe für 243 Messungen des Winkels $\gamma$ bei willkürlicher Heftlage ergaben im Mittel $\leftarrow$ 18.8; dieKleinheit derselben rührt davon her, dass die willkürlichen Heftlagen sich meist der schiefen Medianlage näherten.

Der Winkel zwischen der Richtungslinie eines Buchstabens und dessen Grundstrich fällt bei gerader und schiefer Medianlage mit dem Winkel $\gamma$ zusammen. Für die 2 mal 93 einzelnen Worte, welche bei Messung des Augenwendungswinkels in gerader und schiefer, stets aber stark ausgeprägter Rechtslage geschrieben wurden, weicht bei ersterer der Grundstrich nur durchschnittlich 5,20 , bei letzterer um $17,6^{\circ}$ von der Richtungslinie nach links $a b$.

Unter den von der $h$ - und $v$-Messung herrührenden Schriftproben wurden in jenen Zeilen, welche mit einem langen Buchstaben begannen, der Grundstrich desselben auf die zum Zeilenanfange gehörige Richtungslinie des Heftes bezogen. Es ergab dies 355 Messungen, davon:

75 Messungen bei Linkslage mit Grundstrichrichtungslinienwinkel von $+17,5$ im Durchschnitt,

59 Messungen bei Medianlage mit Grundstrichrichtungslinienwinkel von $+13,2$ im Durchschnitt,

142 Messungen bei geringer Rechtslage mit Grundstrich richtungslinienwinkel von $+6,3$ im Durchschnitt.

79 Messungen bei starker Rechtslage mit Grundstrichrjchtungslinienwinkel ron $+0,6$ im Durchschnitt.

Die Zahlen sind in den einzelnen Rubriken zu klein, 
um sichere Schlüsse zu ziehen. Doch scheint es, dass die positiven Werthe immer kleiner werden, je weiter das Heft nach rechts rückt und dass sie bei sehr starker Rechtslage negativen Werth annehmen.

Es wurde schon erwähnt, dass bei 275 Zeilen, in denen die Richtung des ersten und letzten langen Grundstriches verglichen wurde, sich die Regel ergab, dass die Richtung des ersten Grundstriches weniger stark geneigt ist, als die des letzten; beide convergiren nach unten hin unter einem Winkel von durchschnittlich 6,$30 ; 13 \mathrm{mal}$ convergirten sie nach oben, $11 \mathrm{mal}$ waren sie parallel.

Diese Beobachtung spricht dafür, dass mit Neigung der Richtungslinie nach rechts auch die Grundstriche sich gegen den Pultranả neigen, dass aber ihre Neigung nicht in demselben Maasse zunimmt, denn die Richtungslinien des ersten und letzten Buchstaben einer Zeile bilden einen weit grösseren Winkel als 60.

Denkt man sich die Zeile so lang, dass das letzte Wort einer starken Rechtslage angehört, so würde die Rechtsneigung des Grundstriches gegen Ende der Zeile zwar wachsen, aber nicht so schnell, als die Neigung der Richtungslinie; sie wurde hinter letzterer zurückbleiben und schliesslich negativ werden, ganz in Uebereinstimmung mit den vorher mitgetheilten Messungsergebnissen.

Zugleich ergibt sich aus dieser Beobachtung die praktische Nutzanwendung, beim Unterrichte nur kurze Zeilen schreiben zu lassen.

Es soll nun, nachdem Kopfhaltung einerseits und Schriftrichtung andererseits unabhängig von einander betrachtet wurden, die Beziehung beider zu einander besprochen und der Winkel in Betracht gezogen werden, welchen der Grundstrich mit der Sagittalebene des Schreibenden bildet; derselbe ist complementär zu dem Winkel zwisehen Grundlinie und Grundstrich. Letzterer ist aus den zusammengehörigen $\mathrm{d}$. h. sich auf denselben Schreibact 
beziehenden 3 Winkeln $v, h$ und $y$ nach folgender Construction berechenbar.

In Fig, 8 sei $E O D$ die horizontale Schreibebene, in der auch $B O$ und $C O$ liegen. Innerhalb dieser Ebene bedeutet $O D$ den Pultrand, $E O$ das auf ihm errichtete Perpendikel, $B O$ den Grundstrich. $A O$ sei die gegen die Horizonlalebene geneigte Basallinie, $O C$ deren senkrechte Projection auf die Horizontalebene. Es sind also, um die

Fig. 8.

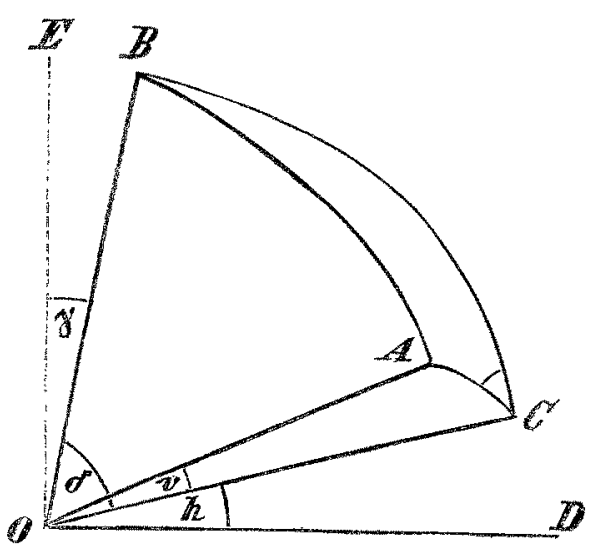

hisherige Bezeichnung beizubehalten, der Winkel EOB $=\gamma ;$ der Winkel $A O C=v$; und der Winkel $C O D=h$. Als Hilfswinkel sei die Bezeichnung $\delta$ für den Winkel $B O C$ eingeführt. Derselbe ist $=1 \mathrm{R}-\gamma-h$. Werden $\gamma$ oder $h$ negativ, so treten sie selbstrerständlich als positiv in die Formel.

Für das sphärische Dreieck $A B C$, welches nach Construction bei $C$ seinen rechten Winkel hat, gilt: cos. $B O A=\cos . \delta$. cos. v.

Weun also $v, h$ und $\gamma$, mithin auch $\delta$ bekannt sind, so findet sich nach genannter Formel der Winkel zwischen 
dem Grundstrich $B O$ und der Basallinie $O A$, und zwar der nach rechts offene Winkel zwischen beiden.

Es bedarf kaum eines Beweises, dass der in dieser Weise berechnete Winkel mit dem Grundlinien-Grundstrich-Winkel Berlin-Rembold's identisch ist. Der Unterschied ist nur der, dass Berlin-Rembold durch einen Punkt des Grundstriches eine Parallele zogen zur Basallinie, während in obiger Construction durch einen Punkt der verlängerten Basallinie eine Parallele zum Grundstrich gezogen wurde. Dass Berlin-Rembold den nach rechts gelegenen Winkel massen, sagen sie zwar nicht ausdrücklich, doeh geht es aus dem Zusammenhang hervor.

Nach dieser Formel wurde der nach rechts offene Grundstrich-Grundlinien-Winkel in 994 Fällen berechnet. Die Logarithmen wurden auch hier nur fünfstellig genommen, Bruchtheile von Winkelgraden, welche kleiner als 30 Minuten waren, wurden ignorirt, Bruchtheile über 30 Minuten als voller Grad gerechnet.

Die Resultate der Messungen sind aus Tabelle IV ersichtlich.

Es zeigt sich, dass der Grundstrich-Grundlinienwinkel bei gerader Medianlage durchschnittlich etwas grösser, bei schiefer Medianlage und bei willkürlicher Heftlage etwas kleiner als $90^{\circ}$ und im Mittel aus allen Messungen $88^{\circ}$ beträgt.

Lehrreicher aber, als dieser Durchschnittswerth ist die Betrachtung der einzelnen Werthe dieses Winkels. Dieselben schwanken zwischen $55^{\circ}$ und $120^{\circ}$. Ordnet man sie in Gruppen von je 50, so zeigt es sich, dass die Summe aller zwischen 70 und $105^{\circ}$ liegenden Winkel 92,8 pCt. sämmtlicher Messungen betragen. Will man also die vereinzelten extremen Fälle als Ausnahme oder als einem an dernVisirtypus angehörig gelten lassen, so bleibt immer noch für den Grundstrich-Grundlinienwinkel ein weiter 
Spielraum von $35^{\circ}$, so dass es nach diesen Messungen nicht wohl angeht, zu sagen, der Winkol betrage in 90 pCt. der Fälle annähernd einen Rechten. Die Messungen von Berlin-Rembold, anf Grund deren das Gesetz von der rechtwinklichen Kreuzung zwischen Grundlinie und Grundstrich aufgestellt wurde, ergaben, dass in 90 pCt. der Falle der Winkel zwischen 75 und 95 liegt, also einen Spielraum von $20^{\circ}$ hat. Die Zahl der publicirten Messungen Berlin-Rembold's beträgt 371. Zwar finden sich Angaben, dass bei der Voruntersuchung an mehr als 300 Kindern dasselbe Verhalten beider Linien zu einander beobachtet wurde und in einer späteren Publication ${ }^{*}$ ), dass es nachträglich bei einer grossen Anzahl von Kindern und Erwachsenen gemessen und genanntem Gesetze entsprechend gefunden wurde; Zahlen aber liegen nur über jene 371 Messungen vor und auch diese lassen die Fintheilung nach Heftlagen leider vermissen.

Die Methode der Messung Berlin-Rembold's schliesst, wie die Autoren selbst zugeben, erhebliche Fehlerquellen ein. Die Basallinie wurde von einem der Untersucher durch „ein über dem Kopfe des Schreibenden parallel mit dessen oberen Ohrmuschelrändern gehaltenes Lineal markirt (Augenmaass). $\nabla$ on dem zur Messung verwendeten Winkelmaass wurde ein Schenkel dem Grundstrich parallel auf das Heft gelegt, der andere vom Visirstandpunkte des einen Untersuchers za jenem Lineal parallel gerichtet (Angenmaass); alsdann geschah auch durch den anderen Untersucher von einem zweiten Visirstandpunkt aus dasselbe (Augenmaass). Das Resultat ist also in dreifacher Hinsicht von einer Schätzung abhängig mithin reine Messung im strengeren Wortsinn.

Bei der von mir gewählten Methode sirid die Winkel

*) Bericht über die 15, Vers. der ophthal. Gesellsch, 1883 , 
$\gamma$ und $v$ derart gemessen, dass die Lage beider Schenkel eines jeden Winkels rollkommen sichergestellt und von keiner Schätzung abhängig ist. Bei Bestimmung des Winkels $h$ ist das Lineal dem Pultrand parallel zu stellen. Es geschieht das mit Hilfe der Wasserwaage, sodass nur die horizontale Abweichnng rom Angenmaasse abhängig ist und es ist der Pultrand, zu welchem die Parallelstellung gesucht werden soll, eine wohl fixirte Linie, was von einem frei über dem Kopfe gehaltenen Lineal nicht gesagt werden kann.

Dennoch hielt ich es nicht für überflüssig, den Winkel zur Controle noch nach einer weiteren Methode zu messen. Es wurden nämlich zwei von einem gemeinsamen Stamm ausgehende unter sich einen Winkel von ca. 700 bildende stricknadeldicke Eisenstäbchen an ihrem Vereinigungspunkt im mehrerwähnten Messgestell auf dem Nasenrücken befestigt, genau über dem Centrum des zur Ablesung des Augenwendungswinkels dienenden Kreisbogens. Die Lage der Stäbchen wurde so fixirt, dass die durch sie gelegte Ebene auf der Basallinie senkrecht stand. Zur Controle dieser Stellung diente der eben genannte Kreisbogen, welcher gegen jedes der Stäbchen geklappt werden konnte und beide mit seinem Nullpunkte treffen musste. Somit befanden sich die Stäbchen genau in der Sagittalebene der Versuchsperson, wenn das Gestell richtig sass, d. h. wenn die Ohrmuschelansätze gleich hoch waren. Von den Stäbchen war bei aufrechter Kopfhaltung eines nach oben, das andere nach vorn gerichtet. (Fig. 1.)

Visirt nun, während das Kind mit vorgebeugtem Kopfe schreibt, der Untersuchende ron oben herab, so gelingt es leicht, die beiden Stäbchen auf dem Schreibheft zur Deckung zu bringen, mithin die Schnittlinie $z w i s c h e n$ Sagittalebene des Kindes und Sehreibfläche direct auf dem Papier verzeichnet zu sehen. Durch zwei schnell markirte Punkte oder Kreuzchen 
ist dann die Lage dieser Schnittlinie für die spätere Messung genau fixir bar und die Kreuzung derselben mit dem Grundstrich kann mittelst des Transporteurs mit jeder hier wünschenswerthen Genauigkeit abgelesen werden.

Bei Ausführung dieser Ontersuchung zeigte sich, was Niemanden befiemden kann, der den vorstehenden Ausfübrungen gefolgt ist: die Visirebenenschnittlinie traf (die gerade Medianlage ausgenommen) nur in sehr seltenen Fällen den zuletzt geschriebenen Buchstaben. Meist lag sie in $1 / 4$ bis $1 / 2$ bis $3 / 4$ Zeilenlänge nach links von demselben entfernt. Nur ausnahmsweise und zwar meist nur bei medianer Lage des zuletzt geschriebenen Buchstabens, war die Sagittalebene auf den Fixationspunkt eingestellt, hin und wieder sogar wurde eine leichte Ueberdrehung nach rechts beobachtet.

Es ist dies nur ein anderer Ausdruck and eine neue Bestätigung der oben durch Messung des Augenwendungswinkels constatirten Thatsache, dass der Kopf der schreibenden Federspitze im Verlaufe der Zeile nur zum Theil folgt, zum anderen sehr erheblichen Theil aber die Verfolgung des fortrückenden Fixationspunktes blosser Augenbewegung überlässt.

Der gemessene Winkel zwischen Sagittalebenenschnittlinie und Grundstrich ist aber als solcher noch nicht $\mathrm{zu}$ verwerthen; es muss, da die Sagittalebene selten auf der Schreibfläche senkrecht steht, der Winkel zwischen Grundstrich und Sagittalebene gesucht werden.

Die Sagittalebenenneigung ist für jeden einzelnen Fall bekannt, weil für jeden Schreibact, bei welchem die Sagittalebenenschnittlinie auf das Papier gezeichnet wurde, auch eine Messung des Winkelpaares $v$ und $h$ stattfand. Es geschah dies nämlich an den 68 Kindern der III. Untersuchungsreihe und zwar wurde an jedem Kinde je 2 mal bei schiefer Medianlage und bei willkürlicher Heftlage gemessen. 
Der Winkel $\mathrm{v}$ gibt nicht nur die Neigung der Basallinie, sondern, da die Grundlinie auf der Sagittalebene senkrecht steht, auch die Neigung der letzteren zur horizontalen, welche gleich ist dem Complementärwinkel von $v$.

In Fig. 9 sei $A O B$ die horizontale Schreibebene, $O B$ der Grundstrich, $A O$ die Sagittalebenenschnittlinie, $A O C$

Fig. 9.

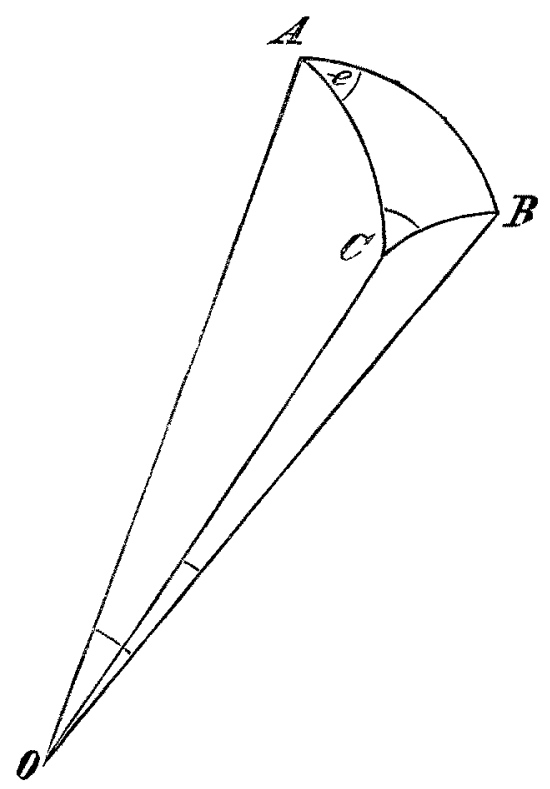

die Sagittalebene, Winkel $e$ der Sagittalebenenneigungswinkel, $O . C$ die rechtwinkliche Projection des Grundstrichs $O B$ auf die Sagittalebene. Mithin ist $C O B$ der gesuchte Winkel zwischen Grundstrich und Sagittalebene. Für ihn gilt, da im sphärischen Dreieck $A C B$ bei $C$ der rechte Winkel liegt, die Formel:

$\sin . C O B=\sin . A O B . \sin . e$. 
In der Figur wurde eine Reehtsneigung der Sagittalebene, d. h. ein negativer Winkel $v$ angenommen; meist ist die Neigung eine umgekehrte, das ändert nichts an der Formel.

Dieser Grundstrich-Sagittalebenenwinkel wurde aus den gemessenen Stücken nach obiger Formel berechnet und zwar 136 mal fiir schiefe Medianlage und ebenso oft für willkürliche Heftlage. Wiederum wurden Bruchtheile von Winkeln zu Ganzen abgerundet.

Ein wesentlicher Unterschied zwischen beiden ist, wie Tab. III. 8. zeigt, nicht zu bemerken. Auch lehrt ein Vergleich dieser Tabelle mit den entsprechenden Rubriken der Tabelle IV, dass der Mittelwerth für diesen Winkel ziemlich genau complementär ist zum Grundstrichgrundlinienwinkel derselben Untersuchungsreihe, wie er durch Berechnung aus $v, h$ und $\gamma$ gefunden wurde. Werden die 272 Grundstrich-Sagittalebenenwinkel in Gruppen zu $\breve{o}^{0}$ geordnet, so zeigt sich wiederum, dass die Gruppen von -5 bis + 30 Grad zusammengefasst werden müssen, um 93 pCt. der gemessenen Winkel zu vereinigen. Auch hier also misst jenes Gebiet, welches Berlin-Rembold die Sagittalzone nennen, $35^{\circ}$.

Schwankungen innerhalb so weiter Greazen erlauben meines Erachtens vielleicht noch die Bezeichnung Regel im Sinne der Grammatik aber kaum werden sie ein physiologisches Grundgesetz genannt werd endürfen.

Es wurde bisher von den Autoren die Frage, ob die Augen einen jeden Grundstrich beim Schreiben verfolgen, theils ans theoretischen Gründen beantwortet, z. B. von Königshöffer*) in verneinendem Sinne, theils aus der Kopfhaltung zu erschliessen gesucht (Berlin-Rembold); directe Beobachtungen aber sind hierüber meines Wissens noch nicht angestellt worden. Und doch hätte,

*) Berl. Klin. Wochenschrift 1883. No. 11. 
bevor man dieser bisher nur supponirten Augenbewegung eine so grosse, die gesammte Physiologie des Schreibens beherrschende Wichtigkeit beilegte, vor allem festgestellt werden sollen, in wie weit sie überhaupt stattfindet.

Dass dies beim Erwachsenen und ganz besonders beim Schnellschreiben nicht geschieht, nehmen auch BerlinRembold an; dass hingegen bei den ersten Schreibversuchen das Auge jeden Federstrich begleitet, ist nahezu selbstverständlich. Wo aber liegt die Grenze?

Für die Knaben der mittleren Schulklassen, auf welche sich die vorliegenden Untersuchungen beziehen, versuchte ich die Grösse jener Grundstriche festzustellen, deren Herstellung nachweisbar mit Blickbewegung verfolgt wird, Zu diesem Zweek waren auf sehwarzüberzogenem Pappdeckel parallele Streifen weissen Papieres von versehiedener Breite geklebt und das Ganze neben dem Heft des schreibenden Kindes so gehalten, dass die Hornhautbildchen der Streifen horizontal verliefen. Das Kind schrieb am Stehpult, nahe dem Fenster; die Beobachtung fand von unten statt, wobei das Augenlid des Kindes leicht gehoben wurde.

Es gelingt auf diese Weise durch die Verschiebung der Hornhautgrenze gegen das Liniensystem des Reflexbildes sehr kleine Blickbewegungen wahrzunehmen. Waren nun bei gewöhnlichem, in diesem Alter noch langsamerem Schreibtempo die Grundstriche länger als $10 \mathrm{~mm}$., dann gelang es regelmässig, eine begleitende Blickbewegung $\mathrm{zu}$ beobachten. Bei erheblich kleineren wurde sie vermisst. Dazwischen lag eine Zone schwankenden Verhaltens.

Diese Beobachtung ist unvollkommen, denn sie erlaubt nicht, den Grad der Augenbewegung za messen, während es doch von Wichtigkeit wäre, zu wissen, ob der Blickwinkel dem zum entsprechenden Buchstaben gehörigen Sehwinkel gleich ist, oder hinter demselben zurückbleibt. Aber es dürfte schwer sein, Apparate, welche an der 
Bewegung des Cornealreflexes die Grösse der Angenbewegung berechnen lassen, bei einem schreibenden Kinde anzuwenden. Wenn es nun hiernach feststeht, dass in den mittleren Schulklassen die langen Grundstriche von der zu den gebräuchlichen Heftliniirungen gehörigen Grösse $(15 \mathrm{~mm})$ mit dem Auge verfolgt werden, dann bedarf es keines Beweises, dass diese Blickbewegung allen jenen Gesetzen gehorcht, welche über Augenbewegung im Allgemeinen festgestellt sind. Eine andere Frage aber ist es, ob gerade diese Augenbewegungen den gesammten Schreibact beherrschen, ob sie wichtiger sind, als jene Blickbewegungen, welche den Verlauf der Zeile regelmässig begleiten und einen ungleich grösseren Winkel durchmessen, als es jemals bei Grundstrichvisirung geschieht; oder ob nicht vielmehr bei einem so complicirten Vorgange, wie es der Schreibact ist, eine Anzahl der den verschiedenen betheiligten Organen zugehörigen Bewegungsgesetze nämlich jene der Augen, des Kopfes und der Hand mit einander collidiren und ob das Resultat nicht in derselben Weise zu Stande kommt, wie die Diagonale im Parallelogramm der Kräfte.

Die Frage aber, $a b$ der Finfluss der Kopf- und Angenbewegungsgesetze einerseits oder jener der Handund Armbewegungsgesetze andererseits überwiegt und die Physiologie des Schreibactes beherrscht, wird nicht einseitig aus dem mehr oder minder häufigen Vorkommen eines Winkels entschieden werden können, sondern nur durch geeignete Versuchsanordnung, bei welcher unter sonst gleichen Bedingungen nur ein oder der andere Factor geändert wird.

Die These Berlin-Rembold's, dass das WundLamansky'sehe Gesetz der Hand die Bewegungsbahn für Herstellung des Grundstriches vorschreibt, von dem erstgenannten Autor in einer späteren Publication sogar dahin pointirt, dass unter Umständen die Buchstaben sogar auf 
den Kopf gestellt werden, um nur die Grundstriche in die Sagittalzone zu bringen*), erschien von vornherein deshalb nicht recht annehmbar, weil der eigenartige Mechanismus der schreibfertig gehaltenen Hand für die Lage der ohne gewaltsame Verdrehungen ausführbaren Grundstriche nur beschränkten Spielraum zulässt, während die Kopfstellung der grössten Sehwankungen fähig ist.

Ueber Parallelversuche, welche geeignet wären, durch entsprechende Aenderung der Bedingungen den bestimmenden Einfluss der Kopfhaltung auf die Grundstrichrichtung darzuthun, berichten Berlin-Rembold nichts. Um dieser Frage näher zu treten, wurde bei einer Reihe von Kindern, nachdem sie einige Zeit bei willkürlicher Heftlage geschrieben hatten, der Auftrag gegeben, ruhig weiter zu schreiben, während der Kopf sanft, aber ausgiebig in andere Richtung gedrückt wurde und in derselben einige Zeit frei verbleiben musste. Weder Veränderung des Winkels $v$, noch solche des Winkels $h$, welche letzteren den Grundstrich-Grundlinien-Winkel stark beinflussen, vermochten an der Richtung der nunmehr geschriebenen Grundstriche dasGeringste zu ändern. Die Kopfhaltung war unbequem und dürfte freiwillig nicht leicht gewählt werden, die Buchstaben aber standen genau wie vor Aenderung der Kopfhaltung.

Das widerlegt die Berlin-Rembold'sche Deutung der in der That häufig, aber nicht gesetzmässig vorkommenden rechtwinkeligen Kreuzung zwischen Grundlinie und Grundstrich ganz und, wie ich glaube, einwandfrei. Stets wurde von mir die Ansicht vertreten, dass die Lage der Schriftelemente ausschliesslich von Hand und Arm abhängen, dass Kopf und Auge die Grundstrich- und Zeilenrichtung als gegebene Thatsachen hinnehmen und sich in gewissem Grade nach derselben mit ihrer Haltung richten. ${ }^{* *}$ )

*) 15. Versammlung der ophth. Gesellsch. 1888.

**) Es beruht offenbar auf Missverständniss, wenn Ellinger 
Kopf und Auge haben für ihre Bewegungen unter den beim Schreiben gegebenen Bedingungen weit mehr Spielraum als die Hand.

In der That sucht der Kopf mit dem gewisse Blickbahnen bevormugenden Auge sich durch Kopfdrehung so zu orientiren, dass die beim Verfolgen der Zeile stattfindende Blickwendung sich jenen bevorzugten Bahnen nähert; das beweist das häufige Auftreten der Basallinienneigung nach links, welche, wie gezeigt wurde, die Wendung des gebeugten Kopfes nur dann begleitet, wenn gesehrieben wird, nicht aber bei gewohnlicher Fixation nach reehts hin; das beweist ferner der Umstand, dass dieselbe Grundlinienneigung bei schiefer Medianlage ungleich grösser ist, als bei gerader Medianlage. Wem diese Năherung sehr selten ihr Ziel, die Zeile in die Visirebene zu bringen, wirklich erreicht, so liegt das, wie gezeigt wurde, an der Anatomie und Physiologie der Kopf- und Halsgelenke, welche einerseits die Drehung um eine senkrechte Achse in den ausschliesslichen Dienst der Seitwärtswendung des Blickpunktes stellen, andererseits eine so ausgiebige Bewegung um die horizontale Achse nicht gestatten, wie sie durchschnittlich erforderlich wäre, um die Zeile in die Visirebene zu bringen. Auch lehren viele Fälle, dass eine gewisse Indolenz gegen die Kreuzung

(Berl. Klin. W. 14. Septb. 1885) meint, ich leugne den Einfluss der Augenmuskelthätigkeit auf Drehung von Kopf und Rumpf; stützen sich doch meine Einwände gegen die schiefe Medianlage grossentheils auf die Unzuträglichkeit der transversalen Blick bewegung beim Verfolgen schräg empor steigender Zeilen; ich behaupte sogar nach wie vor, dass der Kope sich zur Seite neigt, nm der transversalen Zeile besser mit den A ugen folgen zu können. Nur lengne ich, dass die Visirung der Grund striche allein in Betracht komme, die Visirang der Zeile aber einflussios sei; auch finde ich die Schwierigkeit transversaler Blickbewegung nicht sowohl in der Thätigkeit der Augenmuskeln, als in den optischen Consequenzen derselben. 
ron Visirebene und Zeile vorliegt, ganz ebenso, wie in schr vielen Fällen die Kreuzung zwischen Grundstrich und Sagittalebenensehnittlinje vom Schreibenden geduldet wird, obgleich letztere zu vermeiden sehr leicht wäre. Diese Gesetze sind eben keineswegs starr, sondern treten, wenn andere Interessen mit ihnen collidiren, als Componente in das Parallelogramm der Kräfte ein, in dessen resultirender Diagonale sie zwar zur Geltung kommen, ohne indessen den Einfluss der anderen Componente zu vernichten.

Da nun directe Beobachtung gelebrt hat, dass in den mittleren Schulklassen die langen Grundstriche mit Augenbewegung verfolgt werden, so wird auch hier das Streben sich geltend machen, diese letzteren mit den bevorzugten Blickbahnen zusammen fallen zu lassen.

Nur kann die kleine Augenbewegung von 30 , wie sie der Grösse der langen Grundstriche entspricht, nicht die gesammte Physiologie des Schreibactes beherrschen, die vielfach grössere aber, welche durchschnittlich beim Verfolgen der Zeile gemacht wird, völlig bedeutungslos bleiben. Ist eine Indolenz schon bei Ausführung des grösseren Zeilenblickwinkels nachweisbar, wie kann dann bei dem kleineren Grundstrichblickwinkel eine unbengsame Zwangslage herrschen? Letzteres wäre theoretisch unerklärbar, wie es auch thatsächlich durch die Messungen widerlegt ist.

Wächst durch grössere Annäherung des Kopfes an das Heft die Grösse des zu einem langen Grundstrich gehörigen Blickwinkels, so wächst ganz ebenso auch der zur Zeile gehörige und wird den ersteren stets um das mehrfache übertreffen. Es soll dabei keineswegs vergessen werden, dass bei erstem Schreibunterricht von einem Einfluss der Zeile noch nicht viel die Rede sein kann, demn das Kind bedarf einer langen Zeit, um auch nur einen Buchstaben zu vollenden. In welchem Stadium der Schreibfertig- 
keit der Einfluss der Zeile sich geltend macht, werden vielleicht weitere Untersuchungen lehren; jedenfalls ist nach meinen Messungen ein solcher im dritten Schuljahre schon vorhanden.

Bei Schülern mit fertiger Handschrift dürfte es sich vielleicht herausstellen, dass die Grundstriche mit Blickbewegung gar nicht mehr verfolgt werden, und Erwachsene, welche sehr viel schreiben, emancipiren ihre Kopfhaltung oft genug anch von der Zeilenrichtung; in vielen Füllen sieht man aber auch bei berufsmässigem Vielschreiben, dass die schiefe Medianlage mit Tiefstand des linken Anges verbunden wird. Doch handelt es sich hier ansschliesslich um Kinder.

Wenn nun die Messungen ergaben, dass der GrundstrichSagittalebenenwinkel durchschnittlich erheblich kleiner ist, als der Zeilen-Visirebenenwinkel, so berechtigt das noch keineswegs, den Einfluss der Grundstrichrichtung als allein herrsehend hinzustellen und jenen der Zeilenrichtung vollkommen zu leugnen. Es muss vielmehr dahin gestellt bleiben, wie gross uberhaupt der Antheil ist, welchen das Wund-Lamansky'sche Gesetz an dem gefundenen Grundstrich-Grundlinienwinkel hat, da dieser Winkel sich ganz ähnlich gestalten müsste, wenn jenes Gesetz gar keine Geltung hätte. Ws wurde das schon an anderem Orte*) dargethan und soll hier nur durch die Messungsresultate auf"s neue erläutert werden.

Bezüglich des Grundstrichgrundlinienwinkels ist zwischen Medianlage und Rechtslage zu unterscheiden; der Umstand, ob gerade oder sehiefe Heftlage vorliegt, kommt bei diesem Winkel nicht in Betracht.

Bei Medianlage hat die Sagittalebenenschnittlinie keine Veranlassung, von jener Lage abzuweichen, welche sie bei

*) Berliner Klin. Wochenschrift 1884. 
primärer Kopfhaltung inne hatte, nämlich senkrecht zum Pultrande. Denn gesetzt auch, das Heft liege schief und die Zeile steige schräg hinauf, in welchem Falle die Basallinie sich nach links neigt, so hat doch solehe Neigung der Basallinie und Sagittalebene gar keinen Einfluss auf den Verlauf der Sagittalebenenschnittlinie; dieselbe bleibt nach wie vor rechtwinkelig zum Pultrand gestellt. Der Grundstrich aber, das geben auch Berlin-Rembold*) zu, hat bei medianer Heftlage stets eine senkrechte Richtung zum Pultrand.

Also decken sich bei medianer Heftlage, auch abgesehen von jedem gegenseitigen Einfluss eines Organs auf das andere, Sagittalebenenschnittlinie und Grundstrich; mithin ist der Grundstrich-Grundlinienwinkel $=90^{\circ}$, die Sagittalebene möge dabei so stark geneigt sein, wie sie wolle.

Bei Rechtslage des Heftes kommt die Richtungslinie des zu schreibenden Buchstaben in Betracht, d. h. die Verbindungslinie desselben mit dem Brustbein des Schreibenden.

Vertauscht man die Schrift mit einem beliebigen rechts gelegenen Fixationsobject, so stellt sich, wie die oben ansgeführten Versuche lehren, der Kopf mit seiner Sagittalebene nicht etwa derart auf diesen Punkt ein, dass von der einfachen Kopfbeugung ausgehend, durch Drehung um eine horizontale Achse der Winkel $h$ der Basallinie Null bleibt, der ganze Drehungswinkel im Winkel $v$ zum Ausdruck kommt, die Sagittalebenensehnittlinie parallel zu sich selbst nach rechts versehoben wird, bis sie den neuen Fixationspunkt in sich aufgenommen hat; sondern ganz im Gegentheil, es erfolgt die Drehung um eine senkrechte Achse, Winkel $v$ bleibt Null, Winkel $h$

*) Untersuchungen etc., pag. 24. 
trägt allein die Kosten der Drehung, die Sagittalebenenschnittlinie fällt mit der Richtungslinie des Fixirpunktes zusammen. Das geschieht also ganz unabhängig von der Grundstrichrichtung, es geschieht ganz ebenso, wenn gar kein Strich vorhanden ist und nur ein Punkt fixirt wird.

Andererseits lehrten andere Messungen, dass Schreiben in Rechtslage Grundstriche zu Tage fördert, welche, allerdings mit einem gewissen Spielraum, im Allgemeinen von der Richtnngslinie des Buchstabens nicht wesentlich abweicht und, was besonders betont werden muss, es lebrten die erwahnten Controleversuche, dass die Grundstrichrichtung weder bei medianer, noch bei seitlicher Heftlage im geringsten sich ändert, wenn der Kopf in andere Lage gebracht wird.

Es congruiren also auch hier wieder sowohl Grundstrichrichtung als Sagittalebenenschnittlinie, beide mit der Richtungslinie des Buchstabens und beide thru es unabhängig von einander.

Wenn dies aber der Fall ist, dann beträgt der Grundstrichgrundlinienwinkel $90^{\circ}$, es möge die Sagittalebene im Uebrigen wie stark sie immer wolle geneigt sein.

Aber in jeder Heftlage haben sowohl Sagittalebenen. schnittlinie als Grundstrichrichtung einen gewissen Spielraum, erstere weil die Versuche lehren, dass beim Schreiben der Fixationspunkt sehr oft in die Sagittalebene gar nicht aufgenommen wird, sondern der Kopf nur ein Stück auf ihn hingedreht, der Rest der Bewegung aber den Augen überlassen bleibt; letztere, weil Abduction des Oberarmes und Abduction sowie Dorsalflexion der Handgelenke wechseln. Es muss sieh daher oft genug ereignen, dass Sagittalebenenschnittlinie und Grundstrich einen Winkel mit einander bilden, der aber nach dem soeben Gesagten, anch abgesehen rom Wund-Lamansky'schen Gesetze, nie selur gross sein kann. 
Ist letzterer Winkel überhaupt vorhanden, dann hơrt die Sagittalebenenneigung auf, bedeutungslos für die Grösse des Grundstrich-Grundlinienwinkels zu sein, vielmehr wirkt jede Neigung der Sagittalebene derart auf diesen Winkel, dass sie ihn einem Rechten nähert, also verkleinert, wenn er über $90^{\circ}$, vergrössert, wenn er unter $90^{\circ}$ betrug.

Das lässt sich leicht an seinem Complementwinkel, dem Sagittalebenen-Grundstrichwinkel zeigen, für welchen die Formel gilt (cf. fig. 9)

$$
\sin . C O B=\sin A O B \text { sin. } e .
$$

$A O B$ ist der Winkel zwischen Grundstrich und Sagittalebenenschnittlinie; er ist dem gesuchten GrundstrichSagittalebenenwinkel $C O B$ gleich, wenn $e$ ein Rechter d. h. die Sagittalebene senkrecht steht, der Basallinienwinkel gleich Null ist. Je kleiner $e$ wird, (was identiseh ist mit dem Anwachsen des Basallinienwinkels $v$ ohne Rücksicht auf die Vorzeichen) desto kleiner auch $C O B$. Wenn jemals $e=$ Null werden könnte, was nicht vorkommt, weil das gleichbedeutend wäre mit lothrechter Stellung der Basallinie, dann wäre auch $C O B=$ Null, wie gross $A O B$ auch sein möge.

Es wird somit dureh jede Abweichung der Sagittalebene von der Verticalstellung der Complementwinkel des Grundstrich-Grundlinienwinkels verkleinert, mithin dieser selbst einem Rechten genähert.

In ähnlicher Weise ergiebt sich dies aus der Formel für den Grundstrich-Grundlinienwinkel in Fig. 8

$$
\cos . B O A=\cos , \delta \cos . v \text {. }
$$

Wenn $v=0$ ist, dann ist $\operatorname{sein}$ Cosinus $=1$, mithin der Grundstrich-Grundlinienwinkel $B O A=\delta$, für welchen Winkel die Formel lautet: $\delta=90^{\circ}-\gamma-h$. Je grösser $v$, desto kleiner der Werth cos. $v$; stets ist aber letzterer ein ächter Bruch, verkleinert also den Werth cos. $\delta$; ist $\delta$ kleiner als $90^{\circ}$, dann wächst sein Werth mit der Verkleinerung seines Cosinus; ist $\delta$ grösser als $90^{\circ}$, dann ist 
sein Cosinus gleich dem Sinus seines Ueberschusswinkels; jede Verkleinerung dieses Sinus verringert aber die Grösse des Ueberschusswinkels selbst und nähert den Hauptwinkel einem Rechten. Somit nähert jede aus beliebigen Gründen eintretende Neigung der Sagittalebene caeteris paribus den Grundstrich-Grundlimienwinkel einem Rechten und dies ist ein weiterer, rein stereometrisoher vom Wund-Lamansky'schen Gesetze gleichfalls unabhängiger Grund für das häufige Vorkommen der $90^{\circ}$ a ahe liegenden Werthe dieses Winkels.

Es ist daher schwer festzustellen, welchen Antheil genanntes Augenbewegungsgesetz an diesem Winkel hat. Doch giebt genaueres Zusehen manchen Anhaltspunkt dafür, dass dieses Gesetz, wenn es mit anderen collidirt, die Rollo der kürzeren Componente im Parallelogramm der Kräfte spielt.

Wenn wir nämlich die Messungen bei senkrechter Schrift und gerader Medianlage betrachten, zeigt es sich, dass der Grundstrich-Grundlinienwinkel durchschnittlich grösser ist als 900, ganz im Gegensatz zu den ubrigen Heftlagen, in welchen er im Durehschnitt kleiner ist. Eine Betrachtung der 3 Winkel $v, h$ and $\gamma$, ans deren Constellation der Grundstrich-Grundlinienwinkel hervorgeht, ergiebt, dass es der negative Werth des Winkels $h$ ist, welcher hier die Schuld trägt. Es ist aber gezeigt worden, dass Winkel $h$ deshalb so überwiegend oft bei dieser Schreibmethode negativ wird, weil die ungewohnte Technik senkrechter Schriftführung ein genaues Hinsehen erzwingt, was eine genauere Einstellung der Sagittalebene zur Folge hat, während sonst die Sagittalebene meist ein Stück links seitwärts von der Federspitze zurückbleibt. Die Einstellung der Sagittalebene aber geschieht um eine annähernd senkrechte Achse, mithin muss diese Drehung auch im negativen Winkel $h$ zum Ausdruck kommen. 
Es ist von Interesse, in den Tabellen die Schwankungen nicht nur des Grundstrich-Grundlinienwinkels, sondern auch des Winkels $v$ bei gerader Medianlage und senkrechter Schrift zu beobachten.

Hier nämlich befinden sich die Augenbewegungen unter den günstigsten Bedingungen, so dass bei einfach gebeugtem Kopfe die Grundstriche in der Sagittalebene und die Zeilen in der Visirebene verlaufen.

In der That ist auch der Durchschnittswerth beider Winkel dieser Stellung entsprechend, was besonders vom Winkell $v$ betont werden muss, gegenüber dem Durchschnittswerth dieses Winkels bei schiefer Medianlage. Gleichwohl zeigen beide Winkel nicht unerhebliche Schwankungen nach beiden Seiten hin, ohne dass für diese Kopfbewegungen immer ein zureichender Grund erkennbar wăre. Daraus geht doch wohl hervor, dass zwar im Allgemeinen die Verschiebungen des Fixationspunktes längs der Sagittalebene oder innerhalb der Visirebene vom Ange bevorzugt werden, dass aber im einzelnen Falle unschwer und zuweilen ohne ersichtliche Collision mit anderen Interessen auch transversale Blickrichtungen gewählt werden.

Der Grundstrich-Grundlinienwinkel ist also zufolge den vorliegenden, mit allen Cautelen und nach zwei verschiedenen Methoden angestellten Messungen nicht gesetz. mässig annähernd ein Rechter, sondern die Hauptmasse der Winkelgrössen schwankt, von den extremen Vorkommnissen ganz abgesehen, innerhalb einer Breite von $35^{\circ}$ und die Mittellage von $90^{\circ}$. Ferner ist für diesen Winkel zum Mindesten nicht ausschliesslich oder vorwiegend das Wund-Lamansky'sche Gesetz verantwortlich, sondern der Winkel würde ebenso ausfallen, wenn wir ihn aus den Bewegungsgesetzen der Hand und des Kopfes herleiten. Aber angenommen selbst, der Winkel sei gesetzmässig, oder sogar er sei 
ausnahmslos $=900$, so folgt daraus nooh keineswegs, was in der Berlin-Rembold'schen Arbeit daraus hergeleitet wird.

Auf pag. 17 der "Untersuchungen" und pag. 273 des Graefe'schen Archivs, XXVIII. 2., heisst es nämlich, nachdem mitgetheilt wurde, ,dass die Hauptsumme der Fälle (es ist rom Grundstrich-Grundlinienwinkel die Rede) um 900 herumliegt." ....

"Wenn wir dagegen die eigentliche diagonale Richtung ins Auge fassen, in welcher thatsächlich die Grundstriche zur Zeile gezogen werden, so stellt es sich heraus, dass diese Richtung der Grundstriche zur Grundlinie überhanpt nicht vorkommt, sondern dass erstere durehschnittlich sämmtlich um $40^{\circ}$, also um fast einen halben Rechten nach links gedreht sind." Hierdurch sei, so heisst es dann weiter, der ,fundamentale Irrthum" jener Autoren orwiesen, welche annabmen, dass beim Schreiben die Zeile in die Visirebene zu liegen komme. Die Beobachtung ergebe „im Gegentheil", dass bei schräger Schrift die Grundlinie die Zeile unter einem Winkel von ca. $45 \mathrm{Grad}$ kreuze. Berlin-Rembold lassen hierbei ausser Acht, dass die Zeile sehr wohl in der Visirebene liegen und dennoch mit der Grandlinie sich unter 45 Grad kreuzen kann.

Thatsăchlich liegt ja allerdings die Zeile sebx selten vôllig in der Visirebene; aber wenn Berlin-Rembold glauben, dass dies daraus geschlossen werden kann, dass der Grundstrich-Grundlinienwinkel niemals $45^{\circ}$ beträgt, so befinden sie sich in einem stereometrischen Irrthum; sie hätten der Erwägung Raum geben sollen, dass eine Grundlinie, welche mit der Zeile in einer Ebene liegt durchaus nicht zum Grundstriche in demselben Winkel stehen muss, den letzteren mit der Zeile bildet. Das ist nur in dem einen, relativ seltenen Falle zutreffend, dass die Basallinie zugleich zur Zeile parallel steht. 
Es heisst dann an der citirten Stelle weiter: „Der Winkel zwischen Grundlinie und Zeile erscheint uns freilich in der Regel bedeutend kleiner als $45^{\circ}$, dies kommt aber daher, weil wir beim Visiren die Grundlinie auf das Heft projiciren und dabei den Winkel, welchen die Grundlinie mit der Tischebene bildet, zu vernachlässigen pflegen."

Hier kommt es aber nicht sowohl auf den Winkel zwischen Grundlinie und Zeile an, als auf den Winkel zwischen Visirebene und Zeile; dieser aber hängt vom Visirebenen-Neigungswinkel, und von dem Winkel $a b$, welchen die innerhalb der Visirebene auf das Heft projicirte Grundlinie mit der Zeile bildet.

Berlin-Rembold stellten ferner Folgendes als die Consequenz reehtwinkeliger Kreuzung zwischen Grundlinie und Grundstrich hin:

„Der Winkel, welchen die projicirte Grundlinie mit der Zeile bildet, ist gleich dem Winkel zwischen den Grundstrichen und dem auf der Zeile erriehteten Perpendikel."

Wenn hier der Ausdruck ,projicirte Grundlinie" in demselben Sinne gemeint ist, in welchem er sonst in jener Arbeit und auch einige Zeilen vor der citirten Stelle gebraucht wird, nämlich als Projection innerhalb der Visirebene, mit anderen Worten: als Schnittlinie zwisehen Visir- and Schreibebene, dann ist der angeführte Satz falsch, wie aus Fig. 10 bewiesen werden soll.

Angenommen, es liegen alle Linien der Figur in einer horizontalen Ebene, mit Ausnahme von $A O$, welehe mit $B O$ den Winkel $v$ einschliesst; dieser Winkel liege in einer senkrechten Ebene, so dass $B O$ die senkrechte Projection von $A O$ darstellt. $A O$ bedeute die Grundlinie $a d$ stelle die Lage einer Zeile dar, $a O$ sei die Verlängerung derselben; $a b$ sei Zeilenperpendikel, $a c$ ein Grundstrich. und seine Richtung senkreeht zu $O B$. Alsdann steht $a c$ 
auch auf der ganzen Ebene $A O B$ senkrecht, mithin anch zu jeder in dieser Ebene liegenden geraden Linie, also auch auf der Basallinie $A O$, was fur Berlin-Rembold's Satz vorausgesetzt ist. Es hindert nun nichts, anzunehmen, dass unter diesen Verhaltnissen der Fixationspunkt des zur Basallinie $A O$ gehörenden Augenpaares in a liege; alsdann fällt $a O A$ mit der Visirebene zusammen und die Linie $O a$ stellt nebst ihrer Verlängerung $a d$ die Schnittlinie zwischen Visir- und Schreibebene dar;

Fig. 10.

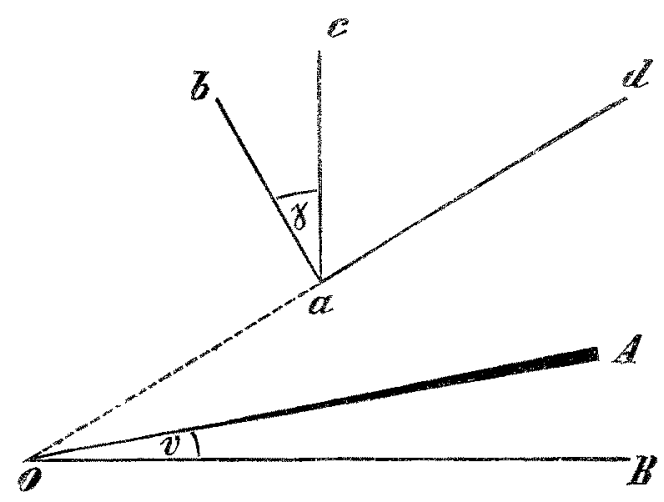

es fällt diese Schnittlinie also mit der Zeile zusammen, so dass der Winkel, den sie mit der Zeile bildet, gleich Null ist, und nicht, wie behauptet wurde $=b a c$.

Jener Satz ist nur dann richtig, wenn mit den Worten „projicirte Grundlinie" deren rechtwinklige Projection auf die horizontale Sehreibebene gemeint war, so dass die Behauptung mit Rücksicht auf die Figur 10 lauten würde, Winkel $d O B$ sei gleich Winkel $b a c$, was ganz richtig ist. Dann aber steht der Satz nicht, wie es dem dortigen Zusammenhang nach der Fall sein 
soll, in Widerspruch damit, dass unter solchen Verhältnissen die Zeile in die Visirebene fallen könne; denn diese Möglichkeit ist ja durch die Figur 10 bewiesen.

Berlin-Rembold scheinen geglaubt zu haben, es sei mit dem Grundstrich-Grundlinienwinkel auch der Visirebenenzeilenwinkel gegeben. Es kann aber die Grundlinie zum Grundstrich rechtwinkelig gestellt, und dabei doch im Raum sehr verschieden gelagert sein. Denn wie aus Figur 10 hervorgeht, kann die Grundlinie innerhalb jeder senkrecht zum Grundstrich $a c$ gelegten Ebene jede beliebige Lage einnehmen, ohne dass dabei der Grundstrich-Grundlinienwinkel aufhört, 90 Grad zu messen. Unter diesen vielen Möglichkeiten muss es auch, wie oben gezeigt wurde, einen gewissen Grad von Linksneigung geben, der zur Folge hat, dass die Zeile in die Visirebene fullt. Stereometrisch steht dem nichts im Wege, und in praxi kommt es, wenn auch selten, vor; durchschnittlich aber näherte sich in den gemessenen Fällen die Visirebene der Zeile bis zu 220.

Wie interessant daher der Grundstrich-Grundlinienwinkel in theoretischer Beziehung sein mag, zur Entscheidung der praktischen Frage, ob in der Schule Steilschrift auf median- und geradeliegendem Heft oder Schiefschrift auf medianund schiefliegendem Heft vorzuziehen sei, vermag derselbe nichts beizutragen.

Der Unterschied der Kopfstellung bei beiden Heftlagen beruht nach meinen Messungen hauptsächlich in dem höheren Durchschnittswerth des Winkels $v$, d. h. also in der häufigeren und stärkeren Neigung der Basallinie bei schiefer Medianlage. Es zeigte sich, um dies nochmals hervorzuheben, bei zusammen 1201 Messungen 
als Durehschnittswerth von 400 Messungen bei gerader Medianlage . . . . , . $v=+2.8$, als Durchschnittswerth von 543 Messungen

bei schiefer Medianlage . . . . . $v=+7.9$, als Durchschnittswerth von 258 Messungen

bei willkürlicher Heftlage . . . . $v=+9.0$.

Hiernach stehen in Bezug auf $v$ die schiefe Medianlage und die willkürliche Heftlage fast auf gleicher Stufe (weil die letztere sich in der Mehrzahl der Fälle der ersteren năherte) und beide sind stark im Nachtheile gegenüber der geraden Nedianlage. Die Arbeit ron Berlin-Rembold hat diesen Winkel gleichfalls berücksichtigt und ihn aus der Differenz des senkrechten Abstaudes beider Augen vom Pulte und aus der Länge der Grundlinie berechnet.

Wie aus der Tabelle auf pag. 40 jener Arbeit hervorgeht, wurde diese Differenz des Augenabstandes

434. mal bei willkürlicher Heftlage,

242 mal bei gerader Medianlage, 386 mal bei schiefer Medianlage,

im Gauzen 1062 mal gemessen. Die Tabelle giebt an, dass bei gerader Medianlage das normale Verhalten seltener war, als bei schiefer Medianlage.

Im Widerspruche mit dieser Tabelle steht allerdings die Curve in derselben Arbeit, bei welcher umgekehrt die bei gerader Medianlage gefundenen Werthe der Norm näher liegen. Inwiefern dies in Uebereinstimmung zu bringen sei, vermag ich nicht zu entscheiden.

Ein Zufall fügt es, dass bei Zugrundelegung einer durchschnittlichen Grundlinienlänge von $55 \mathrm{Mm}$. jedem Tieferstehen eines Auges um $1 \mathrm{Mm}$. innerhalb der hier überhaupt vorkommenden Werthe fast genau einer Neigung 
der Basallinie um $1^{0}$ entspricht, so dass die Untersuchungsergebnisse von Berlin-Rembold und mir, obgleich ganz anders ausgedrückt, doch direct verglichen werden können.

Jedenfalls werden bei ferneren Messungen gerade diese Verhältnisse zu berücksichtigen sein und es muss sich zeigen, $o b$ in der That, wie ich aus meinen Messungen schliessen muss, die gerade Medianlage in dieser Beziehung weitaus den Vorzug verdient.

Freilich hat Fuchs Recht, wenn or in seiner Preisschrift sagt, endgiltig könne diese Frage nur entschieden werden, wenn man eine Anzahl Kinder vom ersten Schulunterricht angefangen senkrechte Schrift auf gerade und median liegendem Hefte schreiben liesse und nach Jahren ihre Haltung messen könnte. Leider ist dies zur Zeit nicht ausführbar und es wird stets das Resultat der Messung getrübt durch den Umstand, dass die Kinder allerlei üble Gewöhnungen, welche von der bisherigen Schreibweise herrühren, in die zu prüfende neue Schreibtechnik mit hinübernahmen.

Es giebt aber noch einen anderen Gesichtspunkt, von dem aus die senkrechte Schrift auf geradliegendem Heft den Vorzug verdient, nämlich die Rücksicht auf die practische Durchführung der als gesundheitsgemäss erkannten Vorschriften. Gesetzt, es sei falsch, was ich soeben zu beweisen mich bemühte, gesetzt, es stehe fest, dass die Kopfhaltung beim Schreiben auf schief medianliegendem Heft nicht schlechter sei, als die auf gerade medianliegendem, so würde die Frage in den Vordergrund treten; mit welchen Mitteln will man verhüten, dass die schiefe Medianlage nicht gelegentlich mit einer der Rechtslagen vertauscht wird? Die Neigung dazu ist gross, darüber belehrten mich die steten Versuche der Kinder, den Körper nach links zu verschieben, wenn das Heft festgehalten 
wurde. Diese Neigung ist auch leicht verständlich, denn da eine sehr stark geneigte Schrift hergestellt werden soll, so kann bei einem Zeilen-Pultrandwinkel von 300 eine senkrecht zum Pultrand gestellte Schrift nicht genügen, sie würde nur $30^{\circ}$ zur Zeile geneigt sein und um ihr eine stärkere Neigung zu geben, müht sich das Kind ab, unter Zuhilfenahme von Handabduction die Buchstaben auch relativ zum Pultrand rechts zu neigen. Der Winkel $\gamma$ war ja nach den Messungen bei schiefer Medianlage durchschnittlich positiv, anstatt Null zu sein. Solche Handstellung wird unbequem, es sucht das Kind durch linksrücken des Körpers auszuweichen und der Vebergang zur Rechtslage ist fertig.

Will man dies verhüten und das Heft so drehen, dass die Zeile sehr schräg verläuft, damit senkrecht zum Pultrand gefertigte Grundstriche die gewünschte Neigung zur Zeile haben, dann nähert sich die schiefe Heftlage jenen Graden, welche als Ueberdrehung bezeichnet werden muss, and wie dies anch Berlin-Rembold zugeben, den ganzen Körper zur Linkswendung zwingt. Die Grenzen der erlaubten Heftlagen sind mithin eng gesteckt, und welche Schreibvorschriften will man geben, dass sie nicht überschritten werden? Man kann auf den Schulbänken schräge Linien einzeichnen lassen, welche den Heftdrehungswinkel angeben; aber kann man das auch fưr die Hausaufgaben der Kinder thun?

Hier wird das Kind von den vielen möglichen Heftlagen, bei welchen schiefe Schrift hergestellt werden kann - (schiefe Medianlage, schiefe und gerade Rechtslage, sowie alle möglichen Uebergänge derselben) - schwerlich immer die strengbegrenzte Medianlage mit einem Heftdrehungswinkel von $30-40^{\circ}$ wählen.

Oft genug konnte während der Versuche beobachtet werden, dass die Kinder im 3 . bis 5. Schuljahr noch keine gewohnheitsmässige Heftlage haben, dass sie das Heft 
sich nicht bequem zurechtlegen, sondern es fast dem Zufall anheimgeben, wie die Heftlage ausfällt. Darf man da erwarten, sie werden daheim stets die gerade Medianlage von $40^{\circ}$ innehalten?

Mit Recht wird in neuerer Zeit wieder ein erhöhter Nachdruck darauf gelegt, dass alle schulbygienischen Verbesseruugen nicht hinreichend fruchten, wenn nicht auch für die Haushygiene der Kinder gesorgt wird. Wir halten Verbesserung des Buchdruckes und der Schreibmaterialien gerade deshalb für besonders heilsam, weil sich der Einfluss dieser Verbesserungen auch auf die Hausanfgaben erstreekt. Eine der wichtigsten Handhaben für die gesundheitsgemässe Anfertigung der sehriftlichen Hausaufgaben besitzen wir aber in der Forderung senkrechter Schrift. Diese kann das Kind gar nicht anders schreiben, als bei gerader Medianlage des Heftes, die senkrechte Schrift erzwingt eine symmetrische Körperhaltung und es ist für den Lehrer und Arzt die Gewissheit vorhanden, dass das Kind, welches in Steilschrift ausgeführte Hausaufgaben vorlegt, bei Anfertigung derselben keine der abenteuerlichen und ber üchtigten Stellungen eingenommen hat, die zu vermeiden Ellinger and Gross bemüht waren, als sie die Schriftrage anregten.

Diesen schwerwiegenden Grund für die senkrechte Sehrift und gerade Medianlage vermag man nicht mit Argumenten zu entkräften, welche im besten Falle nur beweisen würden, dass unter gewissen Cautelen die schiefe Medianlage gleich gute Haltung erlaubt.

Wenn es freilich richtig wäre, dass die Zeilenführung bei gerader Medianlage den Bewegungsgesetzen der Hand zuwider ist, dann würde diese Heftlage keine Zukunft haben können. Das Wahre an diesem Einwurf ist aber 
nur, dass sich die sebräge Zeilenführung besser zur Sehnellschrift eignet. Sie soll auch Erwachsenen mit fertiger Handschrift anheimgestellt bleiben, denn nach vollendetem Wachsthum sind die Gefahren für Wirbelsäule und Augen verschwindend klein. In der Schule aber handelt es sich nicht um Schnellschrift; hier möge das Kind weniger hastig sehreiben, wenn es dabei eine gesündere Körperhaltung innezuhalten vermag.

Uebrigens muss in diesen Dingen doch auch die Erfahrung gehört werden. Ich habe daher vor 6 Jahren, als mich diese Frage zu beschäftigen begann, meinebis dahin ausschliesslich geübte schiefe sogenannte deutsche Currentschrift anfgegeben, und schreibe seither nur noch steile lateinische Rundschrift bei gerader Medianlage. Die Umgewöhnung vollzog sich verhältnissmässig rasch, sodass ich bald auch für schnelles Schreiben die Steilschrift bequem fand. Die Gewohnheit thut viel, aber sie wïrde nicht bewirken kőnnen, dass eine naturwidrige Handhaltung auf die Dauer vorgezogen wird. Allerdings muss man den Arm im Verlauf der Zeile ofter rücken, doch kann darin nichts Schädliches erblickt werden; thun dies doch ungeübte Kinder oft genug auch bei schräger Heftlage.*) Weitere Untersuchungen darüber anzustellen, ob die gerade Medianlage unphysiologisch ist, dessen überheben uns die Jahrtansende alten Geplogenheiten aller Culturvölker. In

*) Man vergleiche in dieser Hinsicht, was Ellinger (l. e) iber die parallel zum Pultrand verlaufende Zeile sagt, dessen Ansicht um so schwerer wiegt, als er, welcher die bygienische Bedeutung der Heftlage zuerst hervorhob, von seiner ursprünglichen Forderung: „Schiefe Schrift auf schräg vor der Mitte lieg'endem Heft" zurückgetreten ist und nummehr zum warmen Vertheidiger senkrechter Schrift und gerader MLdianlage geworden ist. Er sagt: ,dass aber die Armachse im rechten Winkel die Zeile treffe, dafür liegt weder ein optischer, noch ein mechanischer, noch sonst ein vernünftiger Grund vor." 
China, Japan und Korea schreibt man senkrechte Zeilen und diese Sohreibweise flndet sich auch aut den ältesten egyptischen Papyrusschriften: Später, wohl im Interesse des schnellen Schreibens*) wählte man wagrechte Zeilen. Die k. k. Hofbibliothek in Wien besitzt eine griechische Genesis-Handschrift aus dem IV. Jahrhundert; schon hier wie in den späteren griechischen, lateinischen und hebräischen Manuscripten steben die Grundstriche senkrecht zur Zeile. Auf altrömischen Wachstäfelchen finden sich steile Schriftzüge; das ganze Mittelalter hindurch bis in die jüngste Zeit war diese Sehriftrichtung die herrschende, und auch heute uben sie Manche, die theoretischer Voreingenommenheit fern stehen.

Am Schluss dieser Arbeit pag. 123 u. ff. sind Reproductionen von Handschriften aus der Sammlung des Germanischen Museums zu Nürnberg zusammengestellt, welche chronologisch geordnet eine fortlaufende, ein volles Jahrtausend umfassende Reihenfolge von Schriftproben, vom 8. bis 18. Jahrhundert darstellen. Stärkere Rechtsneigung der Grundstriche findet sich in den älteren Schriften sehr selten und bis zum 17. Jahrhundert nie in dem jetzt üblichen und in den Schulen vorgeschriebenen Grade $\left(45^{\circ}\right)$. Die meisten langen Grundstriche weichen, wenn überhaupt, nur um 10 bis 15 , hochstens $20^{\circ}$ von der Senkrechten nach rechts $a b$, die kurzen Grundstriche sind häufig und nicht unerheblich nach links geneigt. In der neueren Zeit finden sich häufig stark rechts geneigte Striche als solche Buchstabenelemente, welche heute den Character des Grundstriches tragen, doch dürfen dieselben. nicht als rechtschiete Grundstriche angesehen werden, da genauere Betrachtung zeigt, dass sie durch Aufstrich des Griffels entstanden, also Haarstriche sind. Die Schrift-

*) Wuttke, Die Entstehnug dex Schrift, 1812, p. 537. 
proben sind nicht mit Rücksicht auf die Grundstrichrichtung herausgewählt, sondern willkürlich herausgegriffen.

Messungen der Grundstrichrichtung stossen bei alten Handschriften auf die Schwierigkeit, dass die Grundstriche selten unter sich parallel sind, sondern in ein und demselben Wort oft erhebliche Divergenz zeigen. Doch kann man meist einen gewissen Grad von Grundstrichrichtung als den vorherrschenden herausfinden und messen. Eine grössere Reihe von Briefen aus dem Ende des 15. and Anfang des 16. Jahrhunderts wurde von mir untersucht, es fand sich meist ein Zeilengrundstrichwinkel von $80-90$, seltener von 70-80, nur einmal von 65 Grad.

In der Wiener Hofbibliothek befindet sich die Originalhandschrift zu Tasso's Gerusalemme conquistata, bei welcher die Zeilen leicht bogenförmig von links unten nach rechts oben emporsteigen und die Grundstriche deutlich, wenn auch in geringerem Grade als bei der modernen Schreibweise nach rechts geneigt sind. Aber man kann hunderte alter Manuscripte durehmustern, bevor man einer solchen Ausnahme begegnet.

Es ist der Einwand erhoben worden, durch alte Handschriften werde nichts bewiesen, weil man damals langsamer sehrieb. Zwar pflegt man sich in dieser Hinsicht übertriebene Vorstellungen zu machen; denn es schrieb z. B. Agambert im Jahre 806 des Hieronymus Commentar zu Jeremias, enthaltend 182 Blatt mit je 32 Zeilen, binnen einem Monat*). Doch ist es im Allgemeinen richtig, dass die Alten sich wie zu allem Anderen so auch zum Sehreiben mehr Zeit liessen. Aber dieser Einwurf würde für mich doch nur dann eine Widerlegung enthalten, wenn ich mit den Schriftproben hätte beweisen

*) Wattenbach, Schriftwesen im Mittelalter, 1875. pg. 240 . 
wollen, dass die senkrechte Schrift sich ganz besonders zur Schnellschrift eigne.

Die Schriftproben sollen aber etwas ganz Anderes darthun, dass nämlich unsere Vorfahren bei gerader Medianlage geschrieben haben, und dass mithin diese Heftlage nicht unphysiologisch sein, nicht den Bewegungsgesetzen der Hand zuwiderlaufen kann. Denn es wäre absurd anzunehmen, man habe seit Erfindung der Buchstabenschrift bis in die neuere Zeit beim Schreiben dieunbequemen, naturwidrigen Handbewegungen vorgezogen, nur weil man mehr übrige Zeit gehabt habe als heute. 


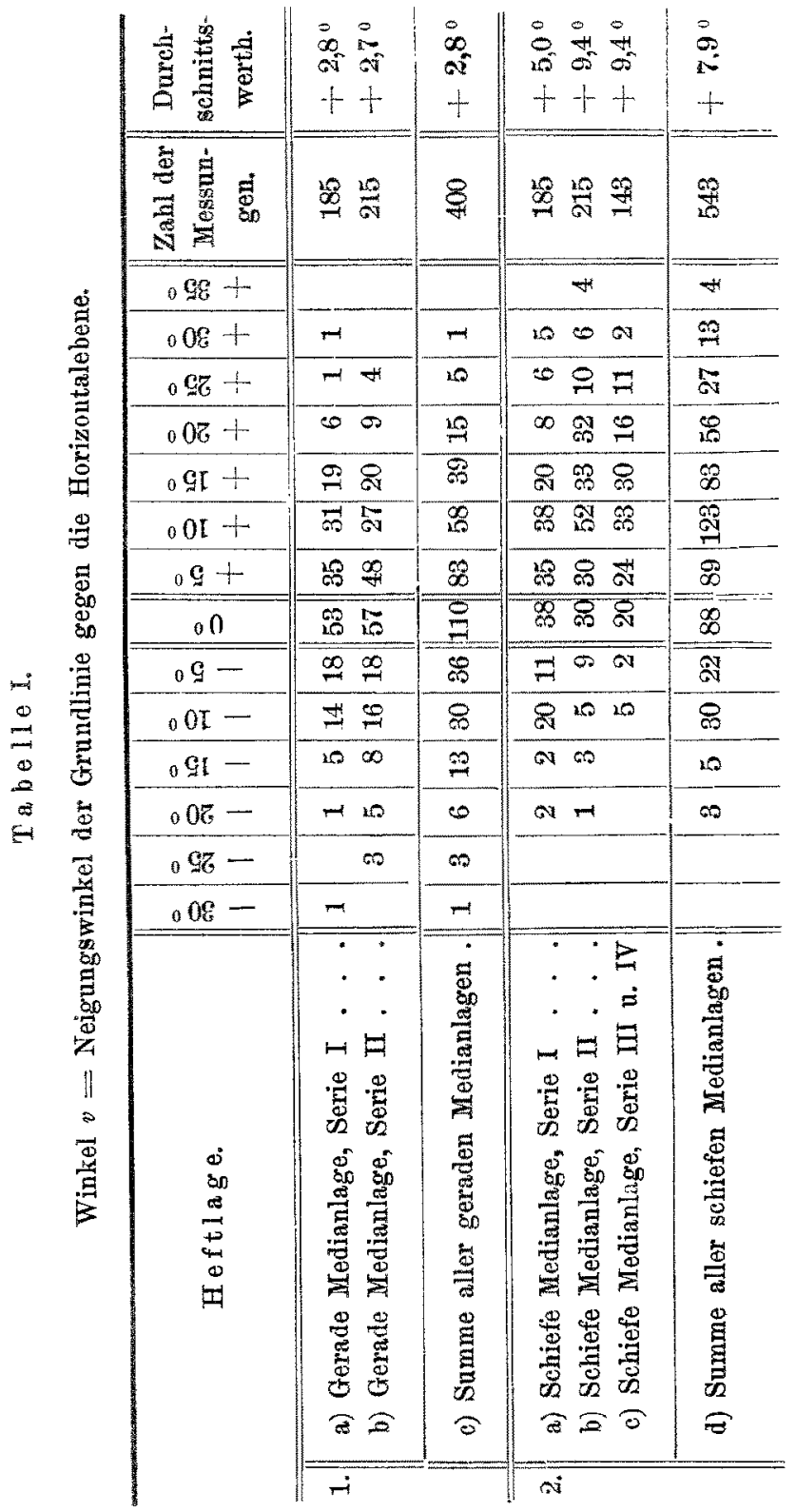


Ueber die Haltung des Kopfes beim Schreiben.

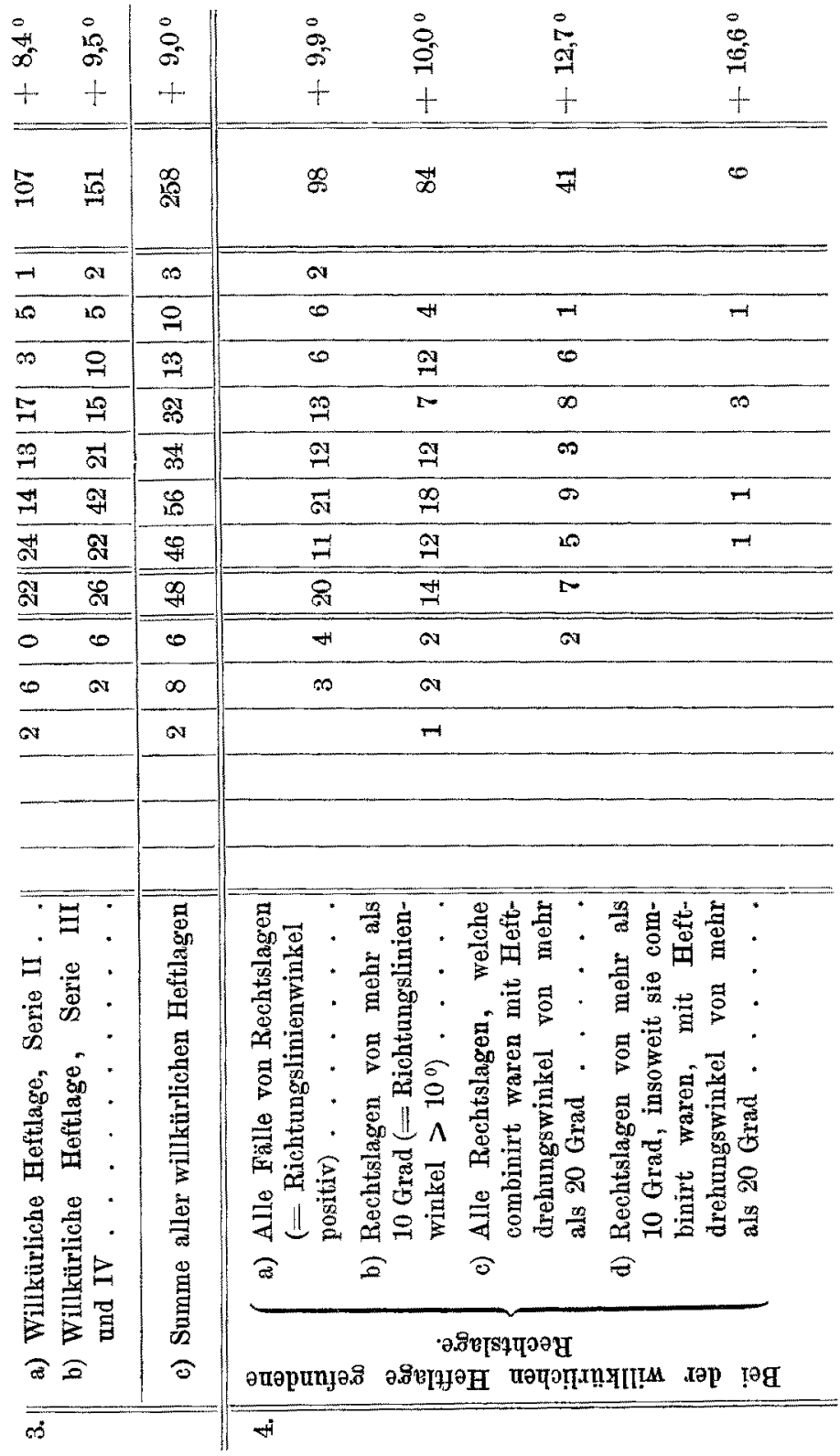


Dr. Paul Schubert.

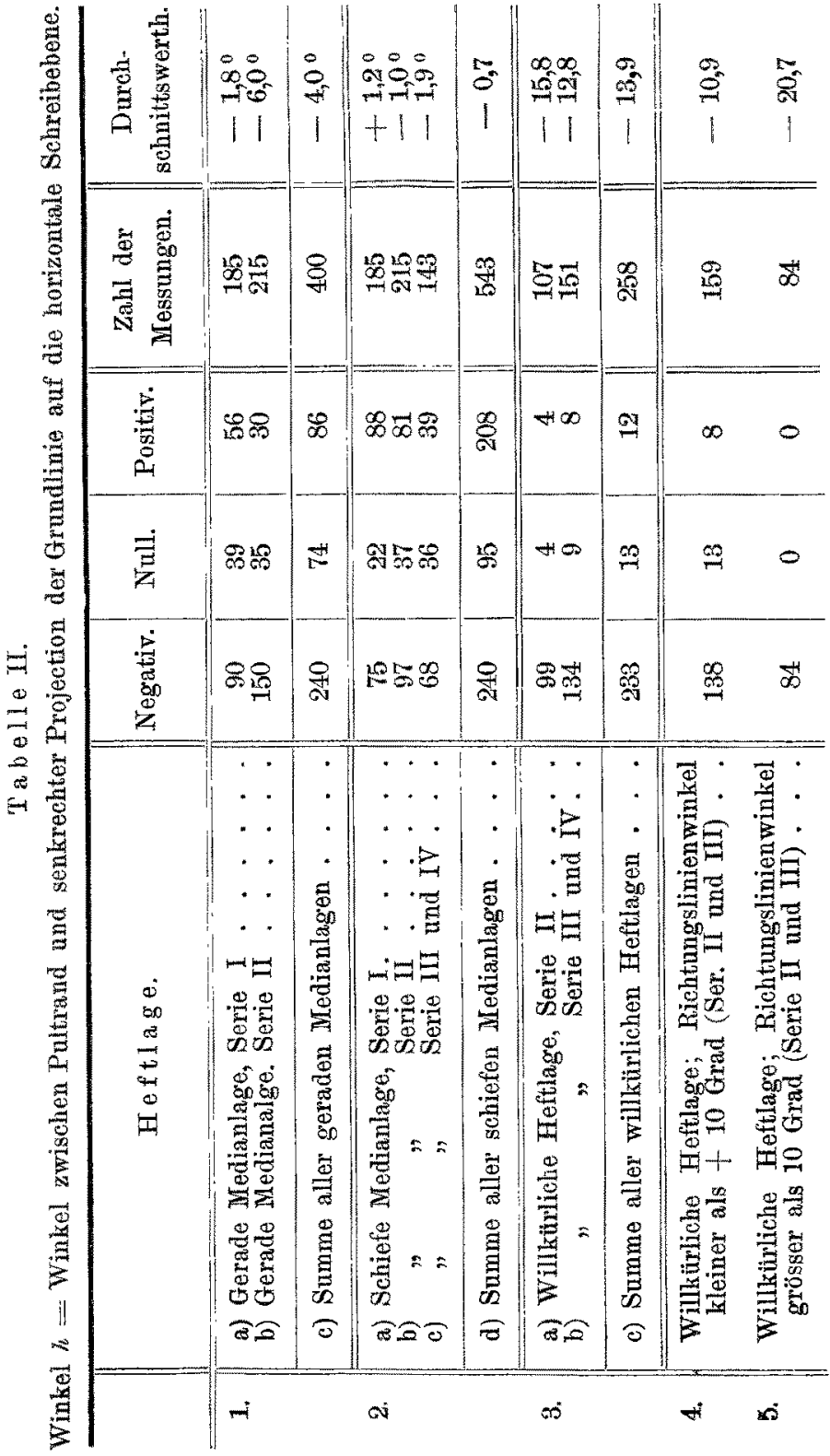


Ueber die Haltung des Kopfes beim Schreiben.

119

\begin{tabular}{|c|c|c|c|c|c|c|c|c|}
\hline 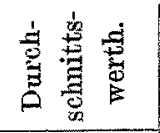 & $\begin{array}{l}80 \\
0.0 \\
++\end{array}$ & $\begin{array}{c}0 \\
0 \\
25 \\
+ \\
\end{array}$ & 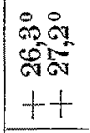 & $\begin{array}{l}0 \\
\text { is. } \\
+ \\
+ \\
\end{array}$ & 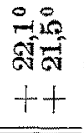 & $\begin{array}{l}\vec{s} \\
\text { जे } \\
+ \\
\end{array}$ & $\begin{array}{l}\stackrel{2}{5} \\
+ \\
+\end{array}$ & $\begin{array}{l}6 \\
+\end{array}$ \\
\hline 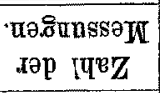 & $\mathbb{g}_{-10}^{\infty}$ & 答 & 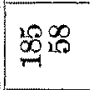 & 羿 & $\stackrel{10}{0}_{10}^{100}$ & जै & 哭 & 昜 \\
\hline $09+$ & $F$ & -1 & + & 7 & & & & \\
\hline $\mathrm{gg}+$ & 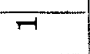 & $\Gamma$ & $\infty$ & का & ज & N & & \\
\hline $0 \mathrm{~g}+$ & & & 000 & $\Rightarrow$ & $\sigma$ & $\mathrm{N}^{-}$ & av & \\
\hline $97+$ & -1 & -1 & $N^{\infty}$ & 20 & $0^{\circ 0}$ & 9 & $\bar{T}$ & \\
\hline $0 \mp+$ & 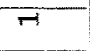 & $\Rightarrow$ & $\nabla^{\infty}$ & $\stackrel{\mathbb{N}}{*}$ & $\pi^{\infty}$ & $\Xi$ & 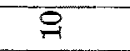 & $\vec{r}$ \\
\hline $\mathrm{g} g+$ & $\sigma$ & $\sigma$ & go & $\frac{\Gamma}{60}$ & $\stackrel{9}{\circ}$ & $\overline{\mathscr{c}}$ & 울 & $\pi$ \\
\hline $08+$ & & & $\stackrel{\sim}{\mathrm{a}}$ & $\infty$ & $\vec{\sigma}_{0}^{20}$ & 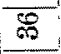 & 5 & $\Gamma$ \\
\hline$g z+$ & H & 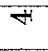 & $\bar{m}=$ & 素 & 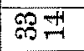 & F & बి & $\sigma$ \\
\hline $0 B+$ & 6. & 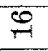 & $F=$ & $\mathscr{g}$ & 899 & $\mathscr{8}$ & $\mathscr{\Omega}$ & 8 \\
\hline gr + & $\stackrel{0}{-1}$ & $\stackrel{\omega}{=}$ & $\stackrel{\infty}{\infty}$ & $\stackrel{5}{-}$ & $\infty_{\infty}^{\infty}$ & $\bar{\sigma}$ & 8 & $\mathscr{\Im}$ \\
\hline $\mathrm{OL}+$ & 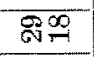 & 5 & मुन & ${ }_{n}^{10}$ & $g^{-1}$ & $\overline{8}$ & त्र & $\stackrel{0}{\circ}$ \\
\hline$g+$ & $8 \%$ & 8 & $\Rightarrow$ & $\infty$ & on & 9 & $\stackrel{\circ}{2}$ & $\sigma$ \\
\hline 0 & श्ञ & क & ल & $\overline{4}$ & $\pi$ & $\overline{7}$ & $\infty$ & $\vec{b}$ \\
\hline$g-$ & ठबन & $\stackrel{9}{\Rightarrow}$ & $\overline{7}$ & $\overline{7}$ & $\overline{7}$ & $\bar{F}$ & का & $\infty$ \\
\hline $0 \mathrm{O}-$ & $H$ & F & & & & & & $\stackrel{\infty}{\sim}$ \\
\hline gI - & & & & & 7 & 5 & & $=$ \\
\hline $08-$ & & & 7 & -1 & & & & 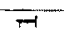 \\
\hline $\mathrm{g} z-$ & & & & & & & & $=$ \\
\hline $08-$ & & & $=$ & 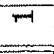 & 7 & 5 & & \\
\hline & 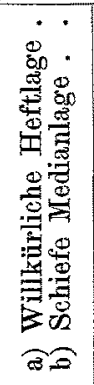 & 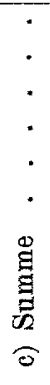 & 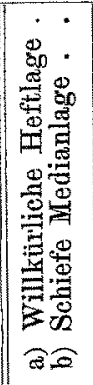 & $\begin{array}{l}\cdot \\
\cdot \\
\cdot \\
\cdot \\
\cdot \\
\dot{g} \\
\tilde{z} \\
0 \\
0\end{array}$ & 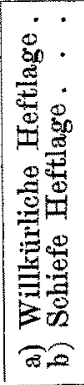 & 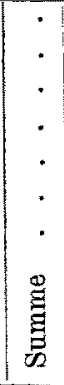 & \multirow{2}{*}{\multicolumn{2}{|c|}{ 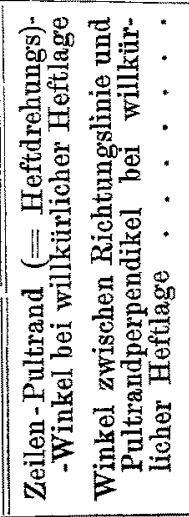 }} \\
\hline & \multicolumn{2}{|c|}{$\dot{8}$} & \multicolumn{2}{|c|}{$\dot{2}$} & \multicolumn{2}{|c|}{ 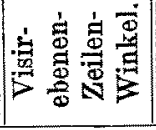 } & & \\
\hline & \multicolumn{2}{|c|}{$-i$} & \multicolumn{2}{|c|}{ oi } & \multicolumn{2}{|l|}{$\infty$} & \multicolumn{2}{|c|}{$f+10$} \\
\hline
\end{tabular}


Dr. Paul Schulvert.

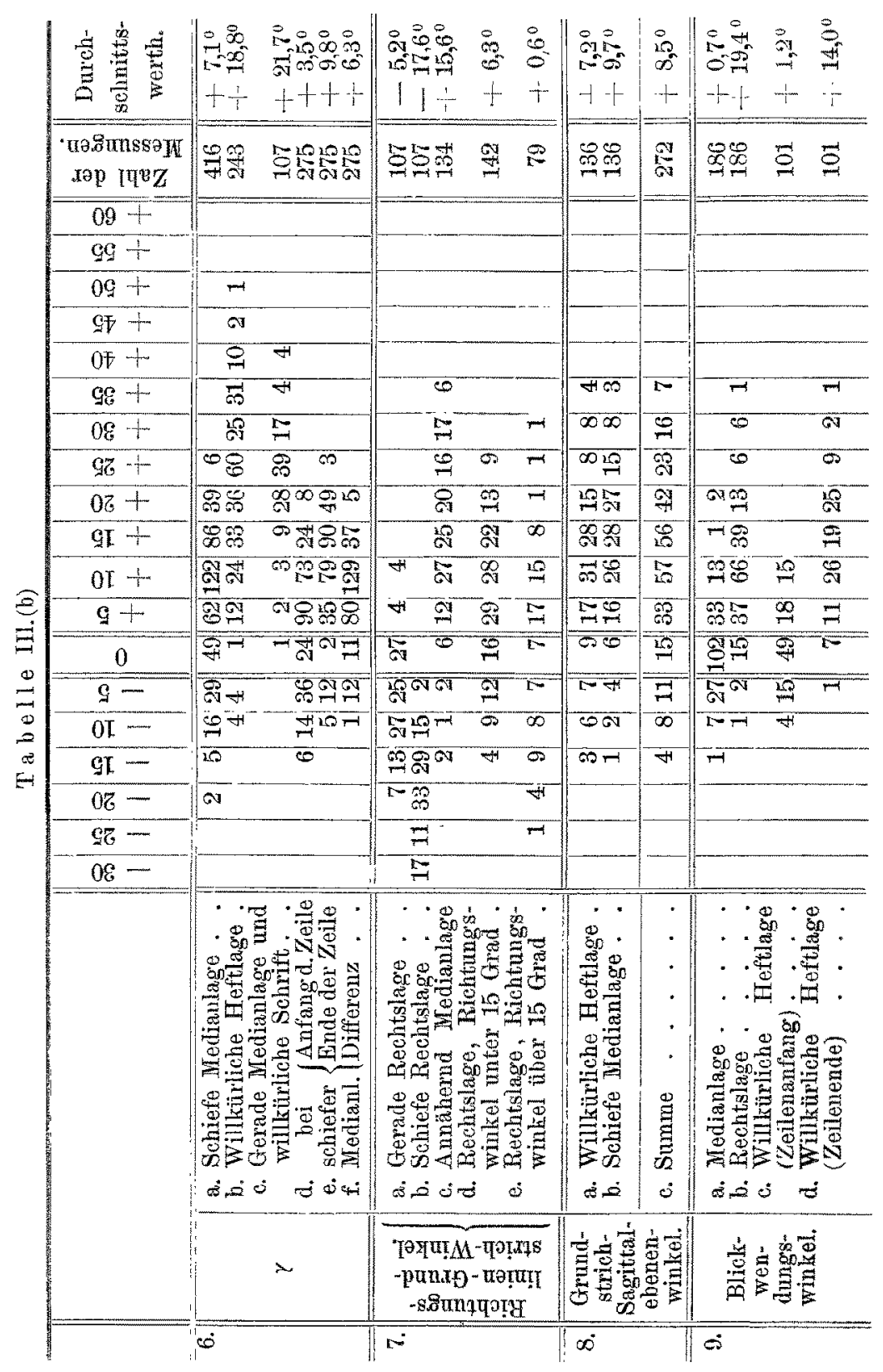


Ueber die Haltung des Kopfes beim Schreiben.

121

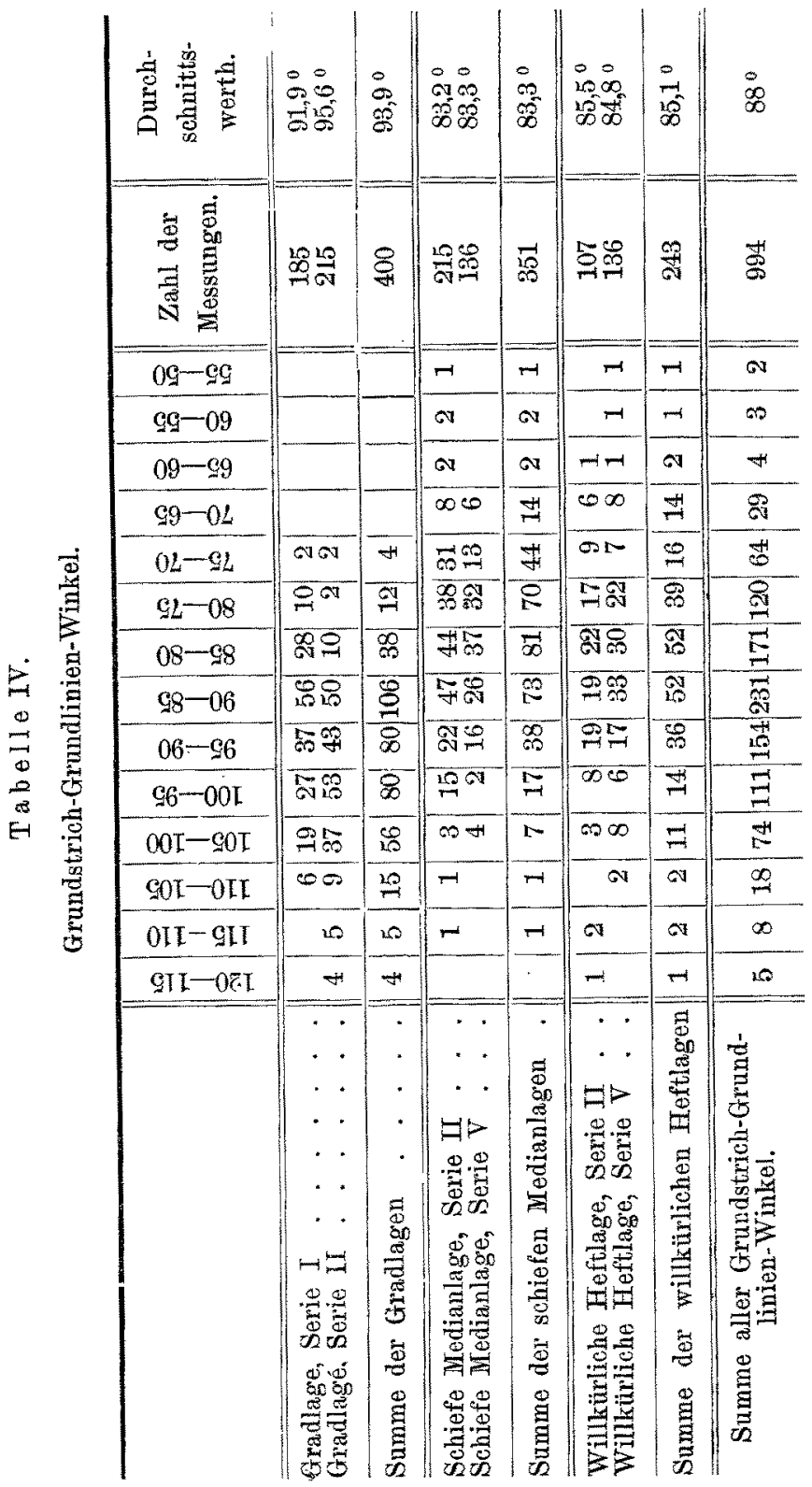




\section{Erklärung der Schriftproben.}

1) 8. Jahrhundert, Vulgata, Pergament.

2) 9 . Jahrbundert, lateinische Predigten.

3) 10. Jahrhandert, Math. Evangelium.

4) 11. Jahrhundert, Helperieus, ars calculatoria.

5) 1193. Schutzbrief Kaiser Heinrich VI.

6) Zwischen 1215 und 1250 Urkunde Kaiser Friedrich 11.

7) 1293. Urkunde König Adolfs.

8) 1315. Urkunde der Bürger von Auerbach.

9) 1363. Urkunde Erzherzogs Rudolph IV. von Oesterreich (ersto eigenhändige Unterschrift eines dentsehen Fïrrsten).

10) 1445. Scbreiben der Marg. Wolkenstein.

11) 1461. Markgraf Johann von Brandenburg.

12) 1512. Quittung von Holzschuher.

13) 1572. Brief von Behaim.

14) 1617. Rechnung.

15) 1688. Actenstück.

16) 1725 . Brief.

17) 1786. Brief. 1777. Patent des Christian Fredrich Carl Alexander, Markgraf zu Brandenburg-Quolzbach. 


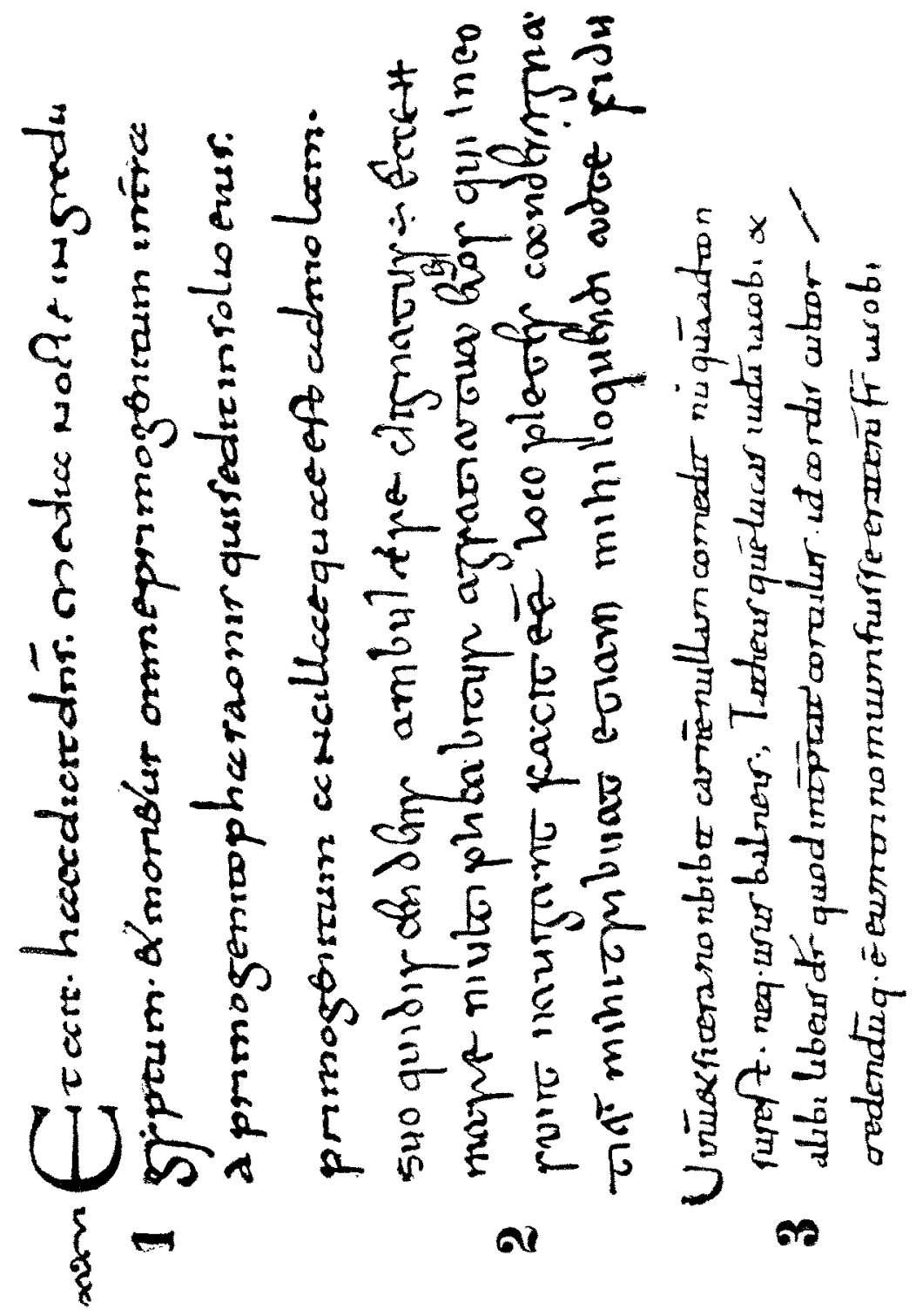


Dr. Paul Schubert.

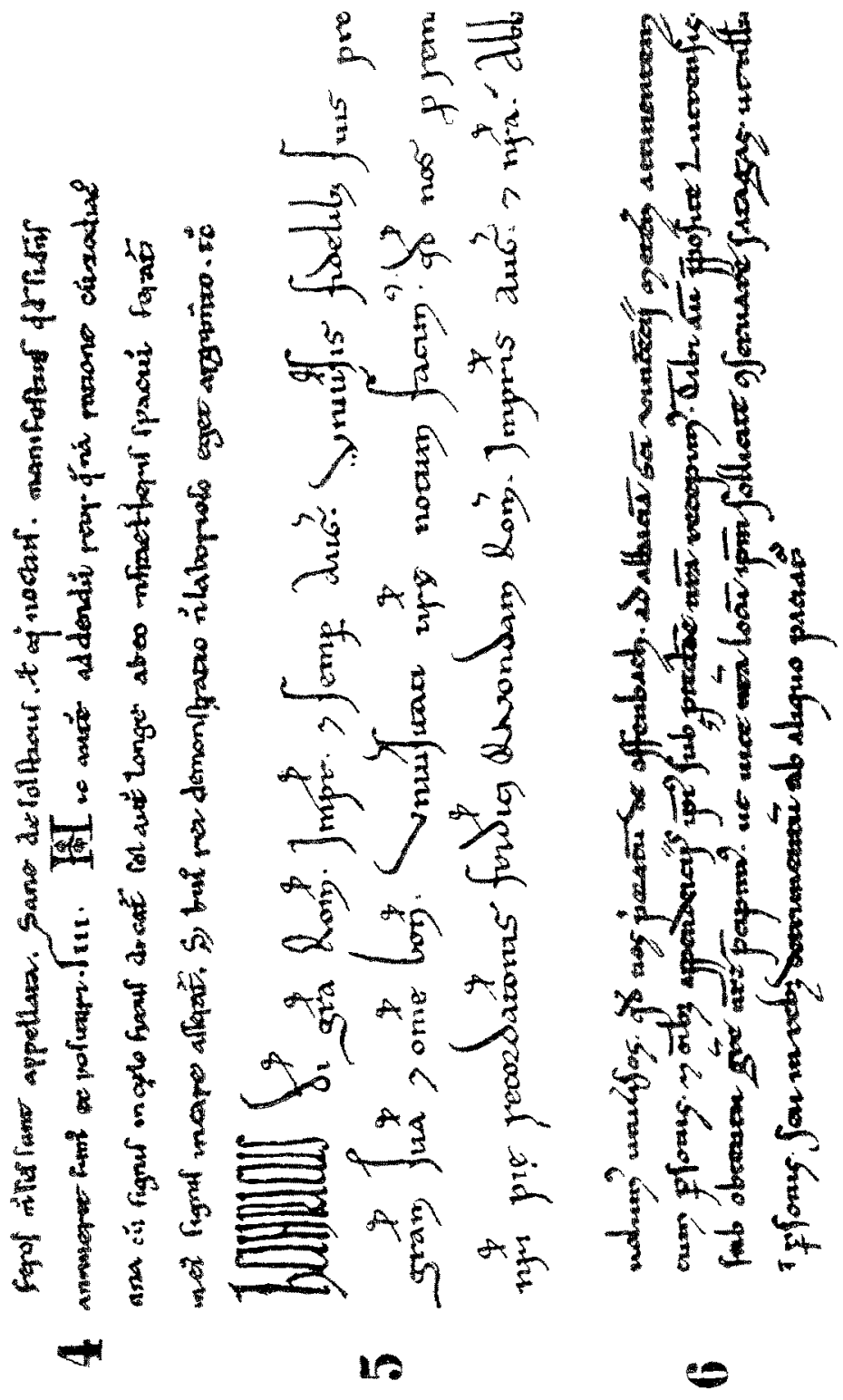




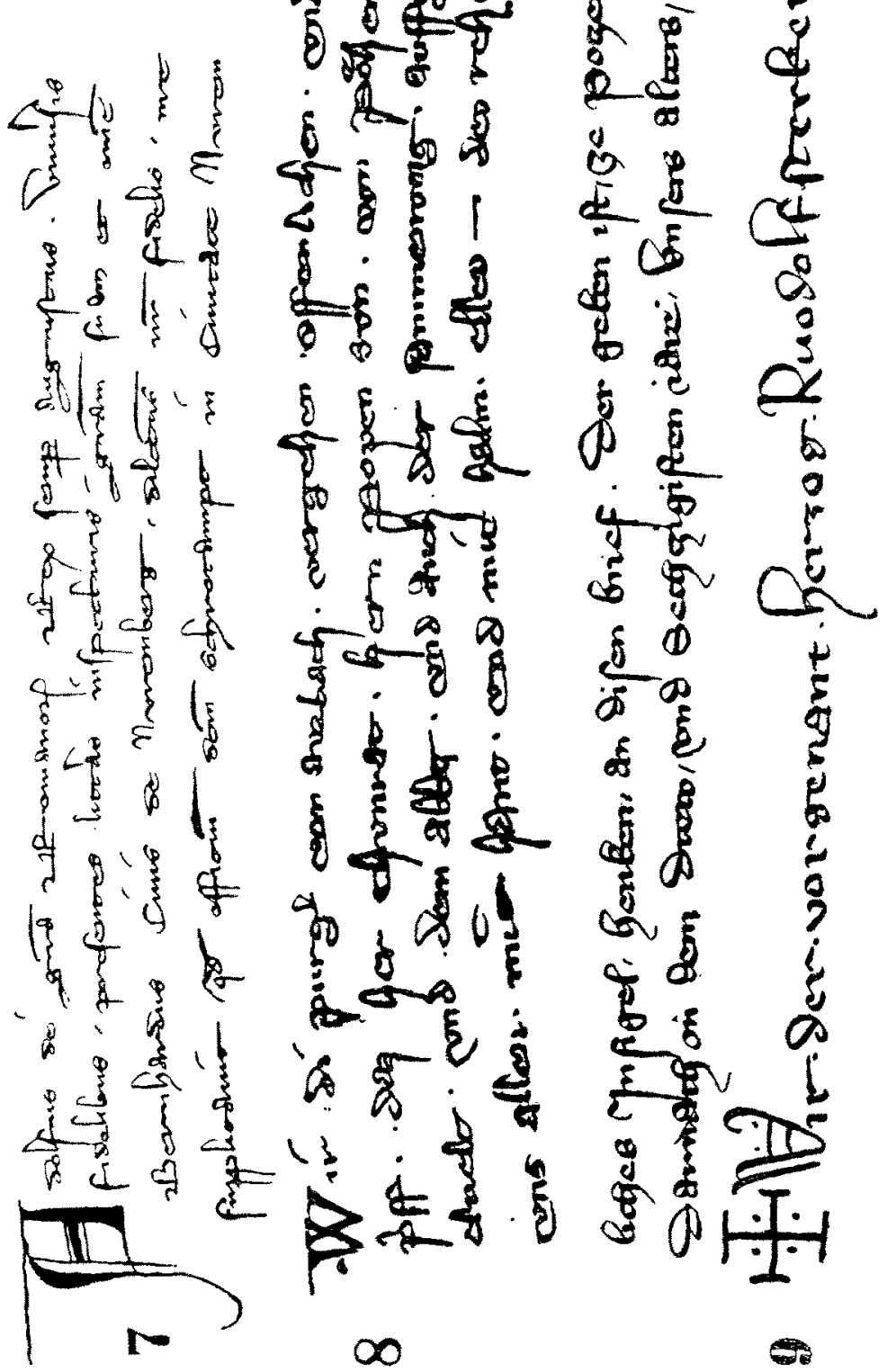




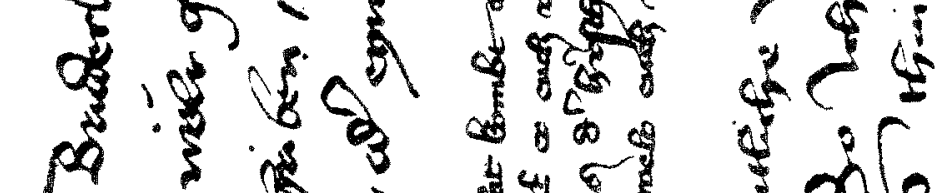
( द

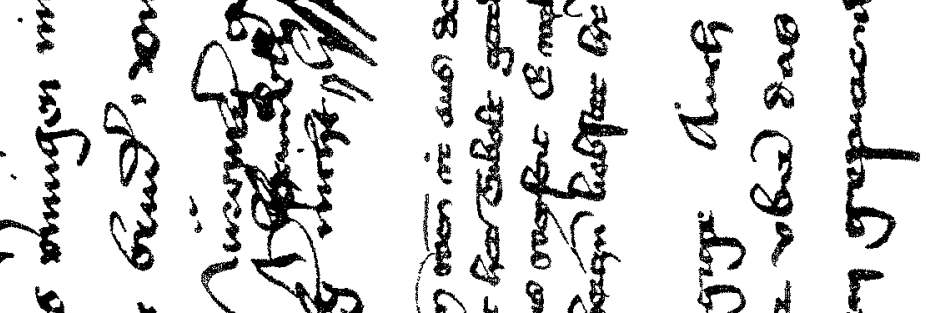

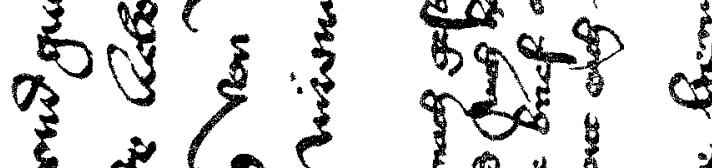

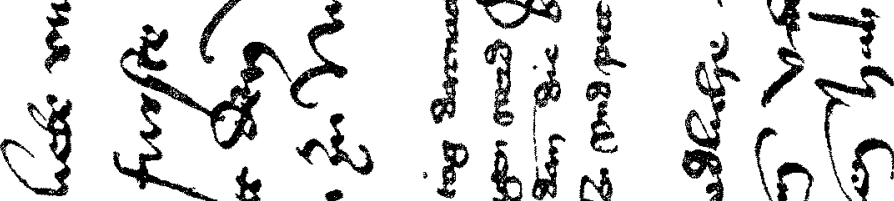
दर

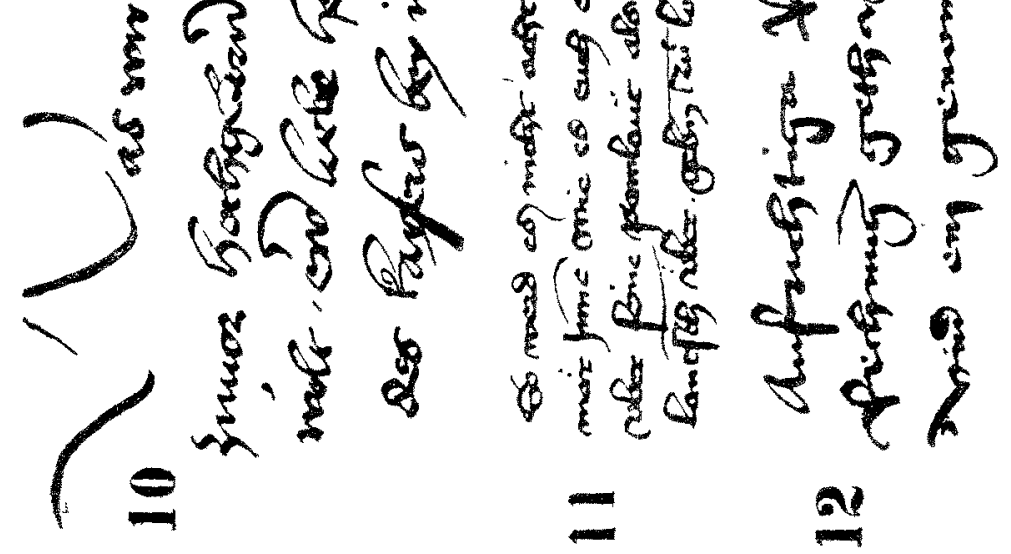


Ueber die Haltung des Kopfes beim Schreiben.

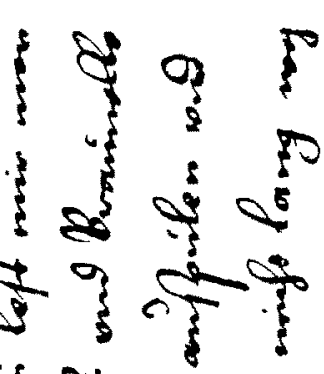

कै के

क क

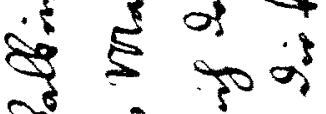

की कूष

बक

\& क क

पद

की की

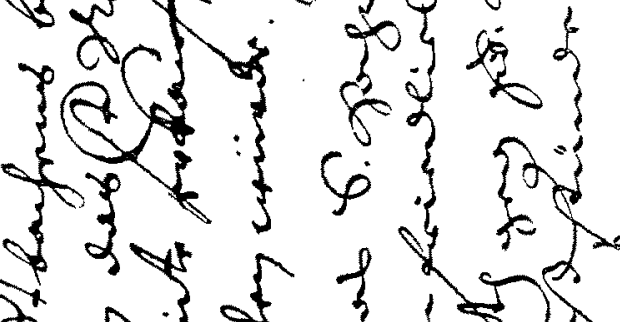
$\left\{\begin{array}{l}5 \\ \{\end{array}\right.$

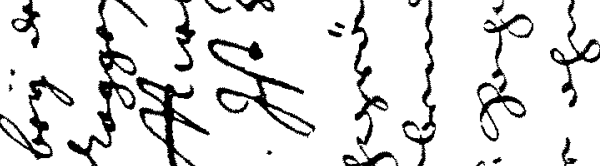

की $\left\{\begin{array}{l}3 \\ \text { की }\end{array}\right.$

$\therefore$ क 55

दै से की

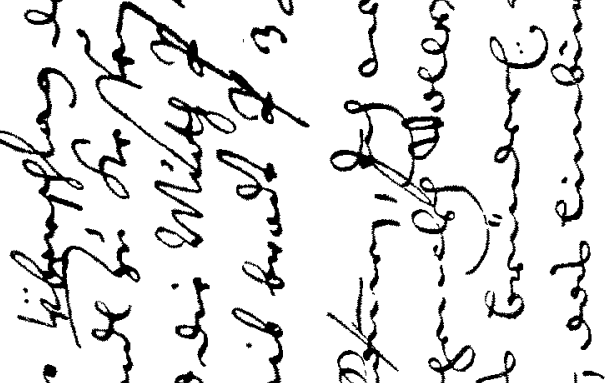

से की की

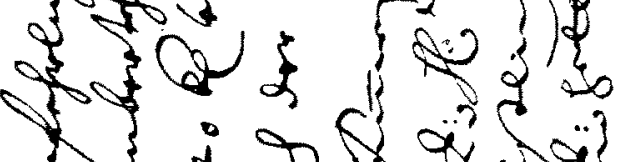

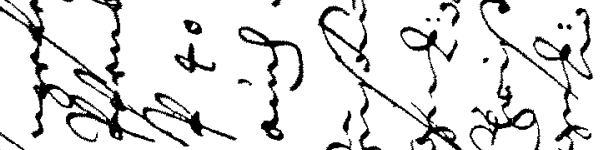

$\Gamma \pm$

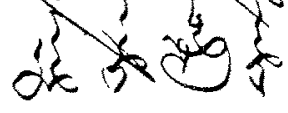

$\because$ 


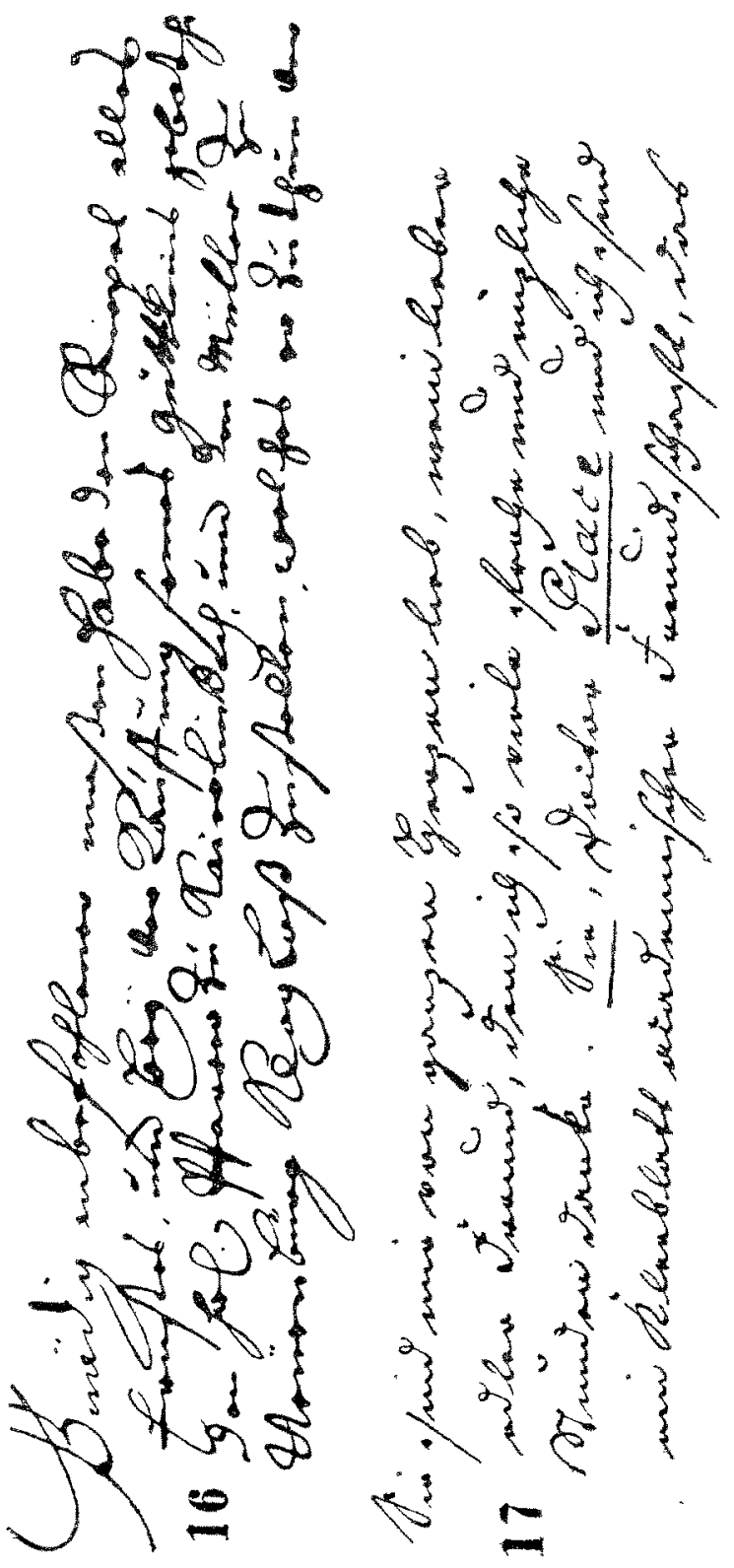

